Portland State University

PDXScholar

$9-27-2021$

\title{
Improved Predictive Modeling Techniques for Non- Linear Solder Material Behavior
}

Arman Millian Ahari

Portland State University

Follow this and additional works at: https://pdxscholar.library.pdx.edu/open_access_etds

Part of the Materials Science and Engineering Commons Let us know how access to this document benefits you.

Recommended Citation

Ahari, Arman Millian, "Improved Predictive Modeling Techniques for Non-Linear Solder Material Behavior" (2021). Dissertations and Theses. Paper 5796.

https://doi.org/10.15760/etd.7667

This Thesis is brought to you for free and open access. It has been accepted for inclusion in Dissertations and Theses by an authorized administrator of PDXScholar. Please contact us if we can make this document more accessible: pdxscholar@pdx.edu. 
Improved Predictive Modeling Techniques for

Non-Linear Solder Material Behavior

by

Arman Millian Ahari

A thesis submitted in partial fulfillment of the requirements for the degree of

\author{
Master of Science \\ in \\ Mechanical Engineering
}

Thesis Committee:

Sung Yi, Chair

Chien Wern

Faryar Etesami

Portland State University

2021 


\begin{abstract}
Accurate prediction of fatigue life of solder joints in electronic packaging applications becomes of critical importance as semiconductor device technology and manufacturing constraints grow in complexity. To gain visibility on IC device performance and reliability, thermo-mechanical simulation is performed based on a unified, viscoplastic material model, which is dependent on nine parameters.

In this study, an improved method of Anand parameter extraction, which involves curve-fitting non-linear experimental stress data, is proposed to improve the accuracy of numerical predictions for solder reliability. Theoretical equations for uni-axial stress-strain response and creep response are derived, then details on their relevance to experimental and numerical data is explained in detail. Numerical analysis is performed using the FiniteElement method, and both uni-axial and full-package representations are used to evaluate creep damage data.

Previous literature is reviewed, and sources of analytical and numerical error are discussed in comparison to similar work completed in both academia and industry. Finally, the widely used Coffin-Manson model is used to predict reliability using damage data obtained through a uni-axial tensile model, performed using Abaqus simulation software. It is found that in comparison to experimental stress-strain data, the proposed method of curve-fitting produces more accurate data, and the new parameters predict higher fatigue life for both the uni-axial tensile and full package models.
\end{abstract}




\section{Acknowledgements}

I extend my most sincere gratitude to God, the most gracious and most merciful, for guiding me to the straight path, for granting me the strength to obtain knowledge that serves the benefit of humanity, and for granting forbearance that enables a pursuit of ideas that inspire hope for myself and others. Thank you to my Mother, my Father, and my brother Milan, for your endless support and sacrifice. Our time together grounds the tenets of purpose, love, and compassion in my life, which in turn, inspire me to fearlessly pursue my dreams. Thank you to Marwah, my fiancé and gentle partner in life, for being a prolific sustainer of dreams, a source of wisdom and comfort, and a special part of sharing unconditional love. Each day with you is truly a blessing.

Many thanks to Dr. Sung Yi, for years of invaluable advising since first beginning my undergraduate studies at Portland State University. Where there was once wavering interest, there is now focused resolve, and for that I will always be grateful. Thank you, professors and faculty of the Mechanical and Materials engineering department, including the members of this committee Dr. Faryar Etesami and Dr. Chien Wern - I promise your efforts toward sharpening my skills as an academic will serve a noble pursuit toward achieving excellence within the engineering profession. And finally, thank you to the Maseeh College of Engineering and Computer Science, and the University as a whole, for providing the tools, resources, and opportunity to grow academically so that I may carry the torch forward, and with eager persistence, let knowledge serve the city. 


\section{Contents}

Abstract

Acknowledgements ii

List of Figures

List of Tables vi vi

1 Introduction 1

1.1 Electronics Packaging . . . . . . . . . . . . . . . . . 1

1.2 Packaging Reliability . . . . . . . . . . . . . . . 3

1.3 SAC-305 Lead-Free Solder Properties . . . . . . . . . . . . . . . . 5

1.4 Constitutive Equations for Solder . . . . . . . . . . . . . . . . 6

2 Verification Studies 9

2.1 Anand viscoplastic constitutive model . . . . . . . . . . . . . . . . 9

2.1.1 Formulation of one-dimensional uni-axial loading condition . . . . . 10

2.1.2 Theoretical formulation of uni-axial stress-strain response . . . . . . 13

2.1.3 Theoretical formulation of Creep response . . . . . . . . . . . . 15

2.2 Comparison of Experimental and Model Data . . . . . . . . . . . . 18

2.2.1 Pre-yield mathematical model . . . . . . . . . . . . . . . . 19

2.2.2 Methods of Anand parameter extraction . . . . . . . . . . . 21

2.2.3 Quantification of numerical accuracy ............. 39

2.2 .4 Discussion of error . . . . . . . . . . . . . . 52

2.2.5 Verification of experimental data . . . . . . . . . . . 54

3 Numerical Models $\quad 56$

3.1 Uni-axial tensile model . . . . . . . . . . . . . . . . . . . 57

3.2 Plastic Ball Grid Array (PBGA) model . . . . . . . . . . . . . . . 60

4 Results $\quad 63$

5 Fatigue Models $\quad 69$

5.1 Overview on various fatigue-life prediction methods . . . . . . . . . 69

5.1.1 Coffin-Manson Model . . . . . . . . . . . . . . . . . . . 72

5.1 .2 Alternative fatigue models . . . . . . . . . . . . . . 73

$\begin{array}{llr}6 & \text { Conclusions } & 79\end{array}$

$\begin{array}{ll}\text { References } & \mathbf{8 1}\end{array}$ 


\section{List of Figures}

1.1 Basic Components of a Ball Grid Array Chip Scale Package . . . . . . . 2

1.2 Typical deformation profile of a quarter representation of a PBGA . . . 4

1.3 Finite-element representation of shearing stresses induced . . . . . . . 5

1.4 Solder elements . . . . . . . . . . . . . . . . . . . . 10

1.5 Typical Creep Behaviors of Solders . . . . . . . . . . . . . . . . . 13

1.6 Elasto-Plastic Behaviors of Solders . . . . . . . . . . . . . 13

2.1 Pre-Yield Strain-Rate-Averaged Elastic Modulus _ . . . . . . . . . . 20

2.2 Stress vs Strain at $298 \mathrm{~K}$ and strain rate of .001 mm/s . . . . . . . . . . 24

2.3 Stress vs Strain at $323 \mathrm{~K}$ and strain rate of $.001 \mathrm{~mm} / \mathrm{s} \ldots \ldots 25$

2.4 Stress vs Strain at $348 \mathrm{~K}$ and strain rate of $.001 \mathrm{~mm} / \mathrm{s} \ldots \ldots 26$

2.5 Stress vs Strain at $373 \mathrm{~K}$ and strain rate of $.001 \mathrm{~mm} / \mathrm{s} \ldots \ldots . . . . .27$

2.6 Stress vs Strain at $398 \mathrm{~K}$ and strain rate of $.001 \mathrm{~mm} / \mathrm{s} \ldots \ldots$. . . . . . . 28

2.7 Stress vs Strain at $298 \mathrm{~K}$ and strain rate of $.0001 \mathrm{~mm} / \mathrm{s} \ldots \ldots$

2.8 Stress vs Strain at $323 \mathrm{~K}$ and strain rate of $.0001 \mathrm{~mm} / \mathrm{s} \ldots \ldots$

2.9 Stress vs Strain at $348 \mathrm{~K}$ and strain rate of $.0001 \mathrm{~mm} / \mathrm{s} \ldots \ldots . . . . .31$

2.10 Stress vs Strain at $373 \mathrm{~K}$ and strain rate of $.0001 \mathrm{~mm} / \mathrm{s}$. . . . . . . . . 32

2.11 Stress vs Strain at $398 \mathrm{~K}$ and strain rate of $.0001 \mathrm{~mm} / \mathrm{s}$. . . . . . . . . 33

2.12 Stress vs Strain at $298 \mathrm{~K}$ and strain rate of $.00001 \mathrm{~mm} / \mathrm{s} \ldots \ldots 34$

2.13 Stress vs Strain at 323K and strain rate of $.00001 \mathrm{~mm} / \mathrm{s} \ldots . . . . . .35$

2.14 Stress vs Strain at $348 \mathrm{~K}$ and strain rate of $.00001 \mathrm{~mm} / \mathrm{s}$. . . . . . . 36

2.15 Stress vs Strain at $373 \mathrm{~K}$ and strain rate of $.00001 \mathrm{~mm} / \mathrm{s}$. . . . . . . . 37

2.16 Stress vs Strain at $398 \mathrm{~K}$ and strain rate of $.00001 \mathrm{~mm} / \mathrm{s} \ldots \ldots$

2.17 Strain-specific maximum difference, Motalab data $.001 \mathrm{~mm} / \mathrm{s}$. . . . . 41

2.18 Strain-specific maximum difference, Motalab data $.0001 \mathrm{~mm} / \mathrm{s}$. . . . 42

2.19 Strain-specific maximum difference, Motalab data $.00001 \mathrm{~mm} / \mathrm{s}$. . . 43

2.20 Kolmogorov-Smirnov Curve-Fit Error, Motalab data .001 mm/s. . . . 44

2.21 Kolmogorov-Smirnov Curve-Fit Error, Motalab data $.0001 \mathrm{~mm} / \mathrm{s}$. . . 45

2.22 Kolmogorov-Smirnov Curve-Fit Error, Motalab data $.0001 \mathrm{~mm} / \mathrm{s}$. . . 46

2.23 Strain-specific Maximum Difference Present Study .001 mm/s . . . 47

2.24 Strain-specific Maximum Difference Present Study $.001 \mathrm{~mm} / \mathrm{s}$. . . 48

2.25 Strain-specific Maximum Difference Present Study .001 mm/s . . . 49

2.26 Kolmogorov-Smirnov Curve-Fit Error, Motalab data dissimilarity . . . 50

3.1 Solder beam geometry, boundary conditions, thermal uni-axial model 57

3.2 Solder beam geometry, boundary conditions, regular uni-axial model 58

3.3 Thermal Profile used for both Uni-Axial and PBGA models . . . . . . 59

3.4 PBGA Package model construction . . . . . . . . . . . . 60

3.5 PBGA Package model mesh distribution . . . . . . . . . . . . . 60

4.1 Contoured Equivalent Creep Strain Distribution for the Solder Bar . . 64

4.2 Equivalent Creep Strain and Maximum Elastic Principal Strains vs time 64

4.3 Solder Joint Array Classification . . . . . . . . . . . . . . . . 65 
4.4 Equivalent Creep-Strain Results for Solder Ball-Grid Array . . . . . . 67

4.5 Equivalent Von-Mises Stress Results for Solder Ball-Grid Array . . . 68

5.1 Total strain versus life equation . . . . . . . . . . 73 


\section{List of Tables}

2.1 Anand Parameters and their respective constraints, present study . . . 22

2.2 Extracted Anand parameters obtained by curve-fitting . . . . . . . . 23

2.3 Kolmogorov-Smirnov comparison: experimental vs M. Model . . . . 51

2.4 Kolmogorov-Smirnov comparison: experimental vs P.S Model . . . . 51

2.5 Calculated Elastic Modulus for M. Experimental Stress-Strain Data . . 54

$3.1 \quad$ PBGA Package Dimensions . . . . . . . . . . . . . . . 61

3.2 PBGA Package Material Properties . . . . . . . . . . . . 62

$5.1 \quad$ Fatigue Models and Classifications . . . . . . . . . . . . . 70

5.2 Fatigue Models and Additional Classifications . . . . . . . . . . . 62

5.3 Coffin-Manson Strain-life parameters for SAC-305 Lead-Free Solder . 77

5.4 Creep-accounting fatigue life parameters . . . . . . . . . . . . 77

5.5 Fatigue-life results and corresponding finite-element result . . . . . 78 


\section{Chapter 1}

\section{Introduction}

\subsection{Electronics Packaging}

The pursuit of building dependable technology can only be achieved through developing a fundamental understanding of materials, processes, and end-use operational conditions of the final product. In the context of ever-complexifying technology and greater device performance demands, scientists and engineers within the semiconductor space are expected to solve greater reliability issues. To meet the pace of Moore's Law, reliability has been at odds with key innovations associated with decreasing feature sizes and increasing power delivery, to meet device performance requirements at lower production costs. With this context, is important to explore semiconductor construction that remains susceptible to reliability issues, namely where packaging becomes the critical enabler of technological innovation in this space.

From an electronics packaging perspective, reliability can be predicted through investigating the mechanical integrity of industry-standard solder material, which forms the electrical connection between components and their respective PCB board. In addition to hosting an electrical function, solder is also important in preserving chemical insulation, stable thermal conduction, and mechanical support during thermal cycles that induce warpage on surrounding package structures.

Predicting the reliability of advanced computing devices becomes of critical importance, especially as several detrimental trends become operational requirements, including, but not limited to increasing package size, increasing power density, increasing 
concentration of interconnects, smaller feature sizes, and co-integration of multiple system components on the same substrate [3]. Despite great advancements in packaging technology, and exotic constructions that mitigate reliability risks through more ingenious allocation of active and non-active materials, the issue that drives failure is unavoidable due to basic tenets of semiconductor packaging construction.

The basic Active silicon must be routed, cooled, protected, mechanically supported, and chemically insulated in either hermetically sealed or plastically-encapsulated package configurations, depending on the end-use operational conditions. Figure 1.1 shows an example of a basic ball-grid array package, where (copper) routing layers are shown in orange, and solder connections are shown in grey.

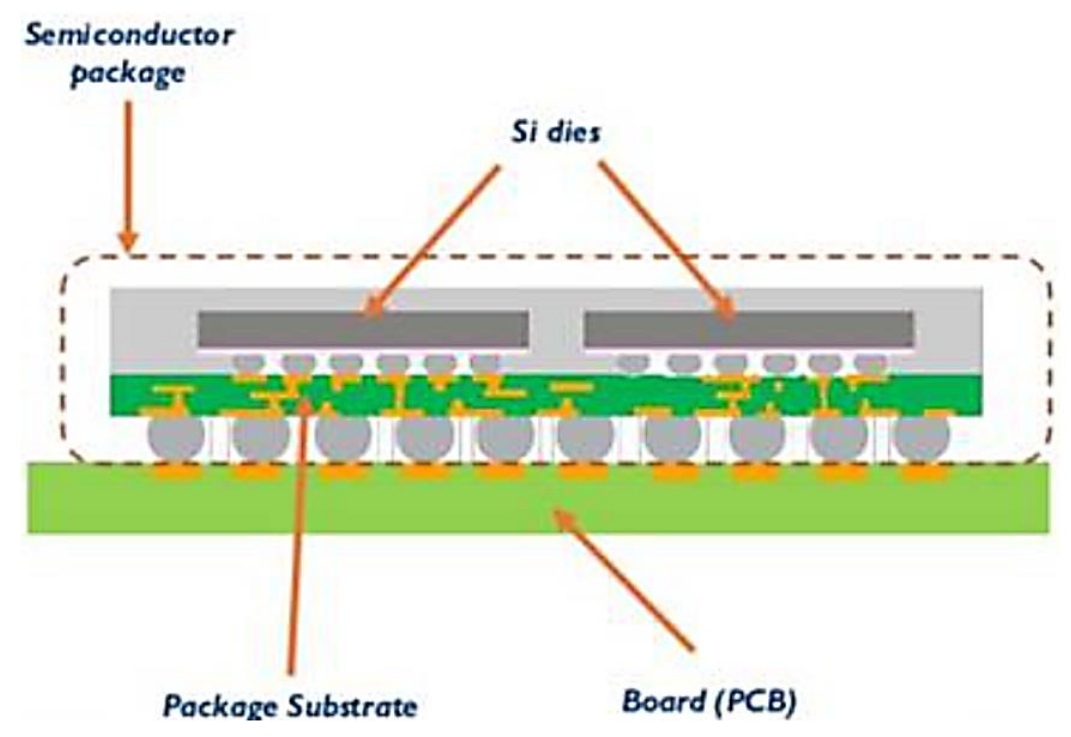

Figure 1.1 Basic Components of a Ball Grid Array (BGA) Chip Scale Package (CSP)

The driving forces behind increased packaging density are due to performance requirements and reducing cost (Yi 2016). Performance increases on the silicon die require 
higher I/O (electrical input/output) count, and despite the fact that packaging cost are decreasing, the cost is expected to rise due to a dramatic increase in chip and package pin count.

Thus, it is of great importance that researchers develop accurate and timely assessments of mechanical reliability, which may depend on a number of factors that depend greatly on the package geometry, materials used, manufacturing processes, and in-field conditions.

\subsection{Packaging Reliability}

Electronic packaging performance is often measured in terms of its reliability, which most generally can be characterized as a probabilistic measure against a pre-determined definition of failure. Generally, there are two categories of failure associated with mechanical systems: shock and fatigue failure. The first type of failure is dependent on the ultimate strength of a material, where short-term reliability is considered a non-issue below this limit. The second type of failure mentioned is associated with large changes in pressure or temperature over a given time (typically the latter), which frames the scope of study around long-term reliability instead [6]. The materials used in these packages vary greatly

in coefficient of thermal expansion (CTE), which leads to several concerns from a reliability perspective.

Depending on end-use operational conditions, electronic packages are often subjected to large differences in temperature, and with each change, components below and above solder connections, namely substrate and printed circuit board (PCB) components, expand greatly due to a large CTE mismatch between silicon, substrate, and PCB components. 


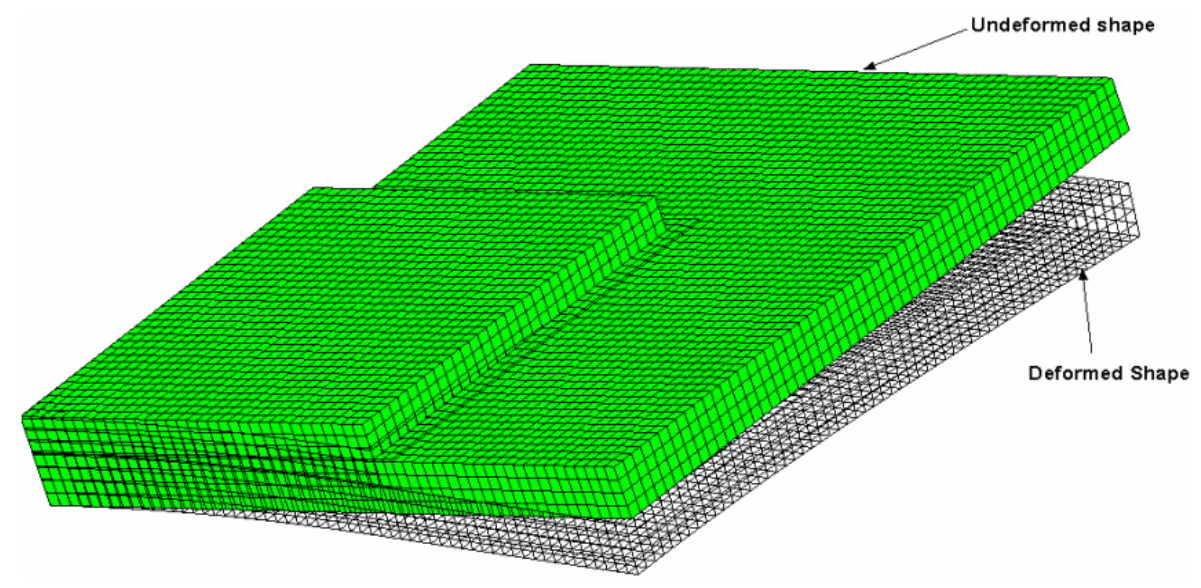

Figure 1.2: Typical deformation profile of a quarter representation of a PBGA package

The most susceptible component to failure based on common package constructions is at the solder-joint, solder-bump, or micro-bump level. This is because the large CTE difference across the solder interface influences large shearing stresses across due to varying expansion rates of the surrounding materials. The two most common types of fatigue include specific factors that play an integral role in accelerating cyclic failure. For solders, failure can be defined based on a specified degree of permanent damage, by the formation of voids, or by a complete electrical short or open, all accelerated by thermomechanical phenomena absorbed at the solder joint-level. This observation lends way to predict electrical and mechanical failures in these devices by observation of solder stresses and strains. As a result, packaging and reliability engineers must become experts in not only predictive modeling techniques, but in the reliability physics governing solder fatigue phenomena. 


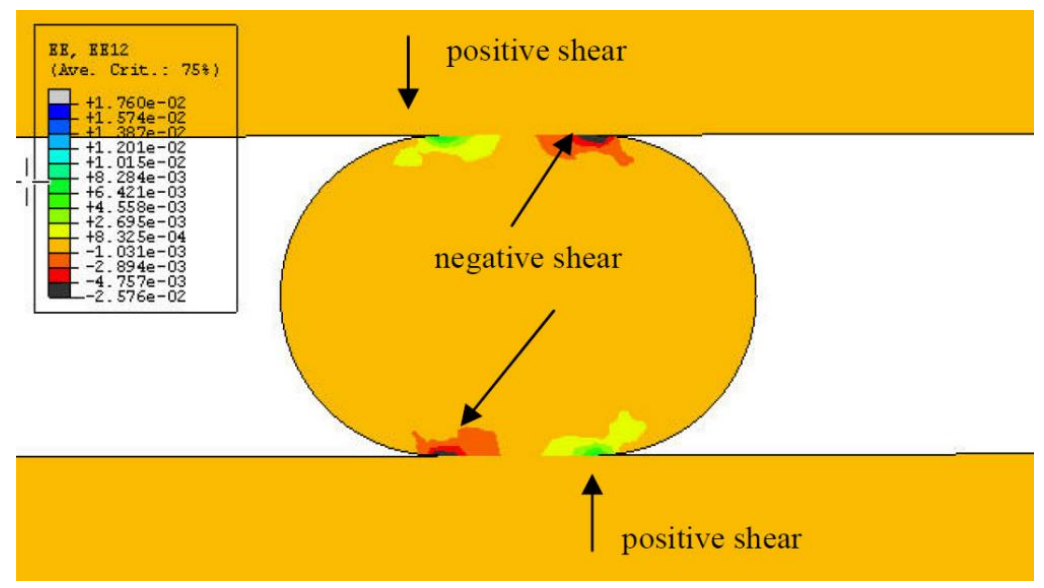

Figure 1.3: Finite-element representation of shearing stresses induced during cooling

\subsection{SAC-305 Lead-Free Solder Properties}

SAC-305 is a solder material that is specifically designed to maximize electrical conductivity and mechanical stability and minizine the risk of failure and cost required to perform quick bumping and reflow operations during manufacture.

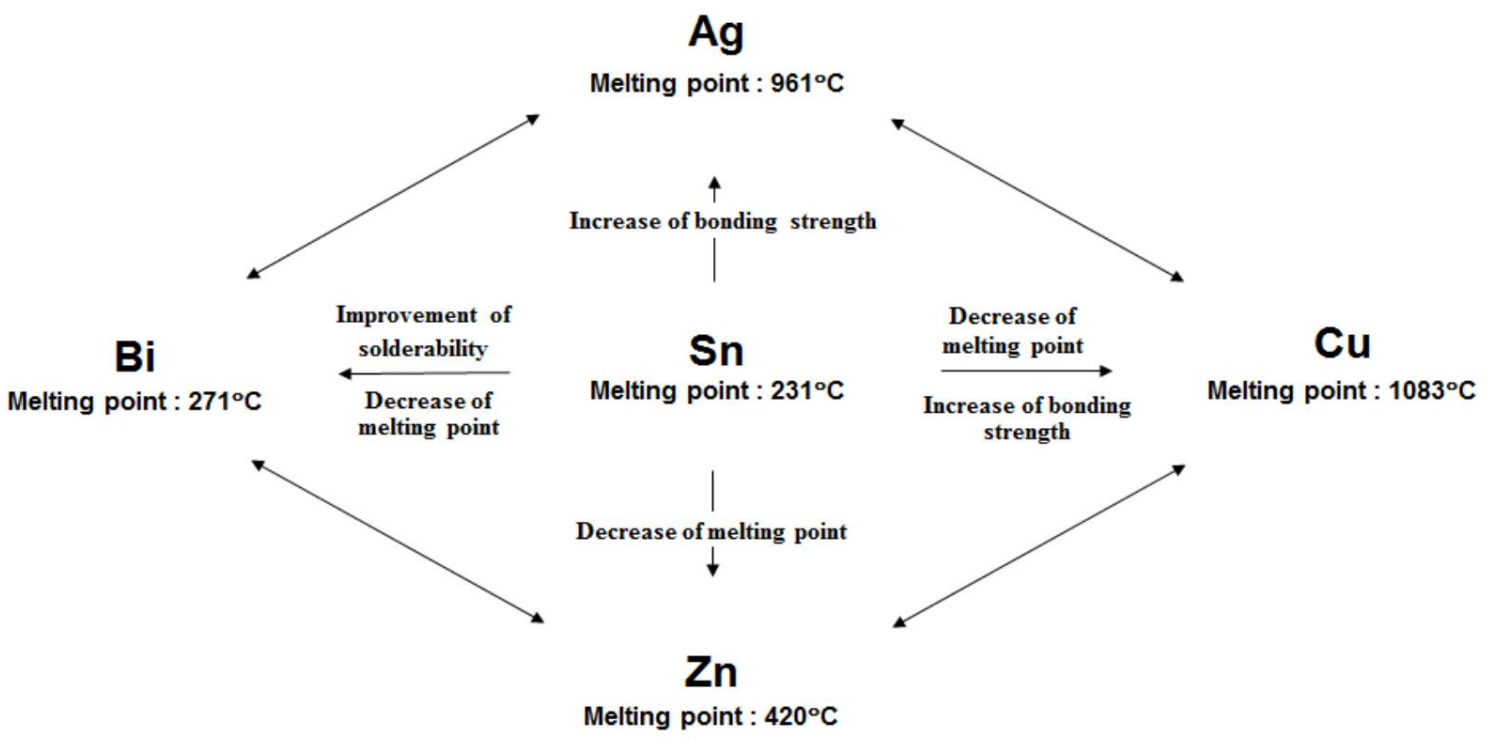

Figure 1.4: Solder elements (Yi 2019) 
Many parameters affect the choice between different lead-free solders, which include requirements on manufacturability (wettability, re-workability, liquidous temperature, solidus temperature, surface tension), mechanical stability (Young's Modulus, Poisson's Ratio, shear strength, tensile strength, hardness, elongation), electrical performance (electrical conductivity, density), and thermal performance (thermal conductivity, thermal diffusivity, density). It is not advised to choose a lower-cost solder option until all of these requirements are met, as the cost of addressing zero-cycle (integration) failures and in-field failures often greatly outweigh the materials purchasing cost.

\subsection{Constitutive Equations for Solder}

Lead-free solder is considered a visco-plastic material where the relationship between stress and plastic strain does not follow a linear path.

$$
\gamma=\gamma^{(e)}+\gamma^{(v p)}
$$

And

$$
\dot{\gamma}=\dot{\gamma}^{(e)}+\dot{\gamma}^{(v p)}
$$

where $\dot{\gamma}$ represents the creep strain component, $\dot{\gamma}^{(e)}$ represents the elastic shear strain component, $\dot{\gamma}^{(p)}$ represents the plastic strain component, and $\dot{\gamma}^{(v p)}$ represents the viscoplastic strain component. Furthermore, we write the elastic shear strain component as 


$$
\dot{\gamma}^{(e)}=\frac{\dot{\tau}}{G}
$$

where $\dot{\tau}$ represents the time-dependent component, and $\mathrm{G}$ represents the modulus of rigidity. Next, the visco-plastic component of strain is expressed as

$$
\dot{\gamma}^{(v p)}=\frac{d \gamma^{(v p)}}{d t}=C_{3} \exp \left[\frac{-\Delta H}{\kappa(T+273.15)}\right] \tau^{n}
$$

where $C_{3}$ is a constant, $\Delta H$ is the activation energy, $\mathrm{K}$ is the Boltzmann's constant (8.63 • $\left.10^{-5} \mathrm{eV} / \mathrm{K}\right)$, $\mathrm{T}$ is operating temperature, and $\mathrm{n}$ is the shear stress component.

Additionally, equation [2] can be written as

$$
\dot{\gamma}=\dot{\gamma}^{(e)}+\dot{\gamma}^{(p)}+\dot{\gamma}^{(c)}
$$

where $\dot{\gamma}^{(c)}$ represents the creep strain component. We consider creep as plastic strain that is dependent on both time and temperature. In building a material models to characterize mechanical behavior, and in building finite-element models for verification, it is critical that chosen methods of analysis match closely with dominant components of plastic strain, which will be discussed further in our study.

The elastic and non-elastic regions of strain are separated by specified progressions of strain during thermal or mechanical loading. Elastic strain that is exhibited pre-yield point does not depend on time, as seen in Figure 1.4. Successive applications of the Anand 
constitutive visco-plastic model accurately predict regions of creep, and methods of accounting for these parameters are explained in detail within Chapter 2.

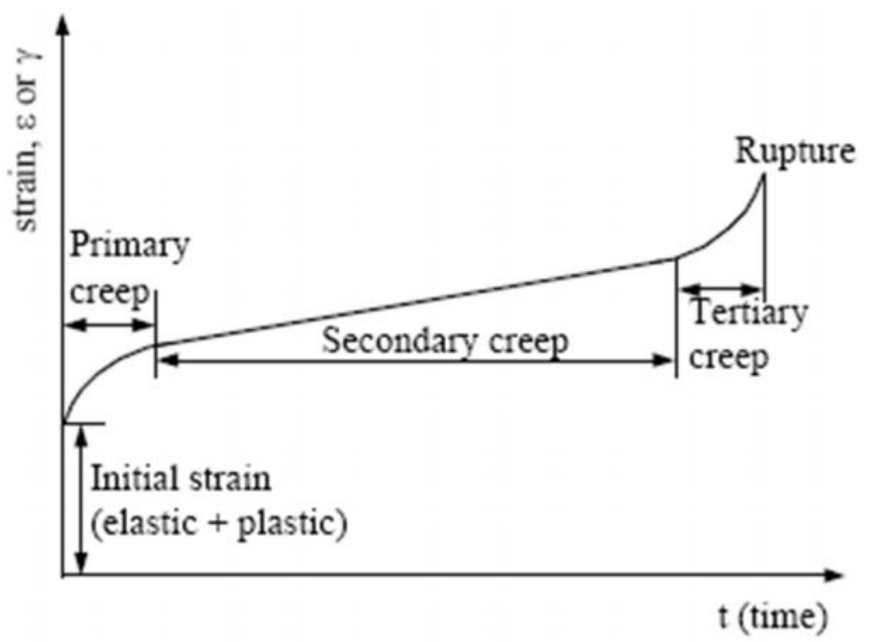

Figure 1.5: Typical Creep Behaviors of Solders

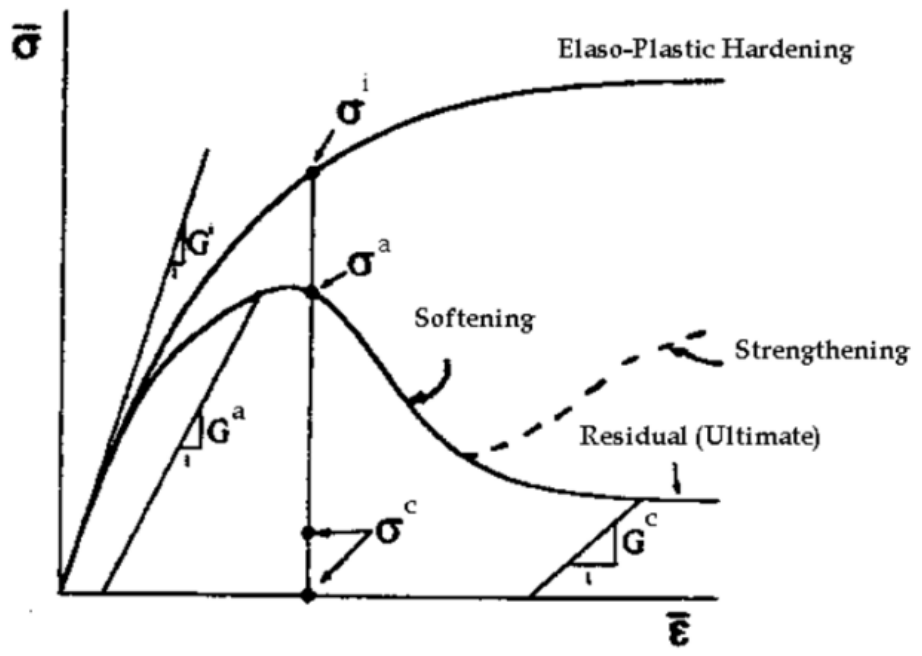

Figure 1.6: Elasto-Plastic Behaviors of Solders 


\section{Chapter 2}

\section{Verification Studies}

To verify the validity of applying the unified Anand constitutive model to describe for lead-free solders, we must apply our knowledge of both elastic and visco-plastic to characterize fundamental connections between stresses, strains, and deformations. Experimental data is curve-fit to extract Anand parameters that are used to build an improved material model, allowing for more accurate fatigue-life predictions for electronic packaging applications.

\subsection{Anand viscoplastic constitutive model}

Solder materials, like most metallic compositions and alloys, is expected to undergo any combination of elastic, plastic, or visco behavior during manufacture or during in-field operation.

Through deriving the constitutive equations for viscoplastic material modeling, we must introduce a scalar internal variable, $\mathrm{s}$, which represents the isotropic resistance to plastic flow. Considering the fundamentals of continuum (solid) mechanics, scalar accounts for differences in the internal state of a material, and successive derivations of this internal state provide a connection between given stress states on viscoplastic materials and the body's resulting deformation. 


\subsubsection{Formulation of one-dimensional uni-axial loading}

For uni-directional stress following cartesian coordinates, we write

$$
\sigma=c s ; \quad c>1
$$

where $\sigma$ represents stress, $\mathrm{c}$ represents a material parameter dependent on both strain rate and temperature, $\mathrm{s}$ is a scalar used to characterize a solid's internal structure and isotropic resistance to plastic flow. Then, we define $\mathrm{c}$ as

$$
c=\frac{1}{\xi} \sinh ^{-1}\left\{\left[\frac{\dot{\epsilon}_{p}}{A} e^{\frac{Q}{R T}}\right]^{m}\right\}
$$

$\mathrm{c}$ is a function of both plastic strain rate and absolute temperature, expressed as

$$
c=c\left(\dot{\epsilon}_{p}, T\right)
$$

Therefore, by substituting equations (2.1) and (2.2) we obtain

$$
\sigma=\frac{s}{\xi} \sinh ^{-1}\left\{\left[\frac{\dot{\epsilon}_{p}}{A} e^{\frac{Q}{R T}}\right]^{m}\right\}
$$

where $\dot{\epsilon}_{p}$ is the plastic strain rate, $\mathrm{A}$ is the pre-exponential factor, $\xi$ is the stress multiplier, $\mathrm{Q}$ is the activation energy, $\mathrm{R}$ is the universal gas constant, and $\mathrm{m}$ is the strain rate sensitivity exponent. 
Re-arranging the expression for stress, Eqn. (2.4), into the strain rate (flow equation) we find

$$
\dot{\epsilon}_{p}=A e^{\left(-\frac{Q}{R T}\right)}\left[\sinh \left(\xi \frac{\sigma}{s}\right)\right]^{\frac{1}{m}}
$$

We assume that the differential form of the evolution equation for internal variable $\mathrm{s}$ is written as

$$
\dot{s}=h(\sigma, s, T) \dot{\epsilon}_{p}
$$

where the function $h(\sigma, s, T)$ associates dynamic hardening and recovery with stress, the internal variable, $\mathrm{s}$, and absolute temperature. Then, we write the expression for the ratedependent internal variable, $s$, as

$$
\dot{s}=\left[h_{o}\left(1-\frac{s}{s^{*}}\right)^{a} \operatorname{sign}\left(1-\frac{s}{s^{*}}\right)\right] \dot{\epsilon}_{p} ; a>1
$$

where $h_{0}$ is the hardening/softening constant, a is the strain rate sensitivity of the hardening/softening process, and $s^{*}$ is expressed as

$$
s^{*}=\hat{s}\left[\frac{\dot{\epsilon}_{p}}{A} e^{\frac{Q}{R T}}\right]^{n}
$$


where $\hat{\mathrm{s}}$ is the coefficient for deformation resistance saturation value, and $\mathrm{n}$ is the strain rate sensitivity of saturation (deformation resistance) value. For $s<s^{*}$, Eqn. (2.7) is rewritten as

$$
d s=h_{o}\left(1-\frac{s}{s^{*}}\right)^{a} d \epsilon_{p}
$$

By integrating Eq. (2.9) we obtain

$$
s=s^{*}-\left[\left(s^{*}-s_{o}\right)^{(1-a)}+(a-1)\left\{\left(h_{o}\right)\left(s^{*}\right)^{-a}\right\} \epsilon_{p}\right]^{\frac{1}{1-a}}
$$

where $s_{0}=s(t=0)$. Substituting Eq. (2.8) into Eq. (2.10), the evolution equation is written as

$$
s=\hat{s}\left[\frac{\dot{\epsilon}_{p}}{A} e^{\frac{Q}{R T}}\right]^{n}-\left[\left[\hat{s}\left[\frac{\dot{\epsilon}_{p}}{A} e^{\frac{Q}{R T}}\right]^{n}-s_{o}\right]^{(1-a)}+(a-1)\left[h_{o}\left(\hat{s}\left[\frac{\dot{\epsilon}_{p}}{A} e^{\frac{Q}{R T}}\right]^{n}\right)^{-a}\right] \epsilon_{p}\right]^{\frac{1}{1-a}}
$$

Therefore, $\mathrm{s}$ is written as a function of both plastic strain rate and plastic strain, expressed as

$$
s=s\left(\dot{\epsilon_{p}}, \epsilon_{p}\right)
$$




\subsubsection{Theoretical formulation of uni-axial stress-strain response}

Depending on the magnitude of stress, solder continuum bodies exhibit mechanical behavior that is either elastic or viscoplastic. For the present study, we consider the region of strain below a material's yield point as containing only elastic behavior, so we write the uni-axial stress-strain response (Hooke's Law) as

$$
\sigma=E \epsilon
$$

for $\epsilon<0.02 \%$, where E represents the elastic modulus of a material. The post-yield stress-strain response is obtained by substitutitng the evolution equation, Eq. (2.11), into the stress equation, Eq. (2.4), as

$$
\begin{aligned}
\sigma & =\frac{1}{\xi} \sinh ^{-1}\left\{\left[\frac{\dot{\epsilon}_{p}}{A} e^{\frac{Q}{R T}}\right]^{m}\right\} \\
& {\left[\hat{s}\left[\frac{\dot{\epsilon}_{p}}{A} e^{\frac{Q}{R T}}\right]^{n}-\left[\left(\hat{s}\left[\frac{\dot{\epsilon}_{p}}{A} e^{\frac{Q}{R T}}\right]^{n}-s_{o}\right)^{(1-a)}+(a-1)\left\{\left(h_{o}\right)\left(\hat{s}\left[\frac{\dot{\epsilon}_{p}}{A} e^{\frac{Q}{R T}}\right]^{n}\right)^{-a}\right\} \epsilon_{p}\right]^{\frac{1}{1-a}}\right.}
\end{aligned}
$$

for $\epsilon>0.02 \%$. Thu: $=$ itress is a function of both plastic strain rate and plastic strain, written as

$$
\sigma=\sigma\left(\dot{\epsilon}_{p}, \epsilon_{p}\right)
$$


For a uni-axial tensile test performed at constant strain rate, $\epsilon_{p}$, and constant temperature, $\mathrm{T}$, a power law is written to account for highly non-linear stress-strain behavior post-yield:

$$
\sigma=\sigma\left(\epsilon_{p}\right)
$$

The Anand model prediction must account for both UTS (maximum / saturation stress) and yield stress by considering the extreme case for the UTS for which $\epsilon_{p} \rightarrow \infty$ in Eq. (2.14), so we can define the UTS as

$$
\sigma^{*}=\frac{\hat{s}}{\xi}\left[\frac{\dot{\epsilon}_{p}}{A} e^{\frac{Q}{R T}}\right]^{n} \sinh ^{-1}\left\{\left[\frac{\dot{\epsilon}_{p}}{A} e^{\frac{Q}{R T}}\right]^{m}\right\}=U T S
$$

and for $\epsilon_{p} \rightarrow 0$ we can define the yield stress as

$$
\sigma_{Y}=\left.\sigma\right|_{\epsilon_{p} \rightarrow 0}=\frac{s_{0}}{\xi} \sinh ^{-1}\left\{\left[\frac{\dot{\epsilon}_{p}}{A} e^{\frac{Q}{R T}}\right]^{m}\right\}=c s_{0} \equiv \sigma_{0}
$$

where $s_{0}=s(t=0)$, and $\mathrm{c}$ is a material parameter. Therefore, Eqn. (2.17) can be used to re-write the post-yield stress-strain response as

$$
\sigma=\sigma^{*}-\left[\left(\sigma^{*}-c s_{o}\right)^{(1-a)}+(a-1)\left\{\left(c h_{o}\right)\left(\sigma^{*}\right)^{-a}\right\} \epsilon_{p}\right]^{\frac{1}{1-a}}
$$




\subsubsection{Theoretical Formulation of Creep Response}

Substituting the evolution formulation Eq. (2.11) in the flow equations, Eq. (2.5) and Eq. (2.20), relates strain rate to applied stress, strain, and temperature, which hereby provides the appropriate strain rate-dependent, temperature-dependent, post-yield creep response for viscoplastic solder:

$$
\dot{\epsilon}_{p}=A e^{\left(-\frac{Q}{R T}\right)}\left[\sinh \left(\xi \frac{\sigma}{s}\right)\right]^{\frac{1}{m}}
$$

where

$$
s=\hat{s}\left(\frac{\dot{\epsilon}_{p}}{A} e^{\frac{Q}{R T}}\right)^{n}-\left[\hat{s}\left(\frac{\dot{\epsilon}_{p}}{A} e^{\frac{Q}{R T}}\right)^{n}-s_{o}{ }^{(1-a)}+(a-1)\left[h_{o} \hat{s}\left(\frac{\dot{\epsilon}_{p}}{A} e^{\frac{Q}{R T}}\right)^{n-a}\right] \epsilon_{p}\right]^{\frac{1}{1-a}}
$$

Internal variable, s, is substituted into Eq. (2.11) to obtain

$$
\begin{aligned}
& \dot{\epsilon}_{p}=A e^{\left(-\frac{Q}{R T}\right)}
\end{aligned}
$$

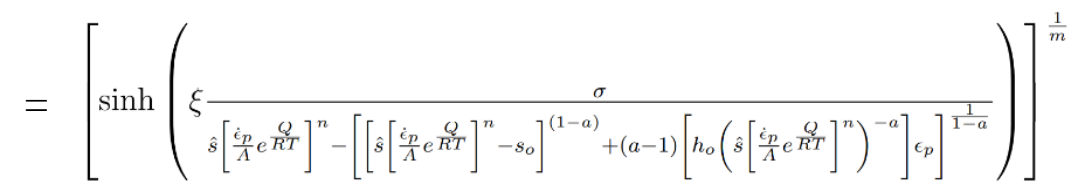

Then, Eq. (2.22) can be re-arranged to solve for plastic strain, where we obtain

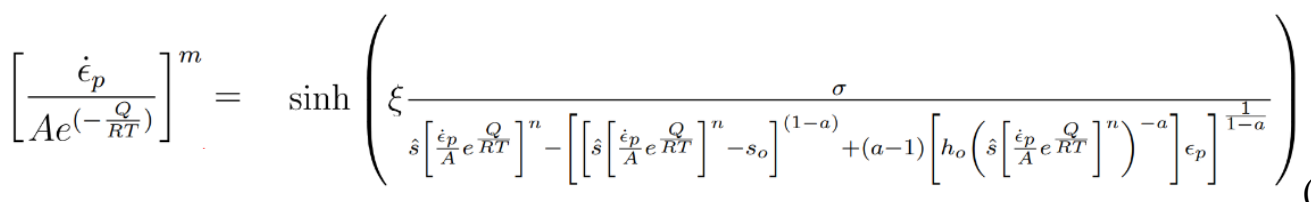


Taking the inverse hyperbolic sine of both sides leads to

$$
\sinh ^{-1}\left[\left[\frac{\dot{\epsilon}_{p}}{A e^{\left(-\frac{Q}{R T}\right)}}\right]^{m}\right]=\left(\frac{\xi \sigma}{\hat{s}\left[\frac{\dot{e}_{p}}{A} e \frac{Q}{R T}\right]^{n}-\left[\left[\hat{s}\left[\frac{\dot{e}_{p}}{A} e \frac{Q}{R T}\right]^{n}-s_{o}\right]^{(1-a)}+(a-1)\left[h_{o}\left(\hat{s}\left[\frac{\dot{e}_{p}}{A} e \frac{Q}{R T}\right]^{n}\right)^{-a}\right]_{\epsilon_{p}}^{\frac{1}{1-a}}\right.}\right)
$$

Next, let us define B as

$$
B=\hat{s}\left[\frac{\dot{\epsilon}_{p}}{A} e^{\frac{Q}{R T}}\right]^{n}
$$

such that Eq. (2.24) can be re-written as

$$
\begin{gathered}
\left.\frac{\xi \sigma}{\sinh ^{-1}\left[\left[\frac{\dot{\epsilon}_{p}}{A e^{\left(-\frac{Q}{R T}\right)}}\right]^{m}\right]}=B-\left[B-s_{o}\right]^{(1-a)}+(a-1)\left[h_{o}(B)^{-a}\right] \epsilon_{p}\right]^{\frac{1}{1-a}} \\
\left.\frac{\xi \sigma}{\sinh ^{-1}\left[\left[\frac{\dot{\epsilon}_{p}}{A e^{\left(-\frac{Q}{R T}\right)}}\right]^{m}\right]}-B=-\left[B-s_{o}\right]^{(1-a)}+(a-1)\left[h_{o}(B)^{-a}\right] \epsilon_{p}\right]^{\frac{1}{1-a}} \\
{\left[\frac{\xi \sigma}{\sinh ^{-1}\left[\left[\frac{\dot{\epsilon}_{p}}{A e^{\left(-\frac{Q}{R T}\right)}}\right]^{m}\right]}-B\right]^{(1-a)}=-\left[\left[B-s_{o}\right]^{(1-a)}+(a-1)\left[h_{o}(B)^{-a}\right] \epsilon_{p}\right]} \\
{\left[\frac{\xi \sigma}{\sinh ^{-1}\left[\left[\frac{\dot{\epsilon}_{p}}{A e^{\left(-\frac{Q}{R T}\right)}}\right]^{m}\right]}-B\right]^{(1-a)}+\left[B-s_{o}\right]^{(1-a)}=-(a-1)\left[h_{o}(B)^{-a}\right] \epsilon_{p}}
\end{gathered}
$$


Then distributing the negative sign through we have

$$
-\left[\frac{\xi \sigma}{\sinh ^{-1}\left[\left[\frac{\dot{\epsilon}_{p}}{A e^{\left(-\frac{Q}{R T}\right)}}\right]^{m}\right]}+B\right]^{(1-a)}+\left[B-s_{o}\right]^{(1-a)}=(a-1)\left[h_{o}(B)^{-a}\right] \epsilon_{p}
$$

Thus, plastic strain is expressed as

$$
\epsilon_{p}=\frac{\left[-\frac{\xi \sigma}{\sinh ^{-1}\left[\left[\frac{\dot{\epsilon}_{p}}{A e^{\left(-\frac{Q}{R T}\right)}}\right]^{m}\right]}-B-\left[B-s_{o}\right]\right]^{(1-a)}}{(a-1) h_{o}(B)^{-a}}
$$

where

$$
\mathrm{B}=\left[\frac{\dot{\epsilon}_{p}}{A} e^{\frac{Q}{R T}}\right]^{n}
$$

Therefore, the theoretical formulation of the Anand Model for creep response is written

as

$$
\epsilon_{p}=\frac{\left[\frac{\xi \sigma}{\sinh ^{-1}\left[\left[\frac{\dot{\epsilon}_{p}}{A e^{\left(-\frac{Q}{R T}\right)}}\right]^{m}\right]}-\hat{s}\left[\frac{\dot{\epsilon}_{p}}{A} e^{\frac{Q}{R T}}\right]^{n}-\left[\hat{s}\left[\frac{\dot{\epsilon}_{p}}{A} e^{\frac{Q}{R T}}\right]^{n}-s_{o}\right]\right]^{(1-a)}}{(a-1) h_{o}\left(\hat{s}\left[\frac{\dot{e}_{p}}{A} e^{\frac{Q}{R T}}\right]^{n}\right)^{-a}}
$$




\subsection{Experimental Data Comparison}

Testing data provides application-specific stress-strain information on the mechanical integrity of modern solder material, which exhibits non-linear accumulation of plastic strain unique to varying thresholds of strain-rate and temperature conditions. Through curve-fitting the Anand visco-plastic constitutive model, researchers can assign nine parameters to model non-linear behavior. However, because the accumulation of plastic strain is unique to each combination of temperature and strain-rate, the accuracy of this method must be verified across varying conditions. This is a critical verification step because the application of these parameters is typically all-encompassing, such as when it is used to model creep in Finite Element Analysis. Thus, error between experimental and modeled stress-strain data across various strain-rate and temperature conditions is investigated to verify the accuracy of improved modeling techniques.

Experimental data is obtained from researchers at Auburn University; in a conference proceeding paper (Motalab 2012) authors Motalab et. al. outlines a standard procedure with the goal of predicting SAC-305 creep behavior using the Anand viscoplastic model. Tests were performed by Motalab et. Al. Stress-strain data is gathered using a uniaxial tension/torsion mechanical tester at five different temperatures and three different strain rates.

The model uses a number of parameters to describe stress over the complete range of strain that can be obtained through standard experimental procedures for five variations of temperature and three variations of strain rate. A rectangular bar composed of the lead-free solder is produced such that a tensile uniaxial test is performed. 
The data of interest produced from these experiments are stress-strain curves, and this data set serves as a basis of understanding preceding efforts to improve modeling accuracy. The data allows us to calculate the Young's Modulus, Ultimate Tensile Strength, and Yield Strength across the fifteen individual cases of varying temperature and strain rate.

\subsubsection{Pre-yield mathematical model}

For regions of strain below $0.02 \%$, linear fitting is performed to strain-rate averaged data for each of the five temperatures. Strain-rate averaging is valid for this data because according to Hooke's Law, stress within the elastic limit is only dependent on temperature by virtue of the elastic modulus of a given material. If strain does not depend on time, that means that we do not assume creep is present, and therefore, this region should not be included in the Anand parameter curve-fitting process.

Available literature highlights varying methods of curve-fitting Anand parameters to experimentally determined stresses, however, most researchers use the entire region of strain to fit the data. To improve the formulation, we will only curve-fit the plastic region of strain for the Anand Parameters. In studying the stress-strain relation for $\mathrm{Pb}$-free solder, we separate the elastic and plastic regions of uni-axial strain, where the initial elastic region can be modeled using a linear formulation that is complimentary to Hooke's Law, while proceeding strains are modeled using the Anand visco-plastic model. According to fundamentals and engineering mechanics, the point that differentiates these two regions is by using a $0.02 \%$ offset from the yield point of the material. 
For each of the five tested temperature conditions, the modulus of elasticity for each strain rate are averaged, and the standard error for each are listed below. According to the constitutive equations for solder: for the initial elastic region of strain, it is known that strain rate is not considered a dependent variable, so the error associated with averaging is sufficient for measuring experimental error.

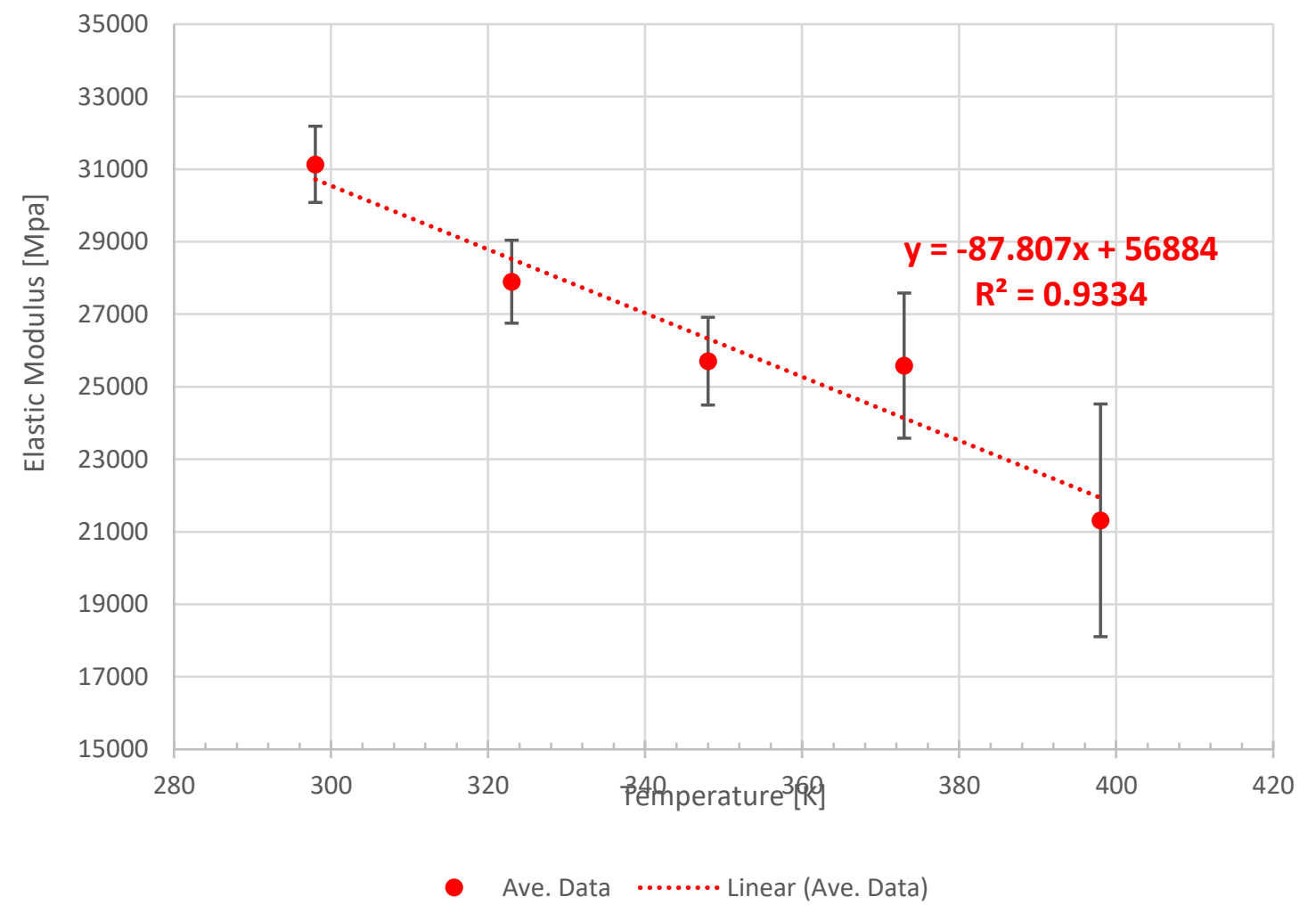

Figure 2.1: Pre-Yield Strain Rate-Averaged Elastic Modulus 


\subsubsection{Methods of Anand Parameter Extraction}

The Anand parameters used for finite-element modeling are found by curve-fitting experimental data conducted by Motalab et. Al. The constitutive parameters are extracted through curve-fitting the post-yield region of strain for the fifteen individual data points of varying strain rate and temperature. Using Microsoft Excel, a Generalized Reduced Gradient (GRG) non-linear solver algorithm is employed to minimize an objective function for standard error between experimental and model stress, Eq. (2.19), written as

$$
\sum_{n=15}^{i}\left(\sigma_{\text {model }}-\sigma_{\text {exp }}\right)^{2}
$$

and subject to constraints included in Table 2.2. The constraints imposed for each Anand parameter represent the smallest and largest values reported in literature. 


\begin{tabular}{|c|c|c|}
\hline $\begin{array}{c}\text { Anand } \\
\text { Parameter }\end{array}$ & Physical Meaning & Constraints \\
\hline$s_{0}$ & $\begin{array}{c}\text { Initial value of } \\
\text { deformation resistance }\end{array}$ & $13 \leq s_{0} \leq 30$ \\
\hline $\mathbf{Q} / \mathbf{R}$ & $\begin{array}{l}\text { Activation energy / } \\
\text { universal gas constant }\end{array}$ & $8200 \leq \mathbf{Q} / \mathbf{R} \leq 14000$ \\
\hline $\mathbf{A}$ & Pre-exponential factor & $3 \leq \mathbf{A} \leq 5$ \\
\hline$\xi$ & Stress multiplier & $0.3 \leq \xi \leq 5.0$ \\
\hline $\mathbf{m}$ & Strain rate sensitivity & $0.13 \leq \mathbf{m} \leq 0.40$ \\
\hline$h_{0}$ & $\begin{array}{l}\text { Hardening / softening } \\
\text { constant }\end{array}$ & $100000 \leq \boldsymbol{h}_{\mathbf{0}} \leq 240000$ \\
\hline$\hat{\boldsymbol{s}}$ & $\begin{array}{c}\text { Coefficient for } \\
\text { deformation resistance } \\
\text { saturation value }\end{array}$ & $20 \leq \hat{\boldsymbol{s}} \leq 55$ \\
\hline $\mathbf{n}$ & $\begin{array}{l}\text { Strain rate sensitivity of } \\
\text { saturation (deformation } \\
\text { resistance) value }\end{array}$ & $0.006 \leq \mathbf{n} \leq 0.03$ \\
\hline $\mathbf{a}$ & $\begin{array}{l}\text { Strain rate sensitivity of } \\
\text { hardening or softening }\end{array}$ & $1.3 \leq \mathbf{a} \leq 3.0$ \\
\hline
\end{tabular}

Table 2.1: Anand Parameters and their respective constraints used for the present study 


\begin{tabular}{ccc}
\hline $\begin{array}{c}\text { Anand } \\
\text { Parameter }\end{array}$ & $\begin{array}{c}\text { Motalab } \\
\text { Model }\end{array}$ & $\begin{array}{c}\text { Present } \\
\text { Model }\end{array}$ \\
\hline $\boldsymbol{s}_{\mathbf{0}}$ & 21.00 & 21.90 \\
$\mathbf{Q} / \mathbf{R}$ & 9320 & 11044 \\
$\mathbf{A}$ & 3501 & 2800 \\
$\boldsymbol{\xi}$ & 4 & 5 \\
$\mathbf{m}$ & 0.25 & 0.13 \\
$\boldsymbol{h}_{\mathbf{0}}$ & 180000 & 100000 \\
$\hat{\boldsymbol{s}}$ & 30.2 & 33.7622 \\
$\mathbf{n}$ & 0.010 & 0.023 \\
$\mathbf{a}$ & 1.78 & 1.98 \\
\hline
\end{tabular}

Table 2.2: Extracted Anand parameters obtained by curve-fitting 


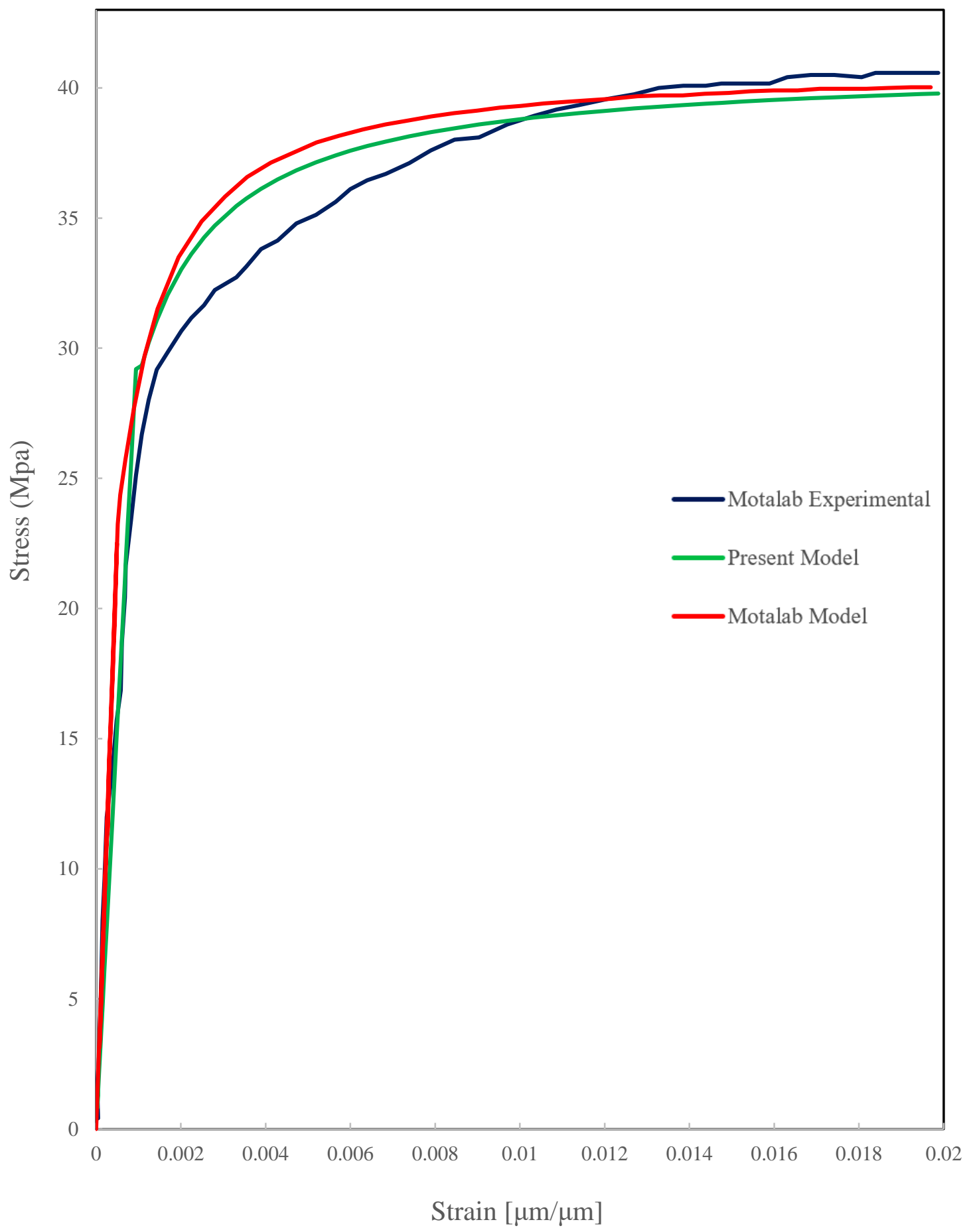

Figure 2.2: Stress vs Strain at $298 \mathrm{~K}$ and strain rate of $.001 \mathrm{~mm} / \mathrm{s}$ 


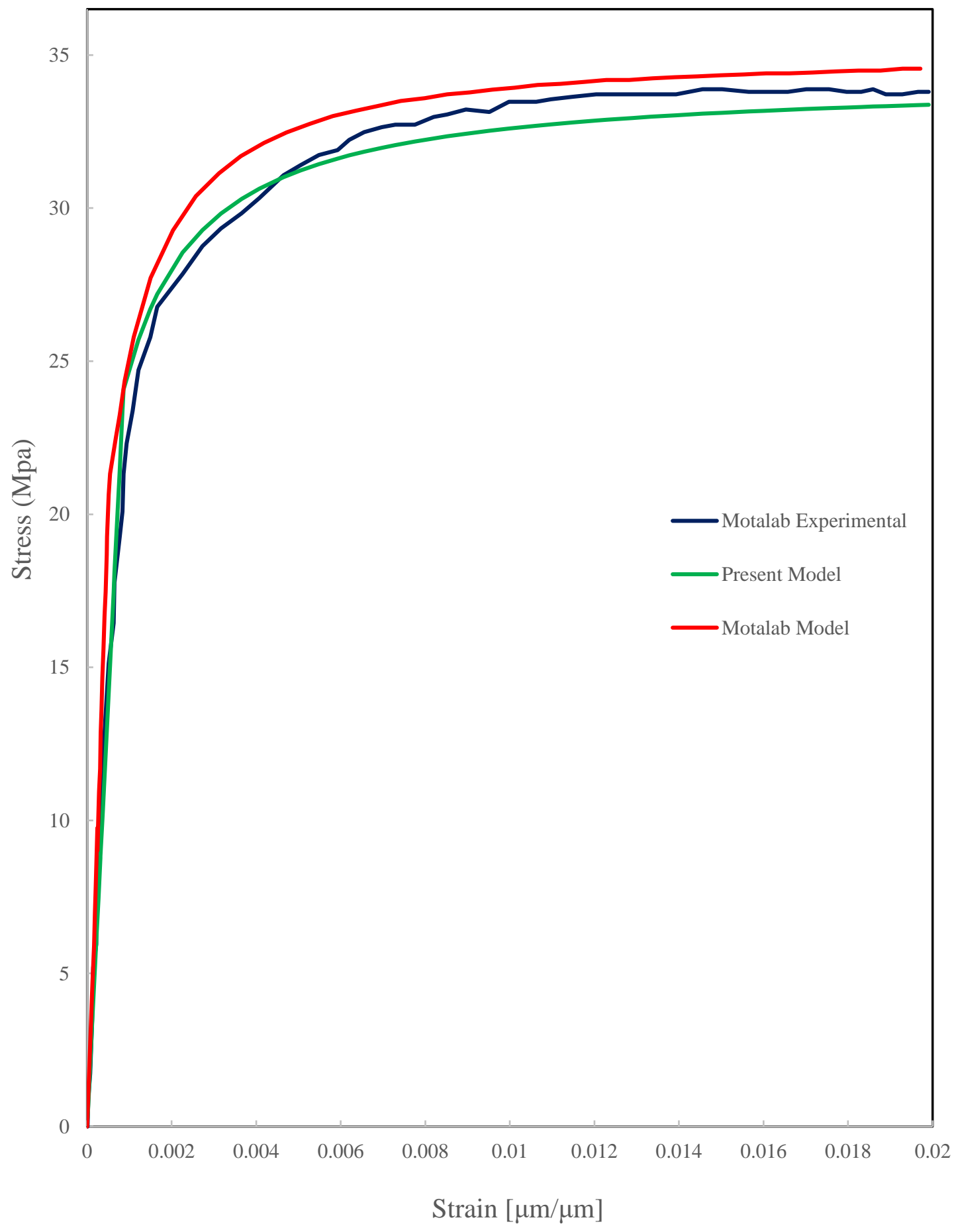

Figure 2.3: Stress vs Strain at $323 \mathrm{~K}$ and strain rate of $.001 \mathrm{~mm} / \mathrm{s}$ 


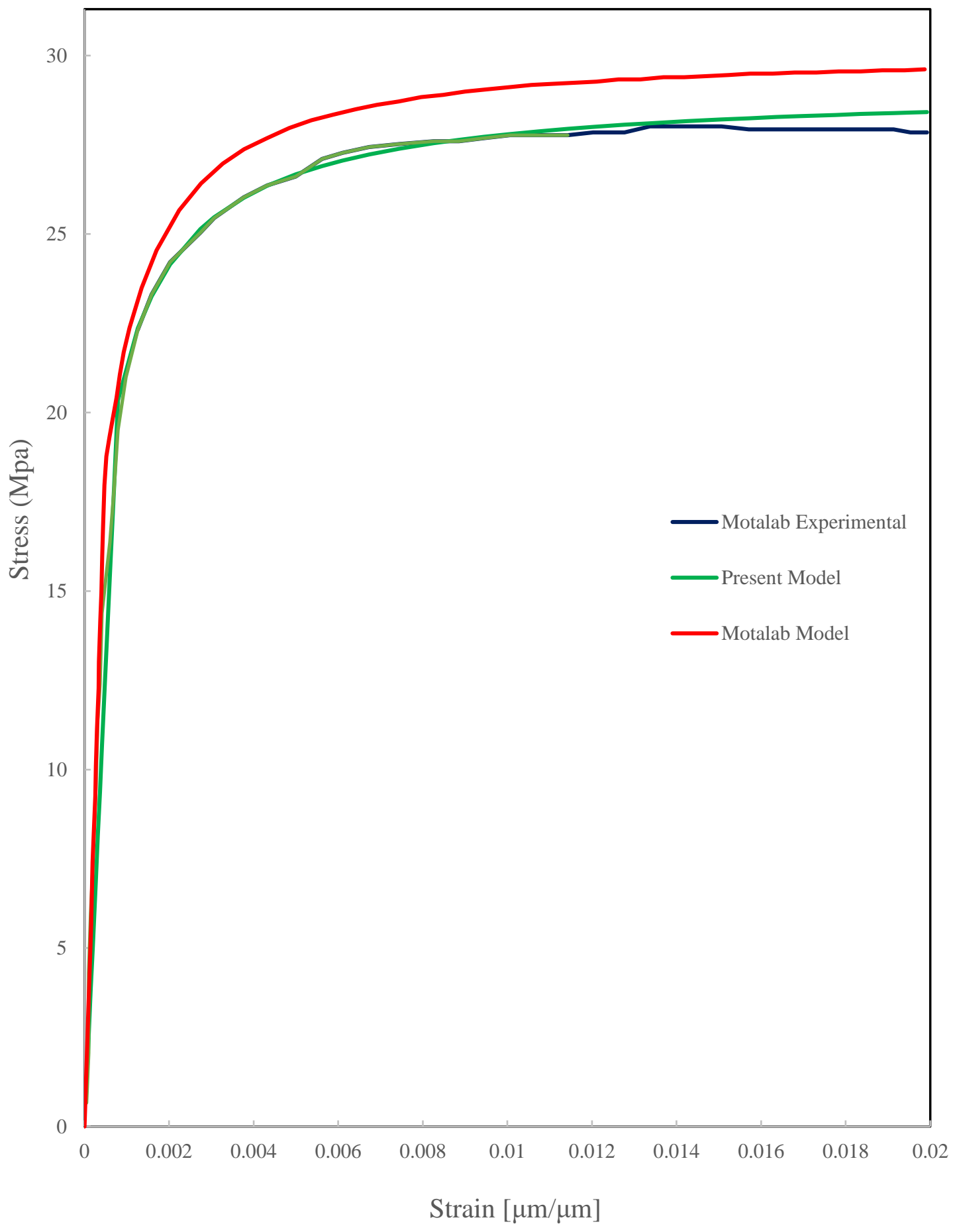

Figure 2.4: Stress vs Strain at $348 \mathrm{~K}$ and strain rate of $.001 \mathrm{~mm} / \mathrm{s}$ 


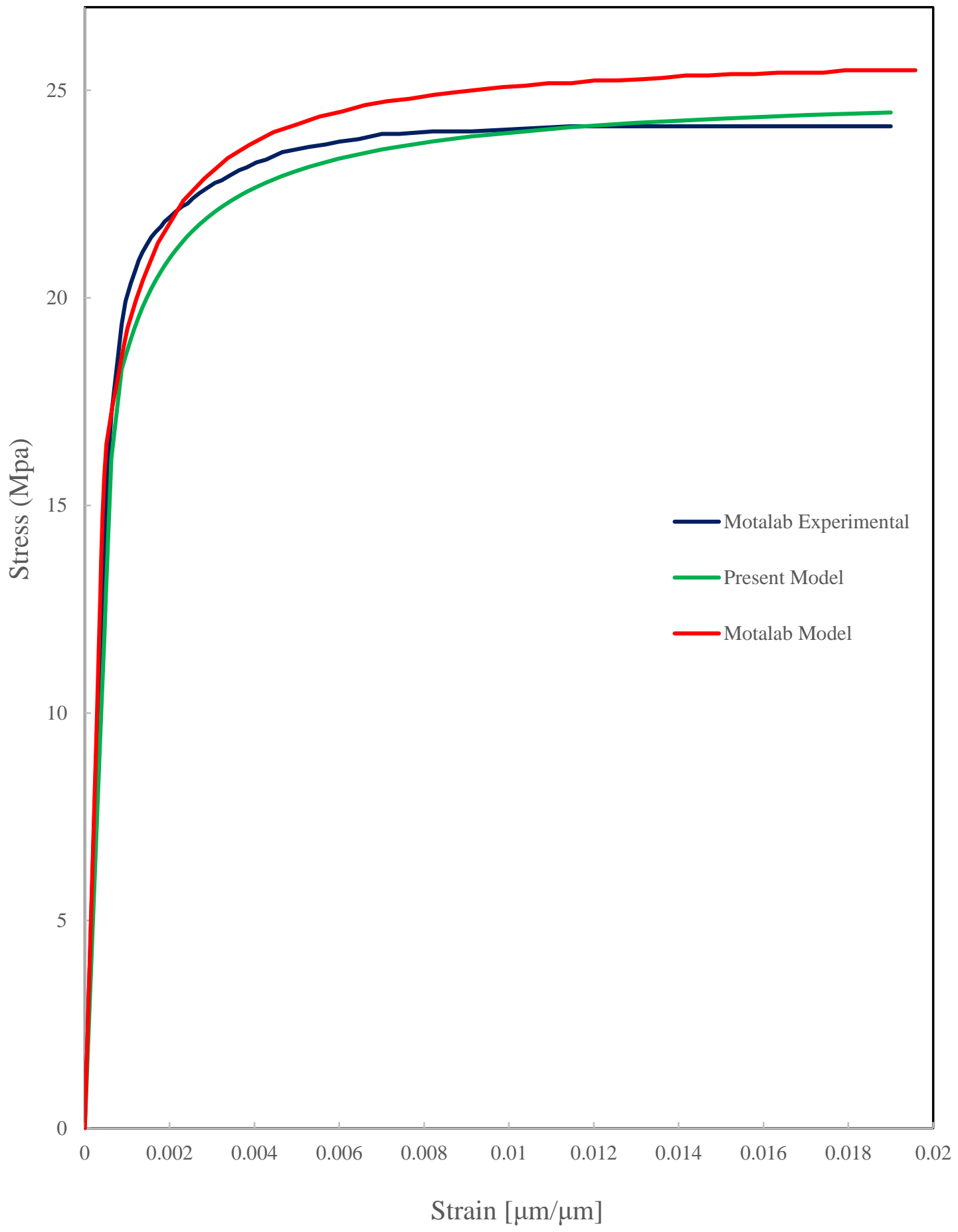

Figure 2.5: Stress vs Strain at $373 \mathrm{~K}$ and strain rate of $.001 \mathrm{~mm} / \mathrm{s}$ 


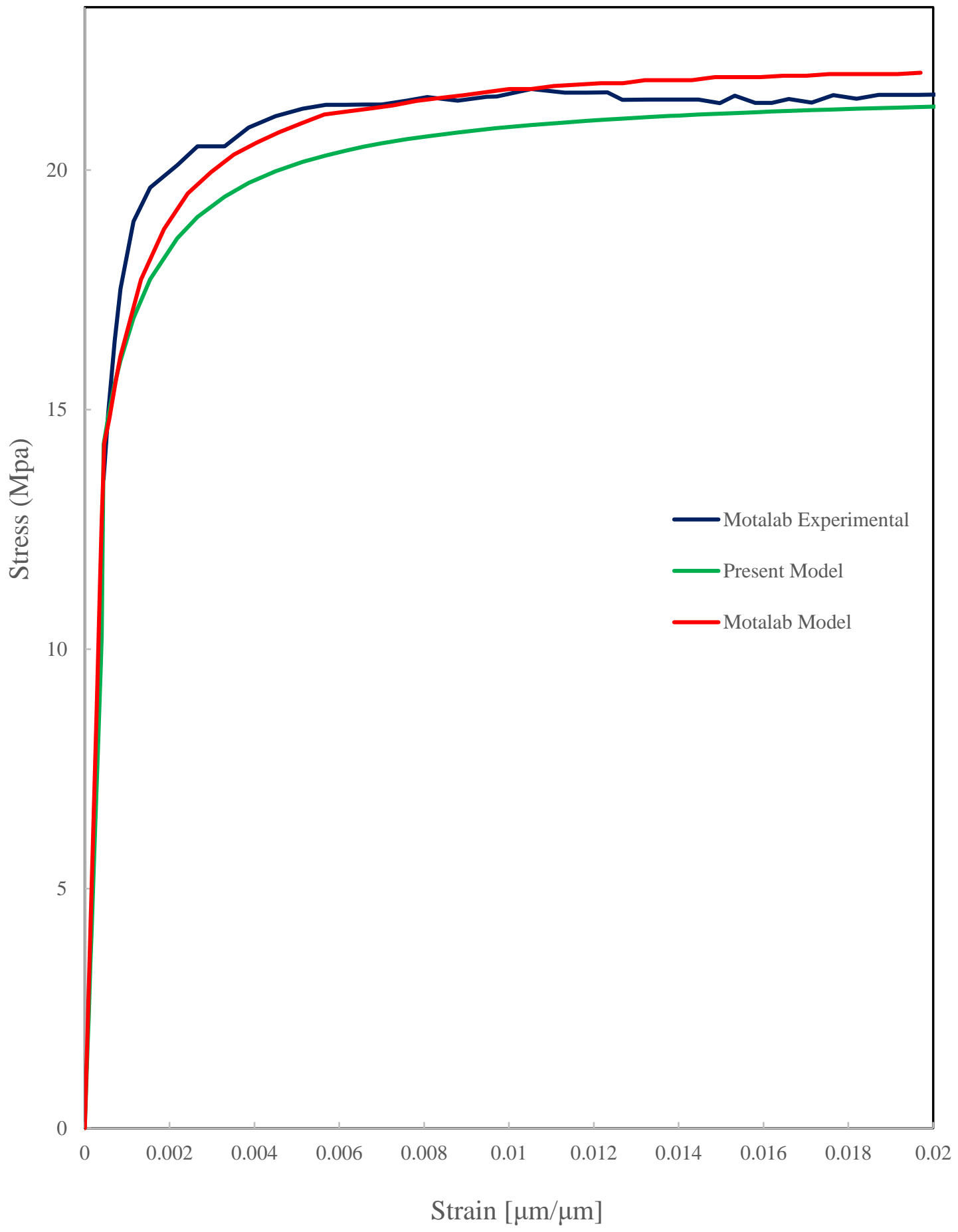

Figure 2.6: Stress vs Strain at $398 \mathrm{~K}$ and strain rate of $.001 \mathrm{~mm} / \mathrm{s}$ 


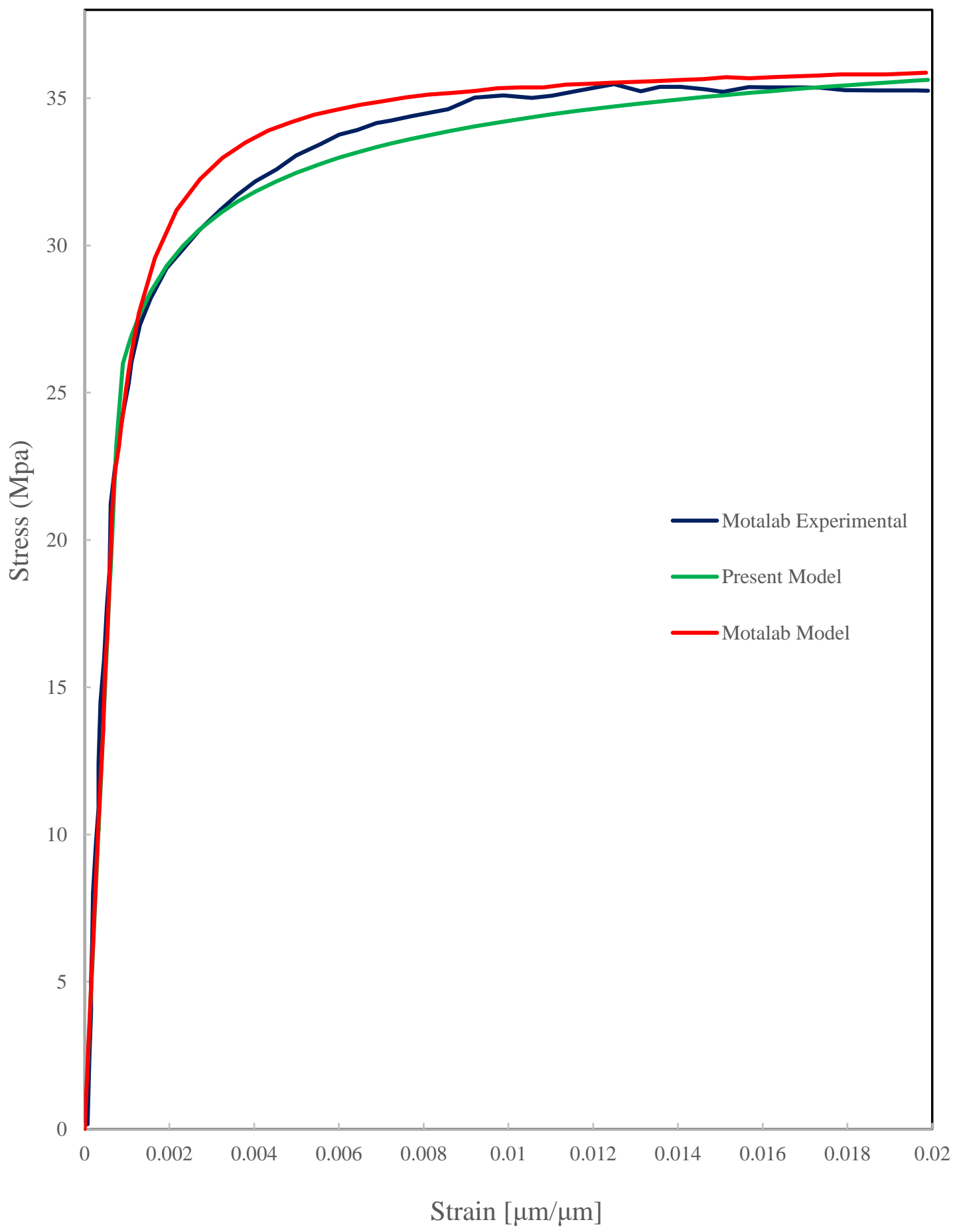

Figure 2.7: Stress vs Strain at $298 \mathrm{~K}$ and strain rate of $.0001 \mathrm{~mm} / \mathrm{s}$ 


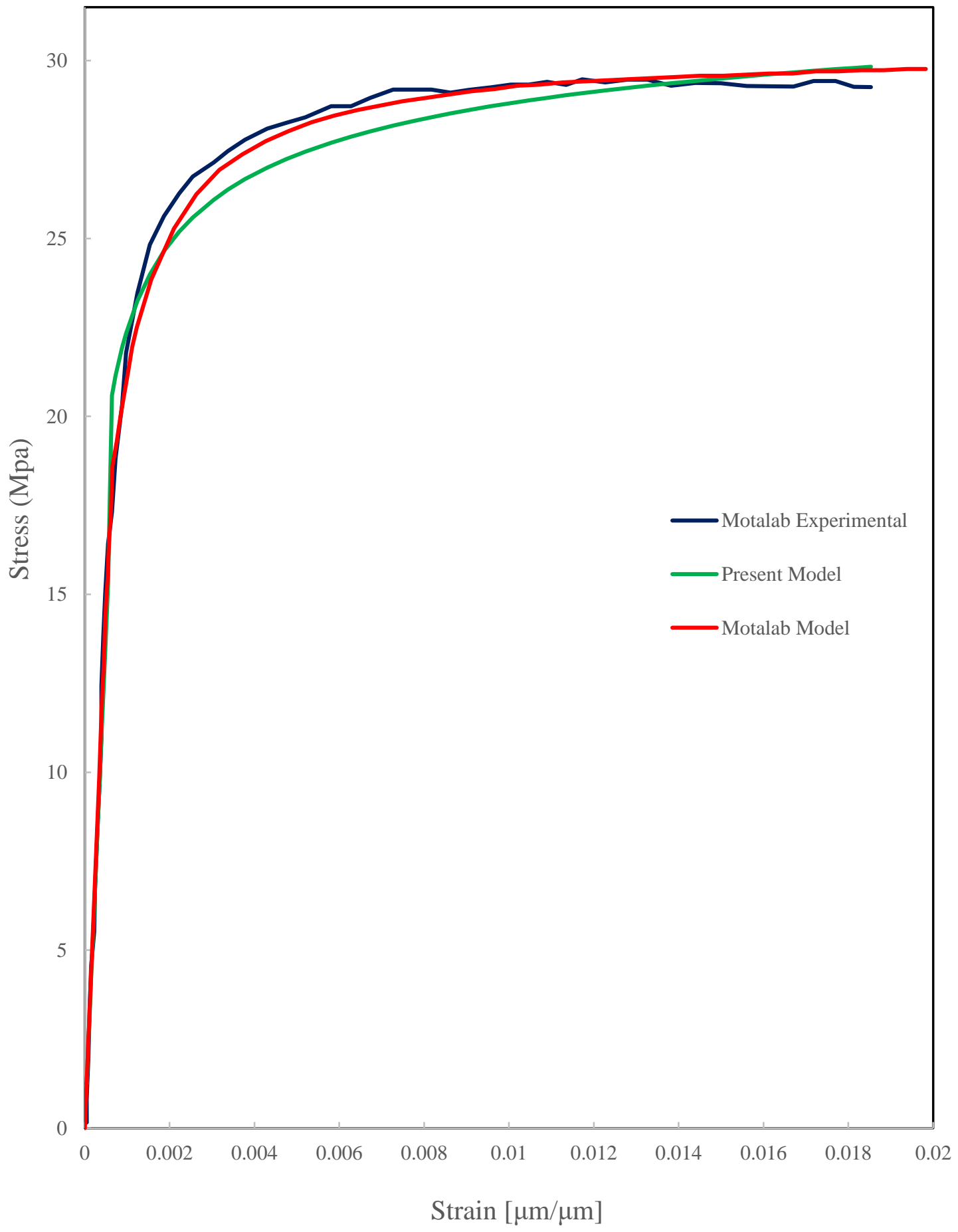

Figure 2.8: Stress vs Strain at $323 \mathrm{~K}$ and strain rate of $.0001 \mathrm{~mm} / \mathrm{s}$ 


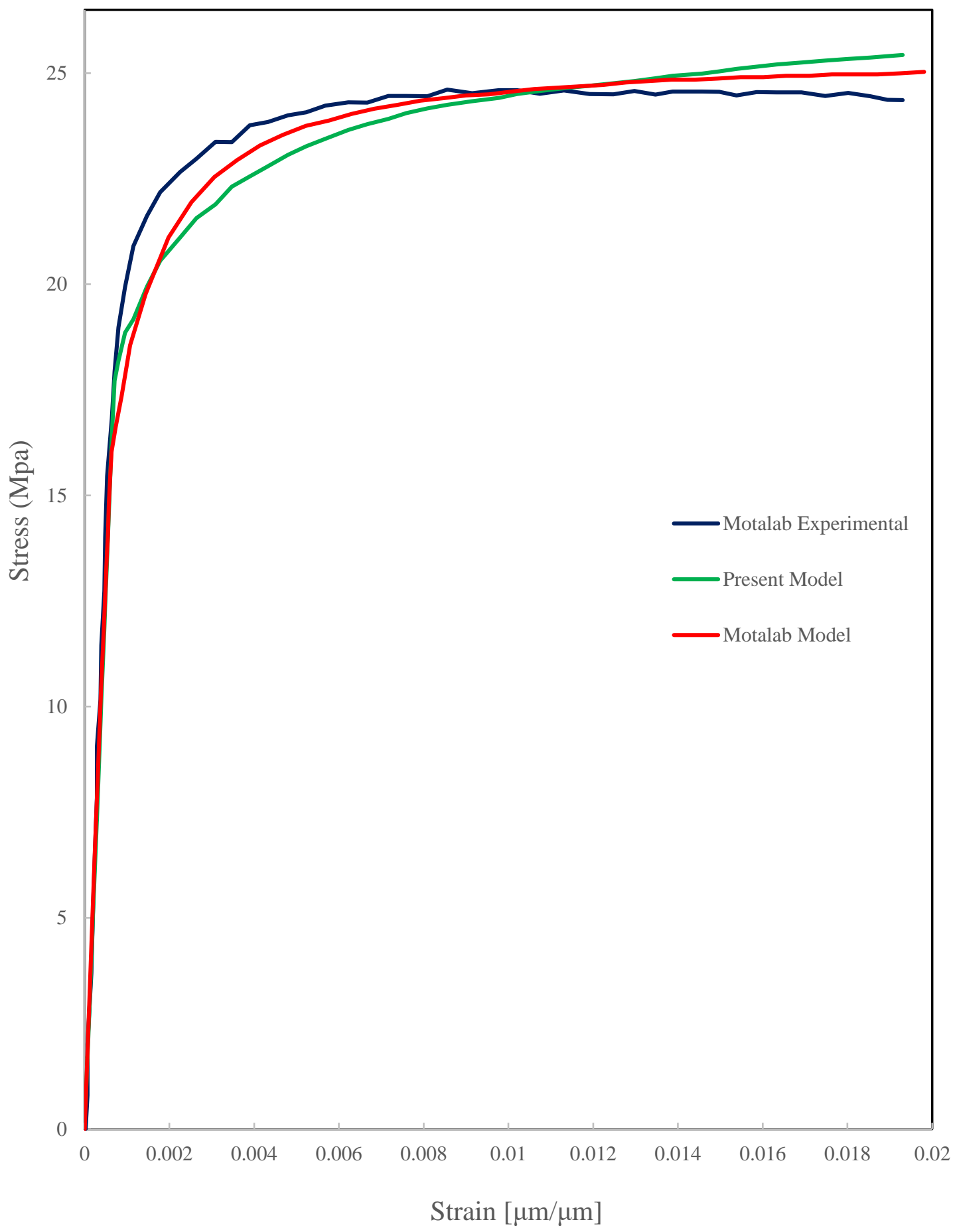

Figure 2.9: Stress vs Strain at 348K and strain rate of $.0001 \mathrm{~mm} / \mathrm{s}$ 


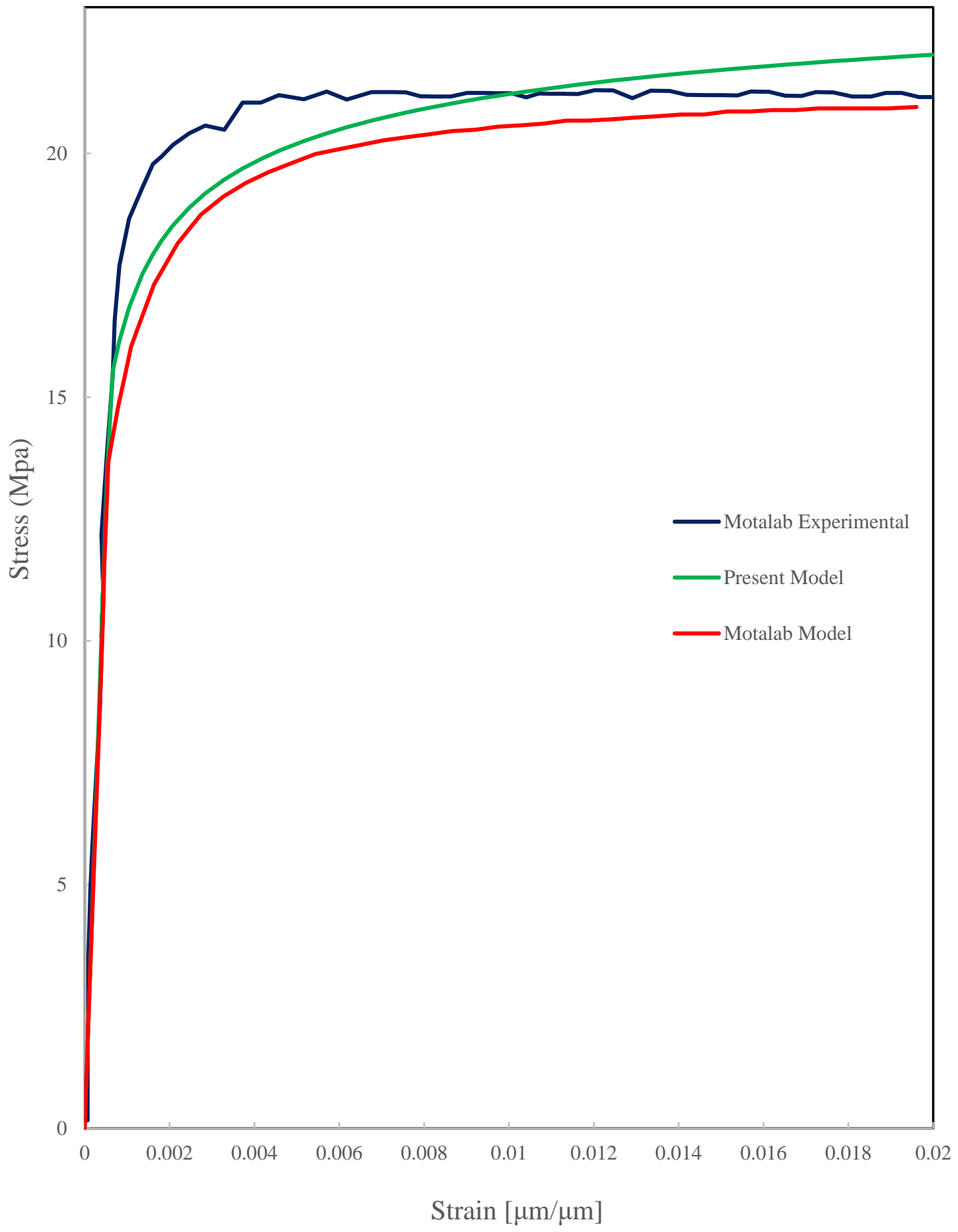

Figure 2.10: Stress vs Strain at $373 \mathrm{~K}$ and strain rate of $.0001 \mathrm{~mm} / \mathrm{s}$ 


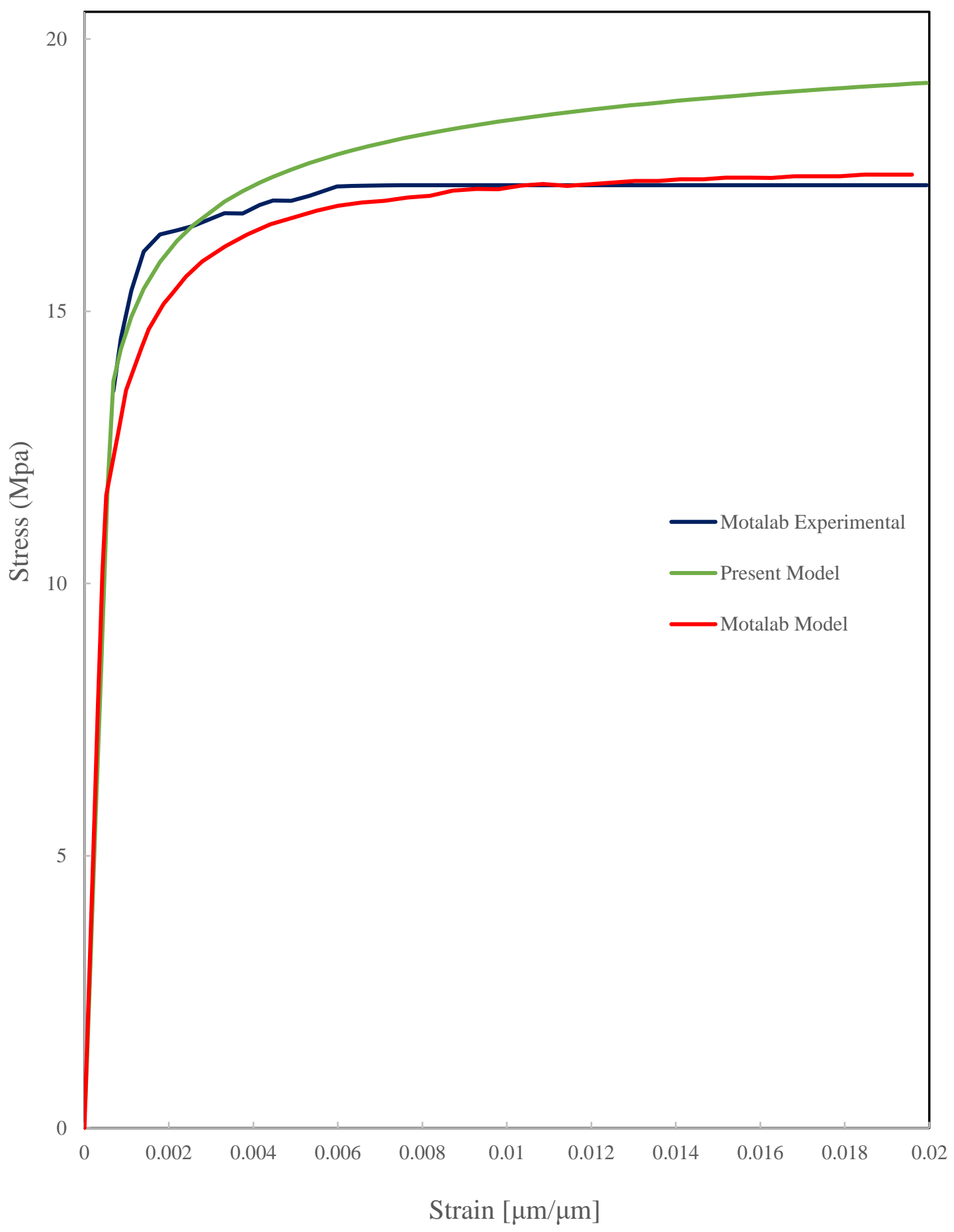

Figure 2.11: Stress vs Strain at 398K and strain rate of $.0001 \mathrm{~mm} / \mathrm{s}$ 


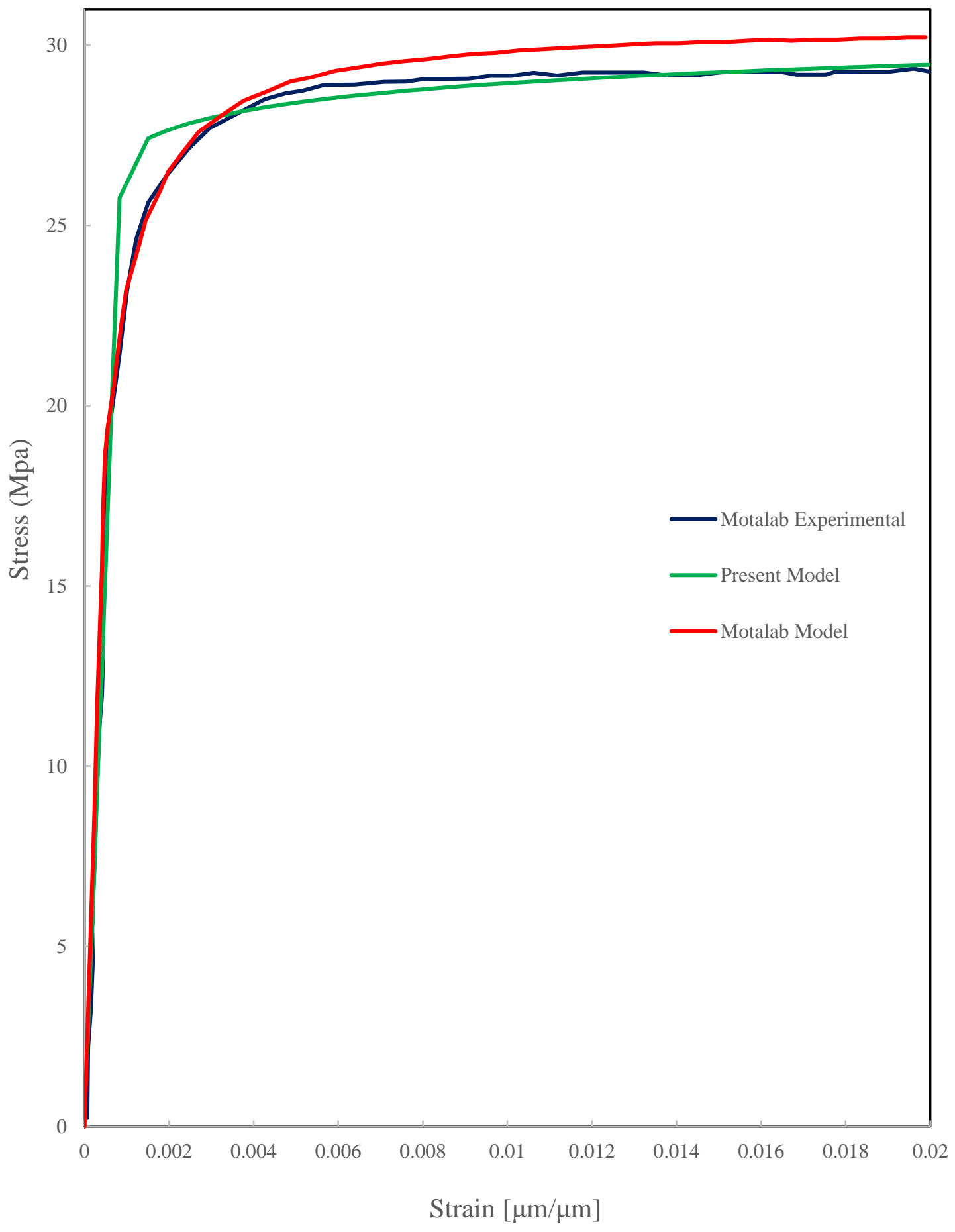

Figure 2.12: Stress vs Strain at $298 \mathrm{~K}$ and strain rate of $.00001 \mathrm{~mm} / \mathrm{s}$ 


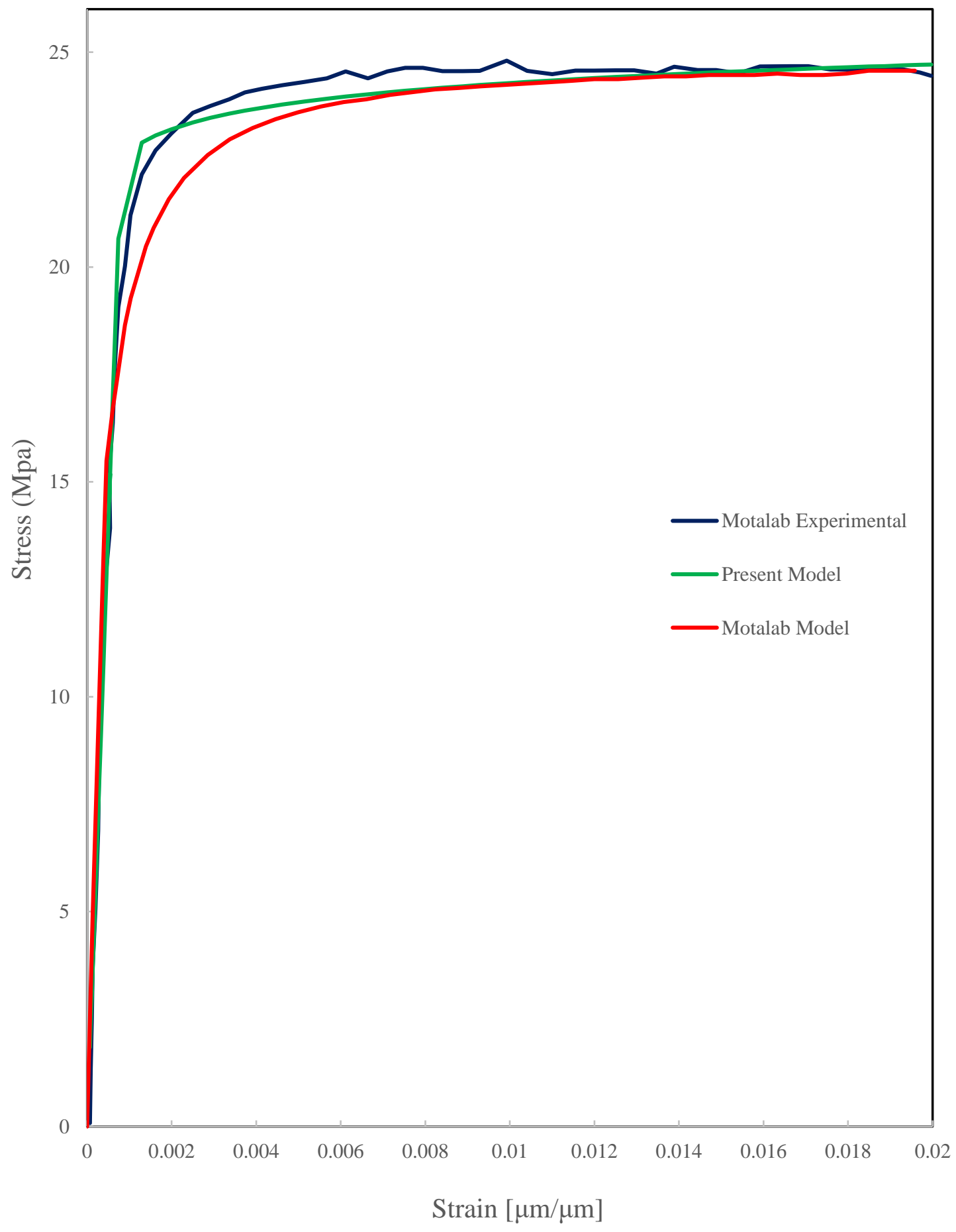

Figure 2.13: Stress vs Strain at $323 \mathrm{~K}$ and strain rate of $.00001 \mathrm{~mm} / \mathrm{s}$ 


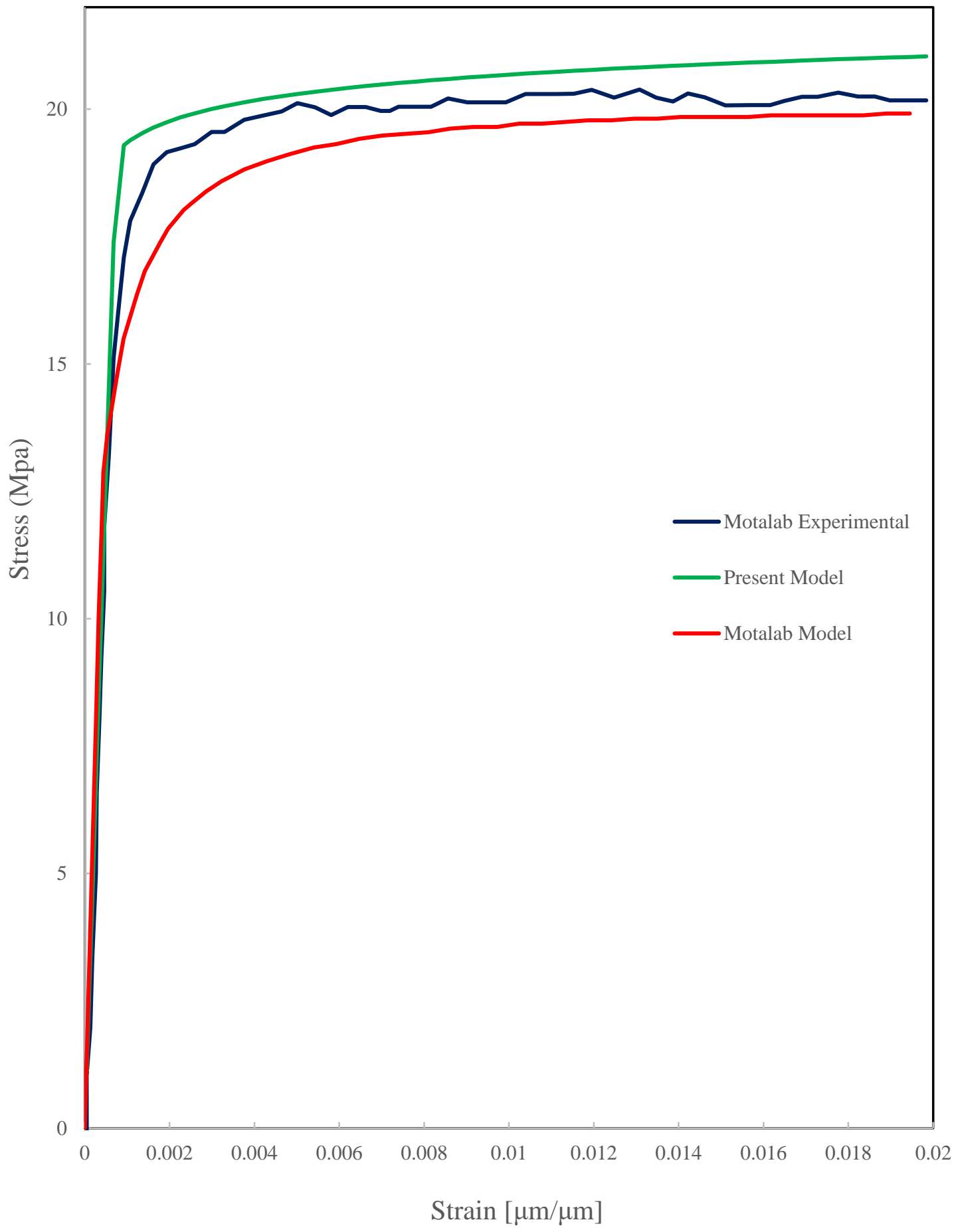

Figure 2.14: Stress vs Strain at $348 \mathrm{~K}$ and strain rate of $.00001 \mathrm{~mm} / \mathrm{s}$ 


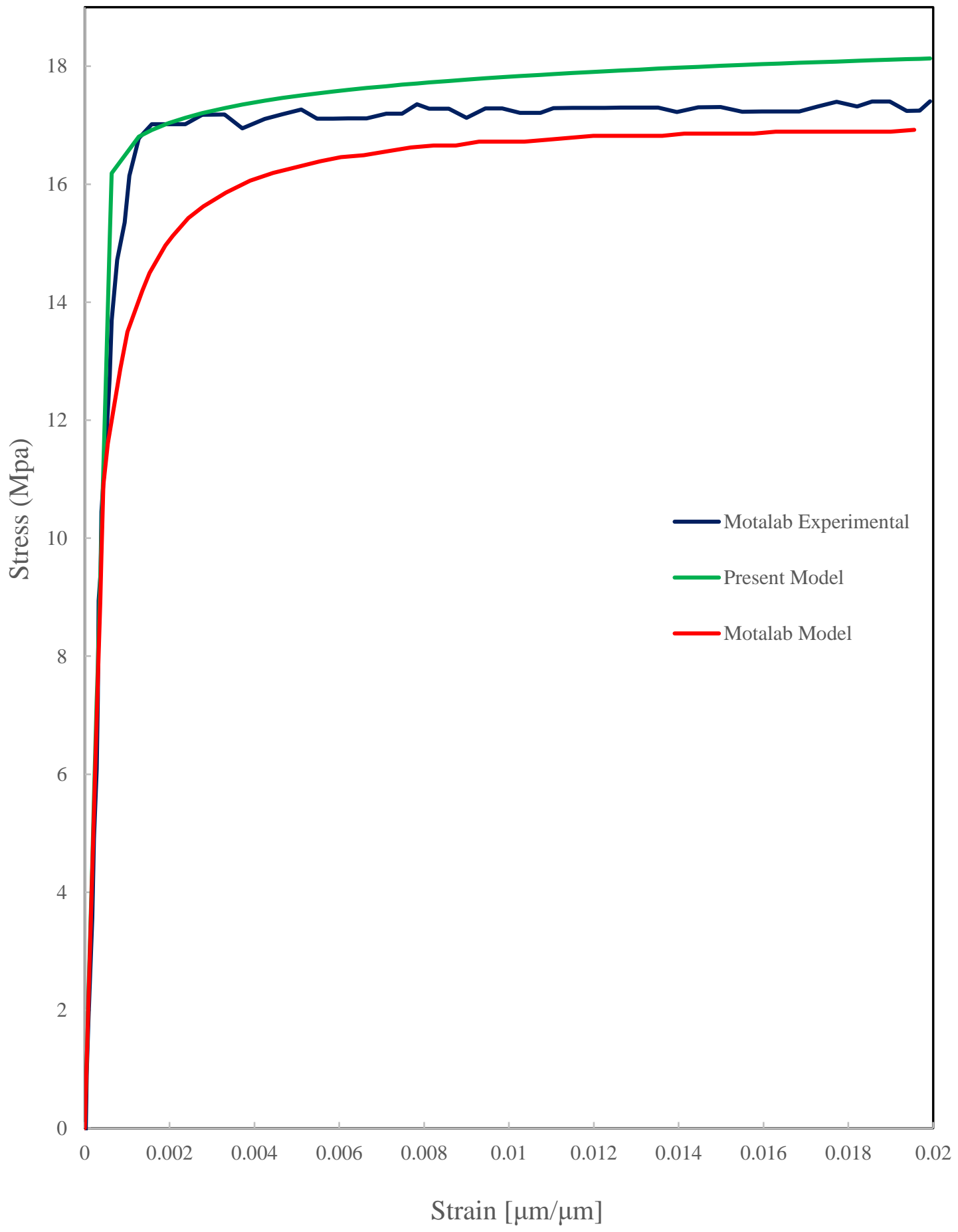

Figure 2.15: Stress vs Strain at $373 \mathrm{~K}$ and strain rate of $.00001 \mathrm{~mm} / \mathrm{s}$ 


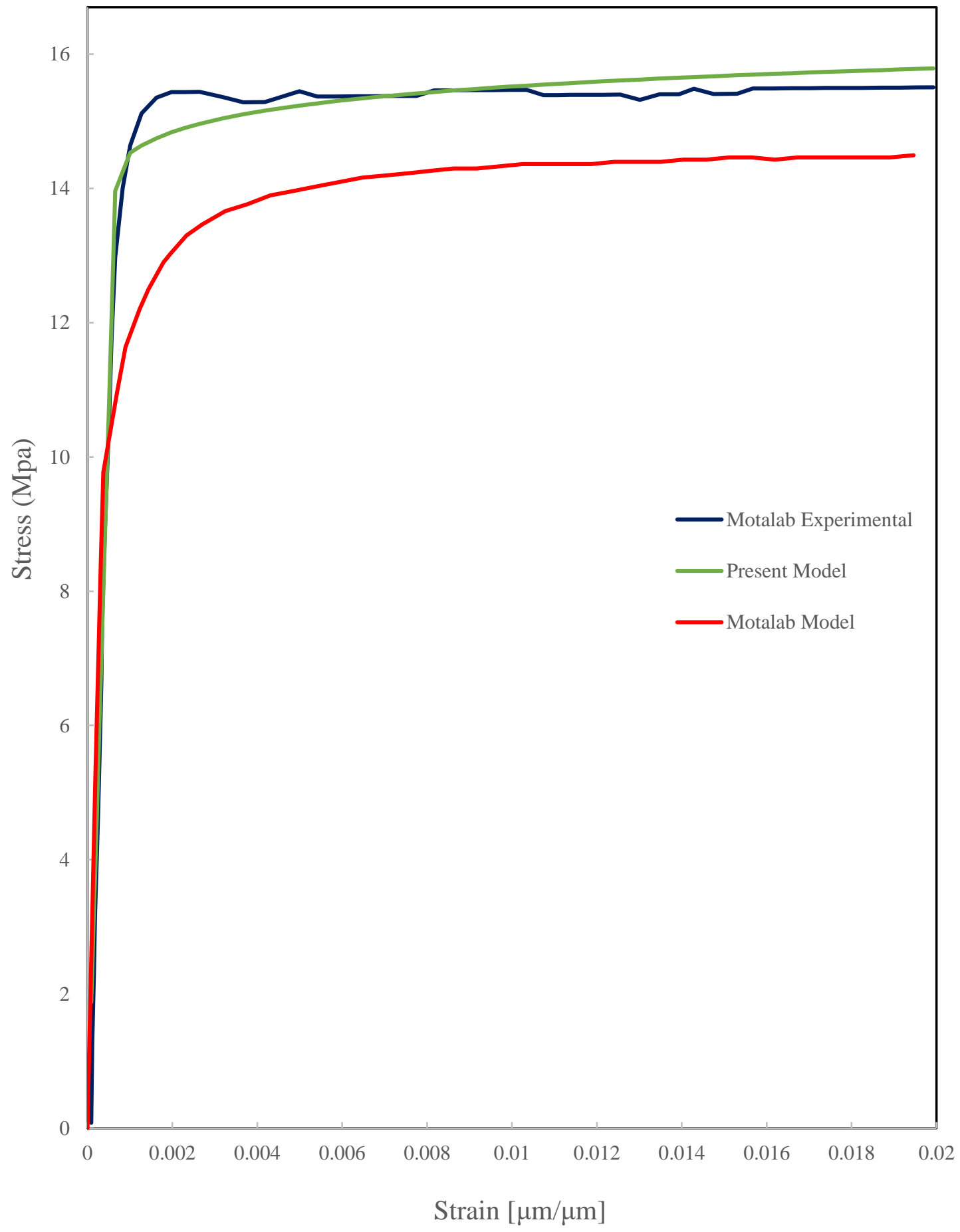

Figure 2.16: Stress vs Strain at 398K and strain rate of $.00001 \mathrm{~mm} / \mathrm{s}$ 


\subsubsection{Quantifying Numerical Accuracy}

Two metrics of model error are used to describe the data set and to compare numerical accuracy between the Motalab model and the present model, in relation to experimental data. The method of calculating error is achieved through a simple strain-specific difference and the Kolmogorov-Smirnov method.

The stress-error obtained through the simple difference method is calculated as

$$
y_{i}=\left|y_{\text {exp }, i}-y_{\text {model }, i}\right|
$$

where $y_{\text {exp }, i}$ captures experimental stress data and $y_{\text {model, } i}$ captures anand curve-fit stress data. The values are then plotted versus the respective strain data that represents both the experimental and modeled stress values. The resulting plot illustrates the maximum distance between each data point.

The Kolmogorov method utilizes the data calculated with equation [1] to provide a measure of dis-similarity between the total data distributions. First, we calculate

$$
\begin{aligned}
& y_{\text {stress, exp }, i}=y_{\text {exp }, i}+y_{\text {exp }, i+n} \\
& y_{\text {stress,model }, i}=y_{\text {model }, i}+y_{\text {model }, i+n}
\end{aligned}
$$

where the respective y components are plotted versus the original strain data. 
Then, we can write

$$
y_{\text {stress }, i}=\left|y_{\text {stress, exp }, i}-y_{\text {stress }, \text { model }, i}\right|
$$

where $y_{\text {stress }, i}$ represents the accumulated dissimilarity between the two curves.

Finally, the Kolmogorov-Smirnov Test Maximum Dissimilarity is recorded as the maximum $y_{\text {stress }, i}$ calculated in the test. 


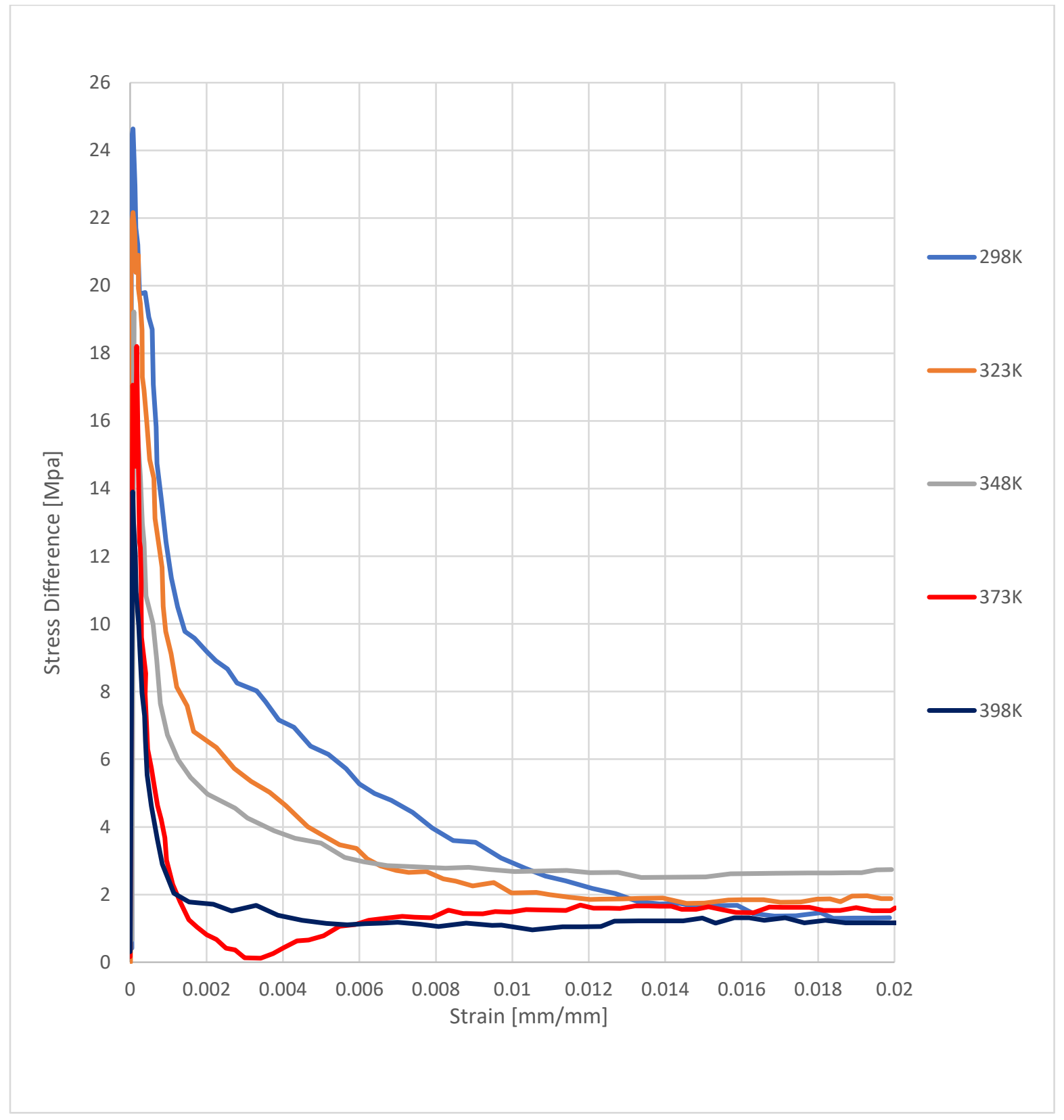

Figure 2.17: Strain-specific Maximum Difference Calculated Error Between Experimental and Motalab Model Data for a Strain-Rate of $0.001 \mu \mathrm{m} / \mathrm{s}$ 


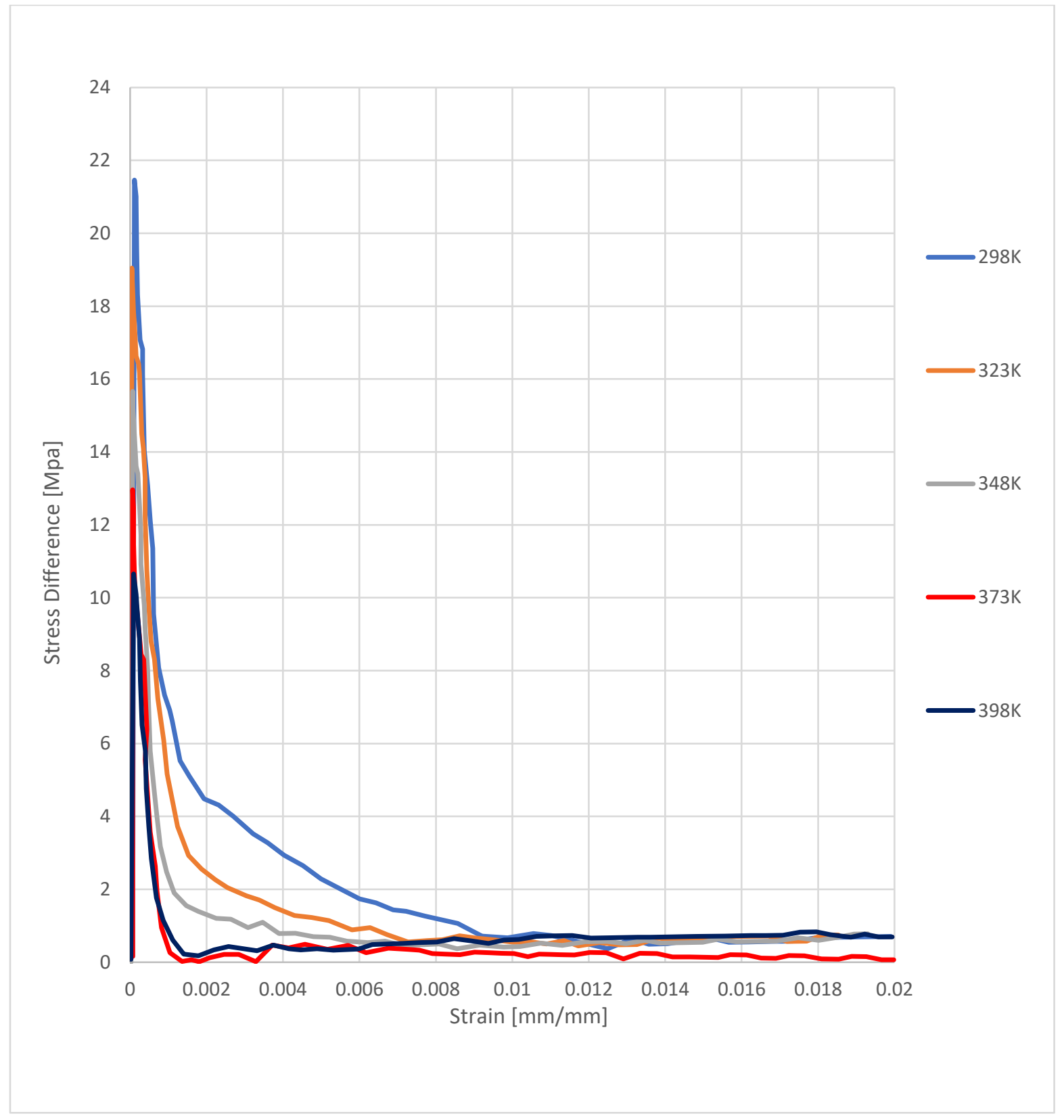

Figure 2.18: Strain-specific Maximum Difference Calculated Error Between Experimental and Motalab Model Data for a Strain-Rate of $0.0001 \mu \mathrm{m} / \mathrm{s}$ 


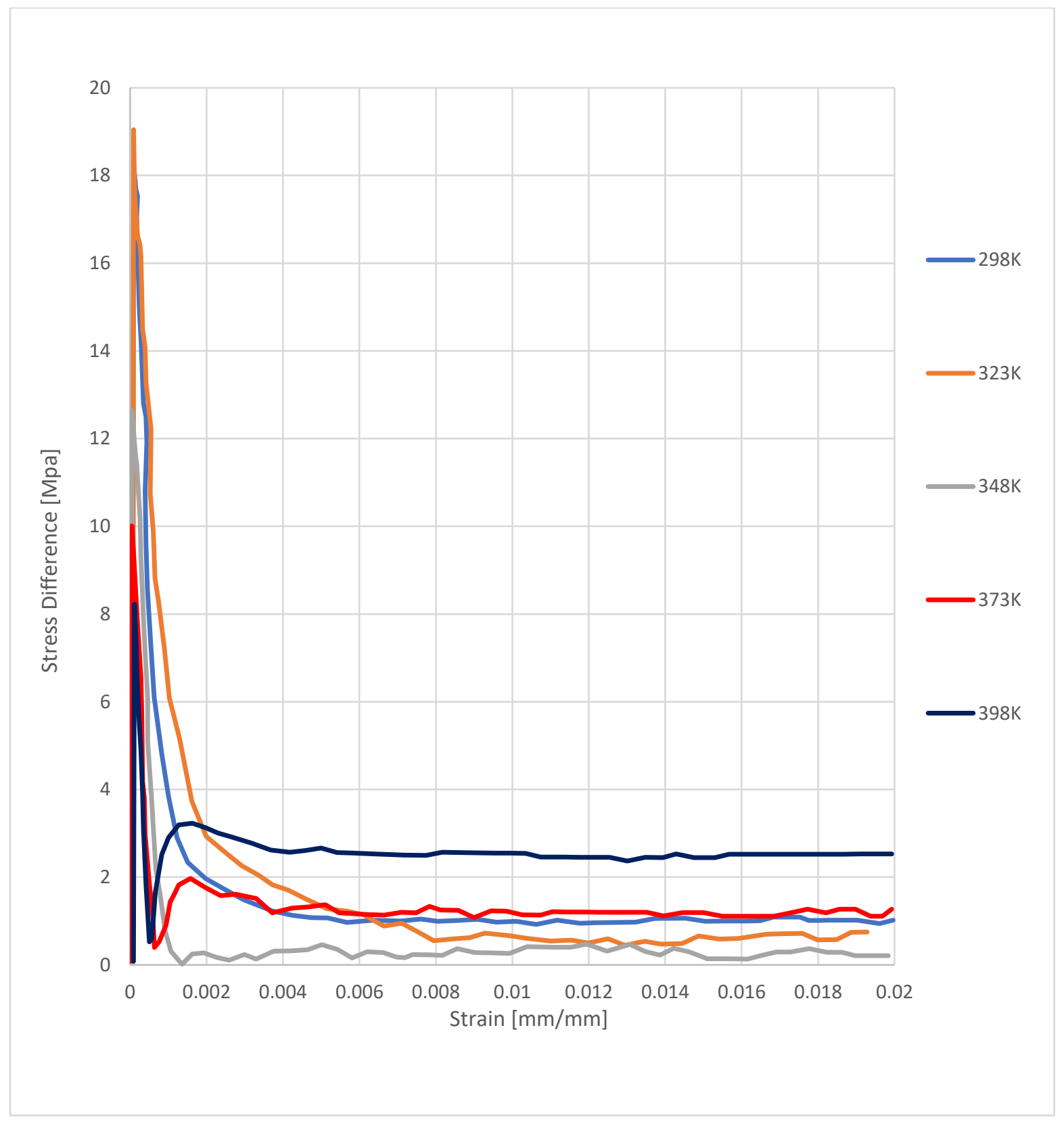

Figure 2.19: Strain-specific Maximum Difference Calculated Error Between Experimental and Motalab Model Data for a Strain-Rate of $0.00001 \mu \mathrm{m} / \mathrm{s}$ 


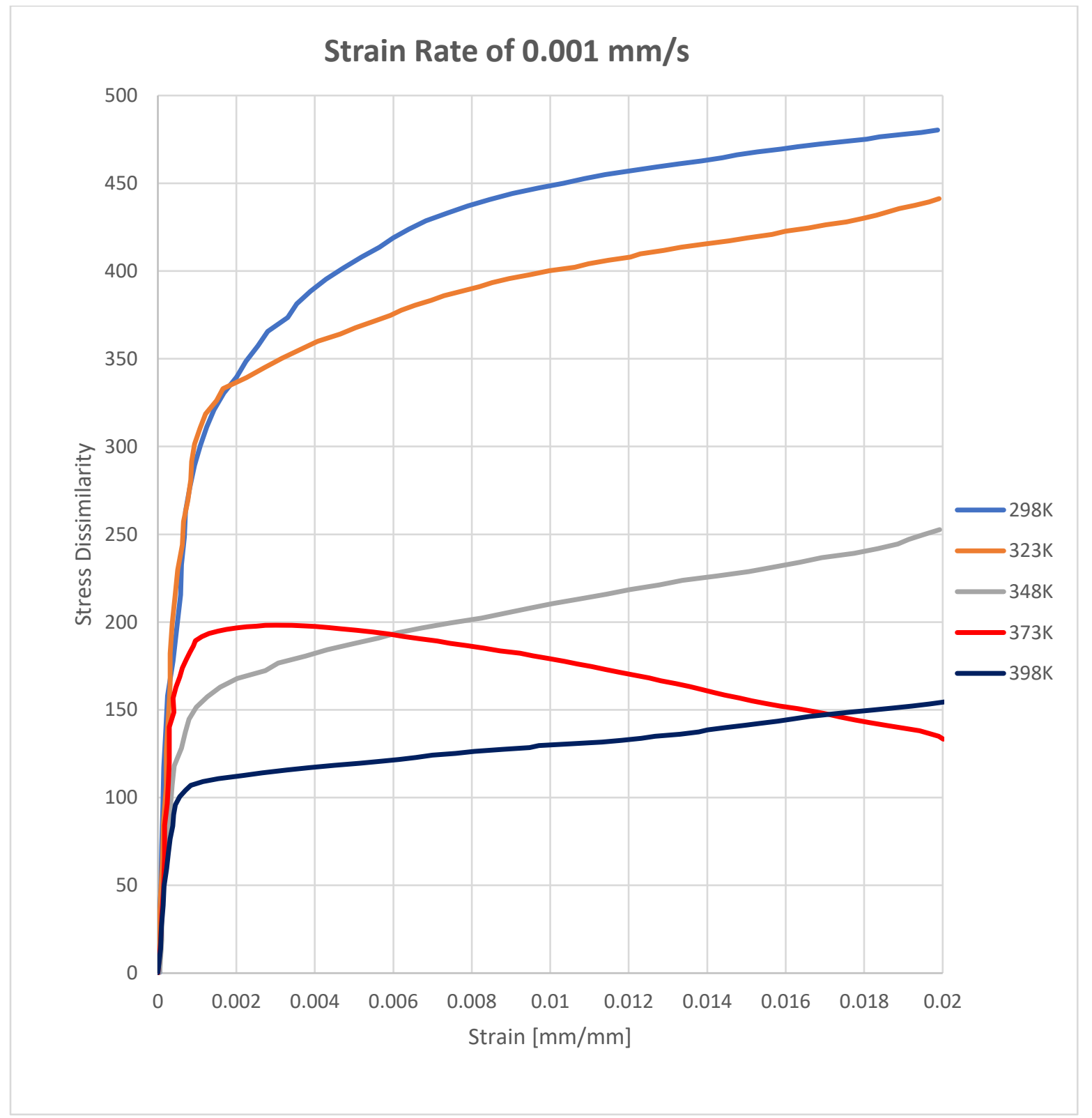

Figure 2.20: Kolmogorov-Smirnov Curve-Fit Error Between Experimental and Motalab Model Data for a Strain-Rate of $0.001 \mu \mathrm{m} / \mathrm{s}$ 


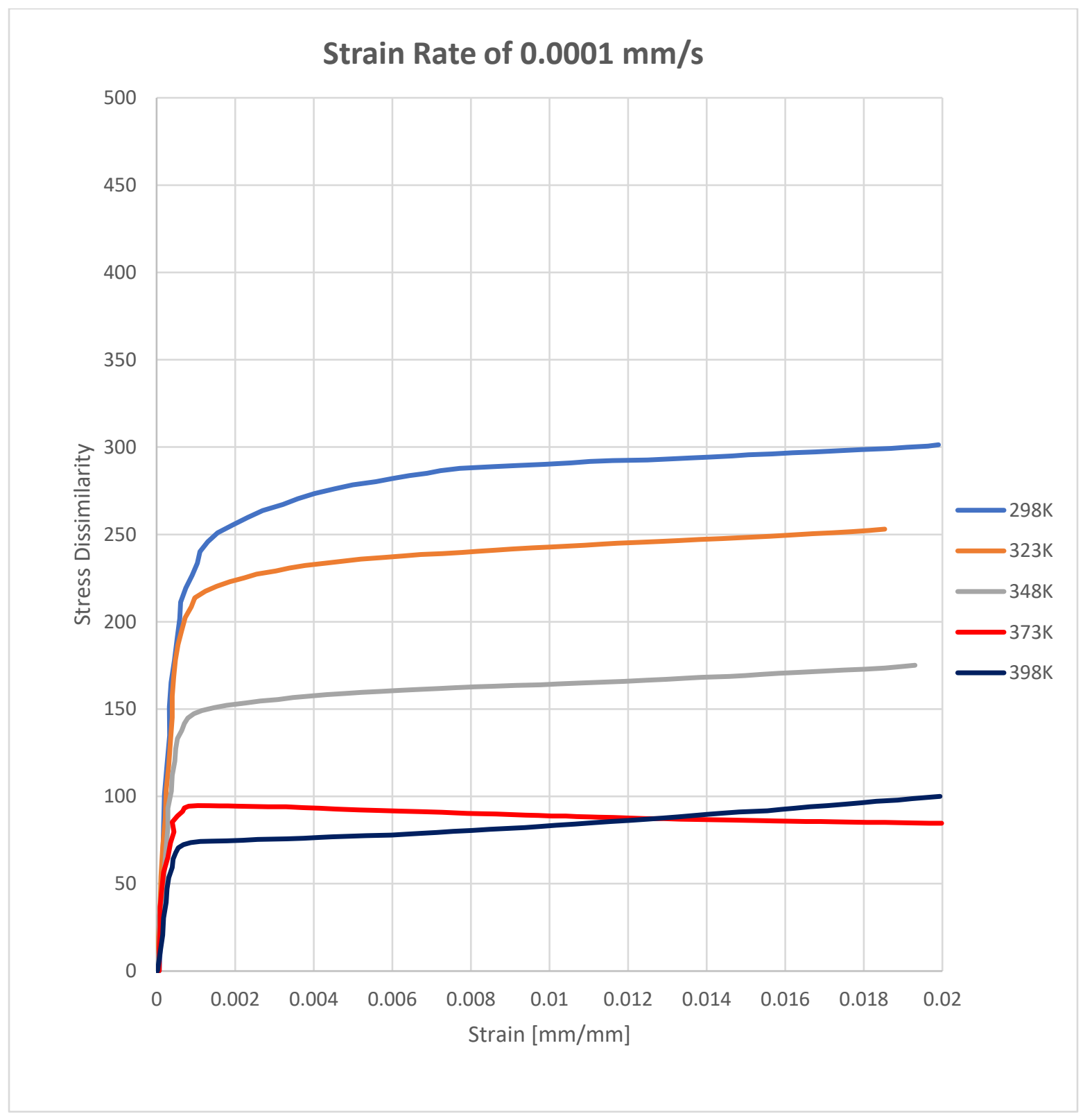

Figure 2.21: Kolmogorov-Smirnov Curve-Fit Error Between Experimental and Motalab Model Data for a Strain-Rate of $0.0001 \mu \mathrm{m} / \mathrm{s}$ 


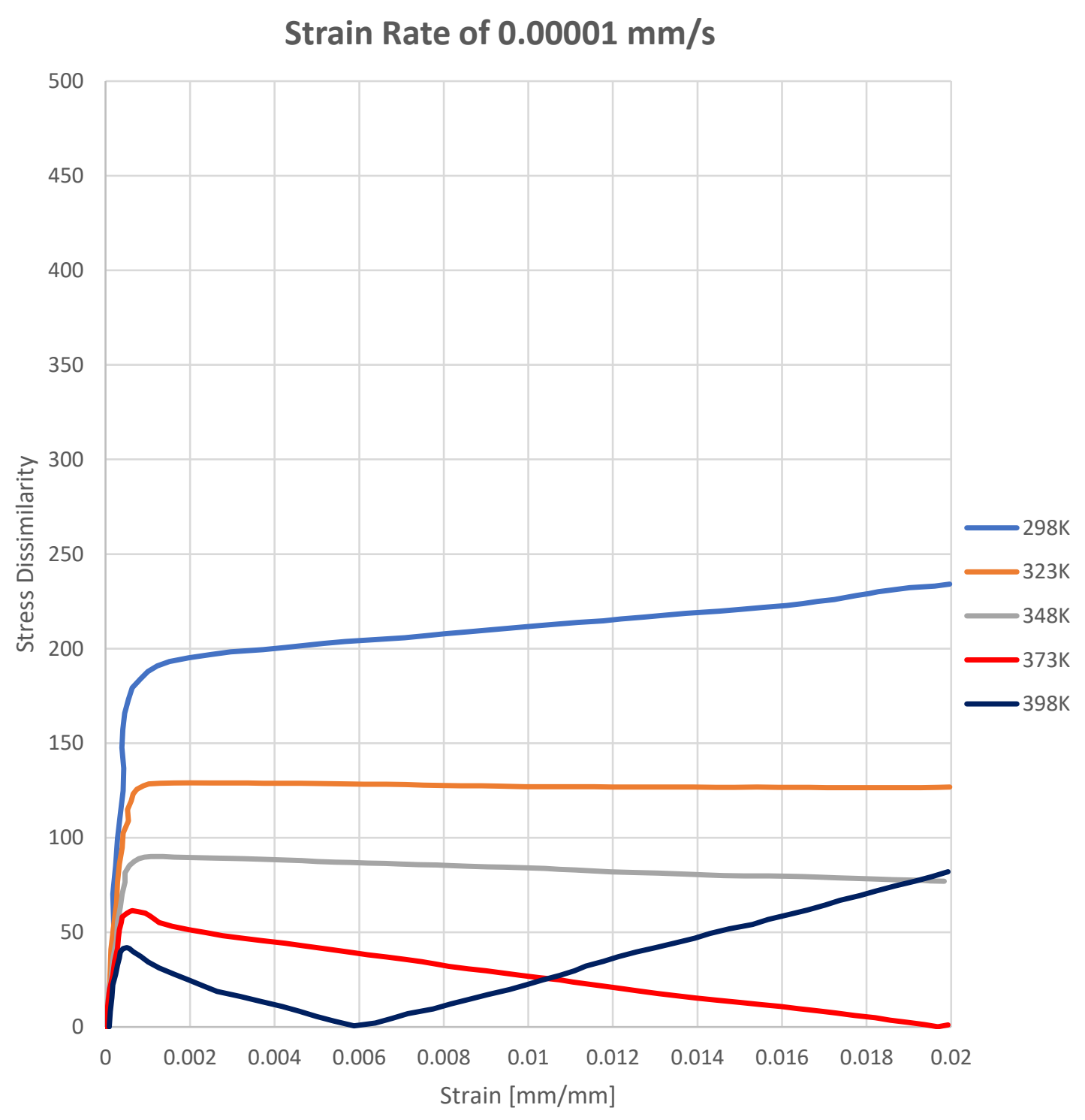

Figure 2.22: Kolmogorov-Smirnov Curve-Fit Error Between Experimental and Motalab Model Data for a Strain-Rate of $0.00001 \mu \mathrm{m} / \mathrm{s}$ 


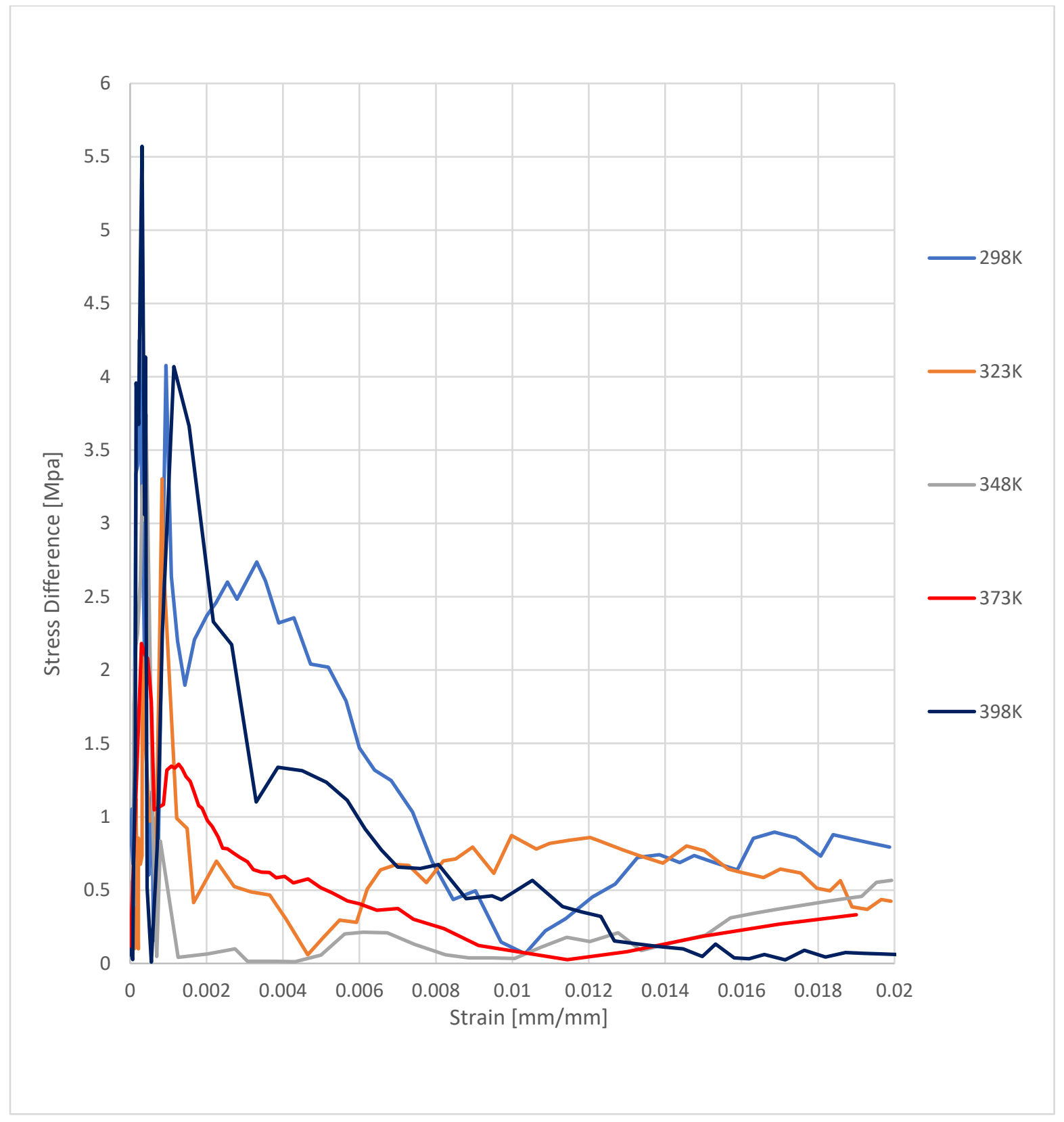

Figure 2.23: Strain-specific Maximum Difference Calculated Error Between Experimental and Present Study Model Data for a Strain-Rate of $0.001 \mu \mathrm{m} / \mathrm{s}$ 


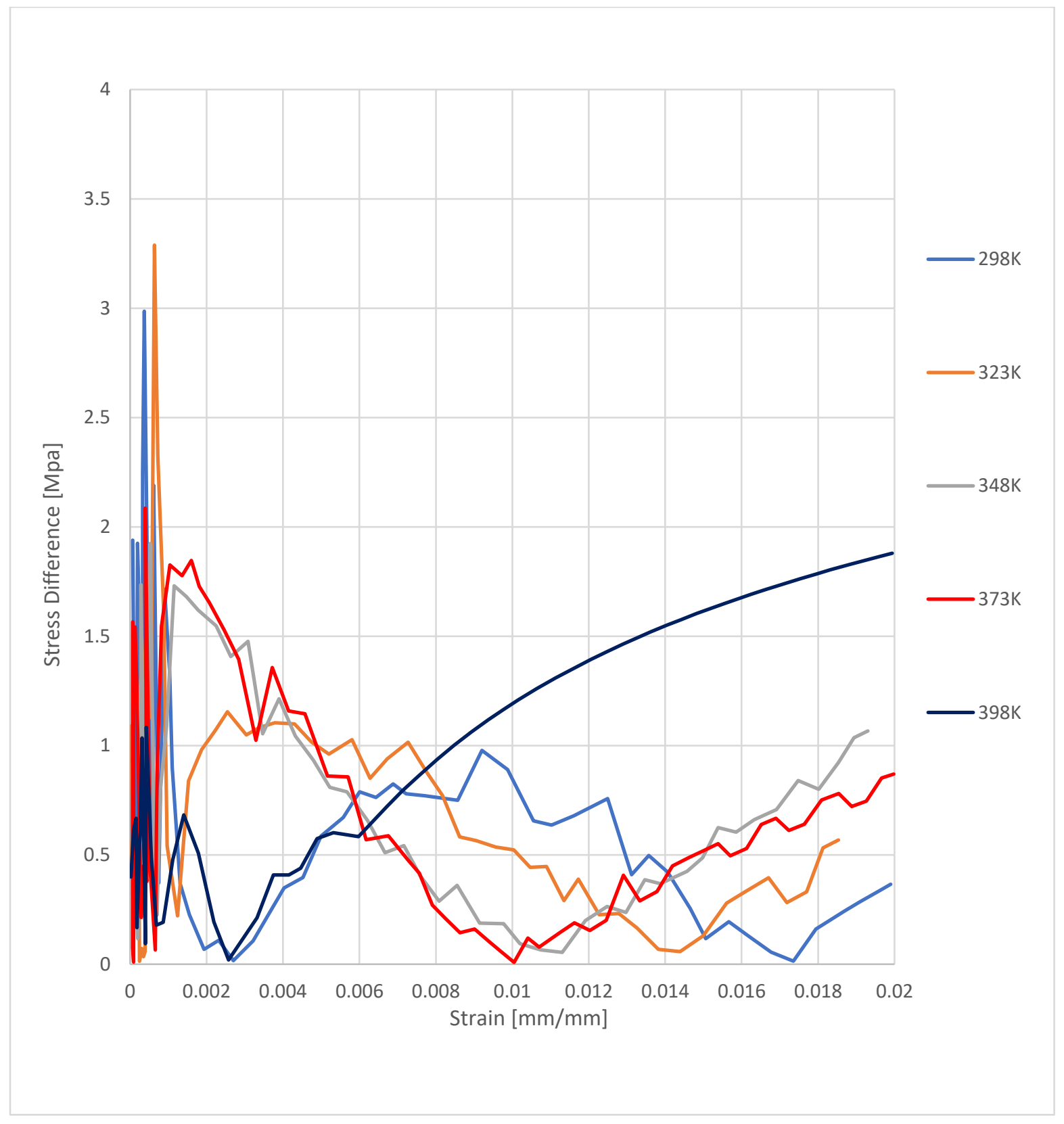

Figure 2.24: Strain-specific Maximum Difference Calculated Error Between Experimental and Present Study Model Data for a Strain-Rate of $0.0001 \mu \mathrm{m} / \mathrm{s}$ 


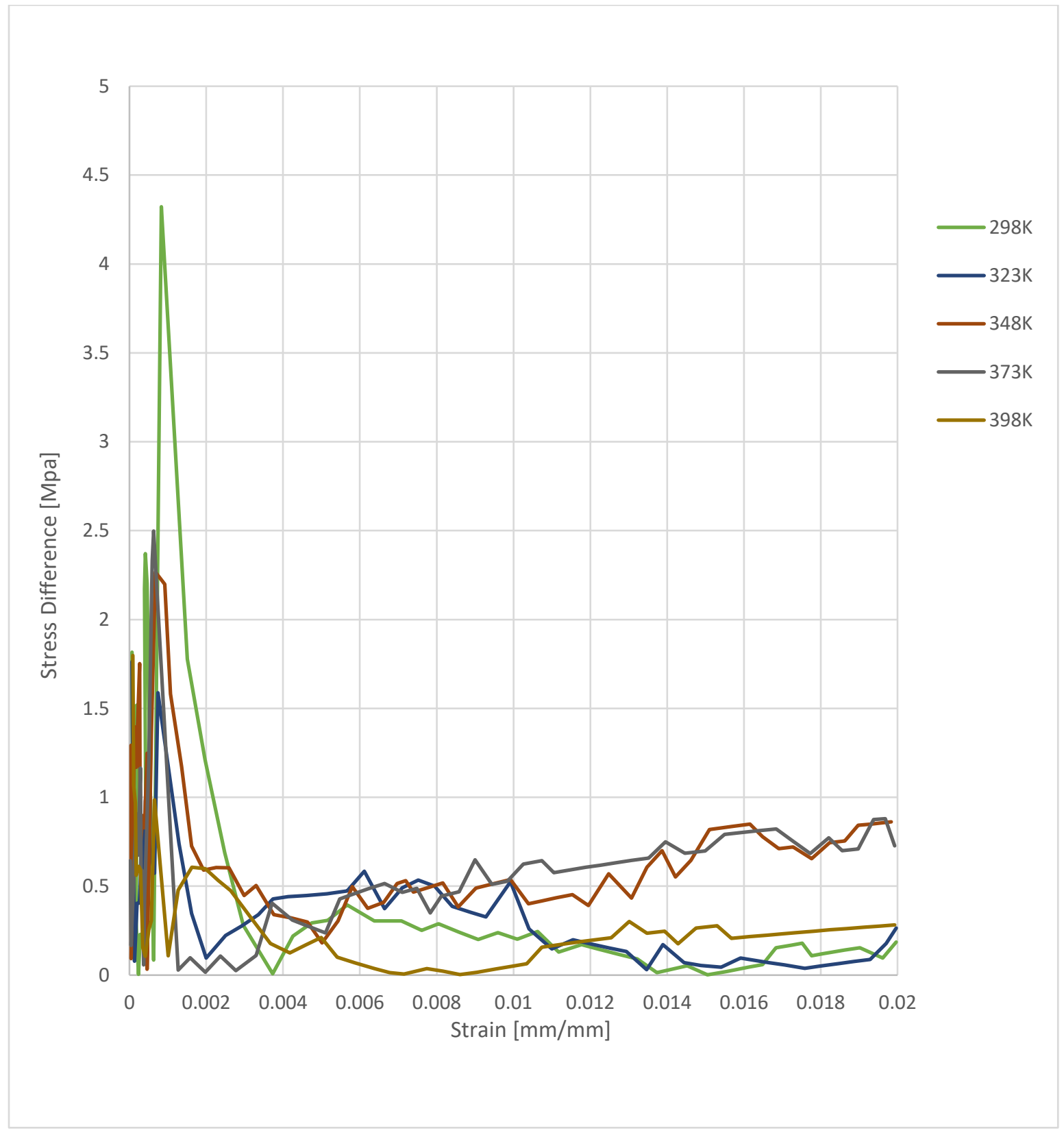

Figure 2.25: Strain-specific Maximum Difference Calculated Error Between Experimental and Present Study Model Data for a Strain-Rate of $0.00001 \mu \mathrm{m} / \mathrm{s}$ 


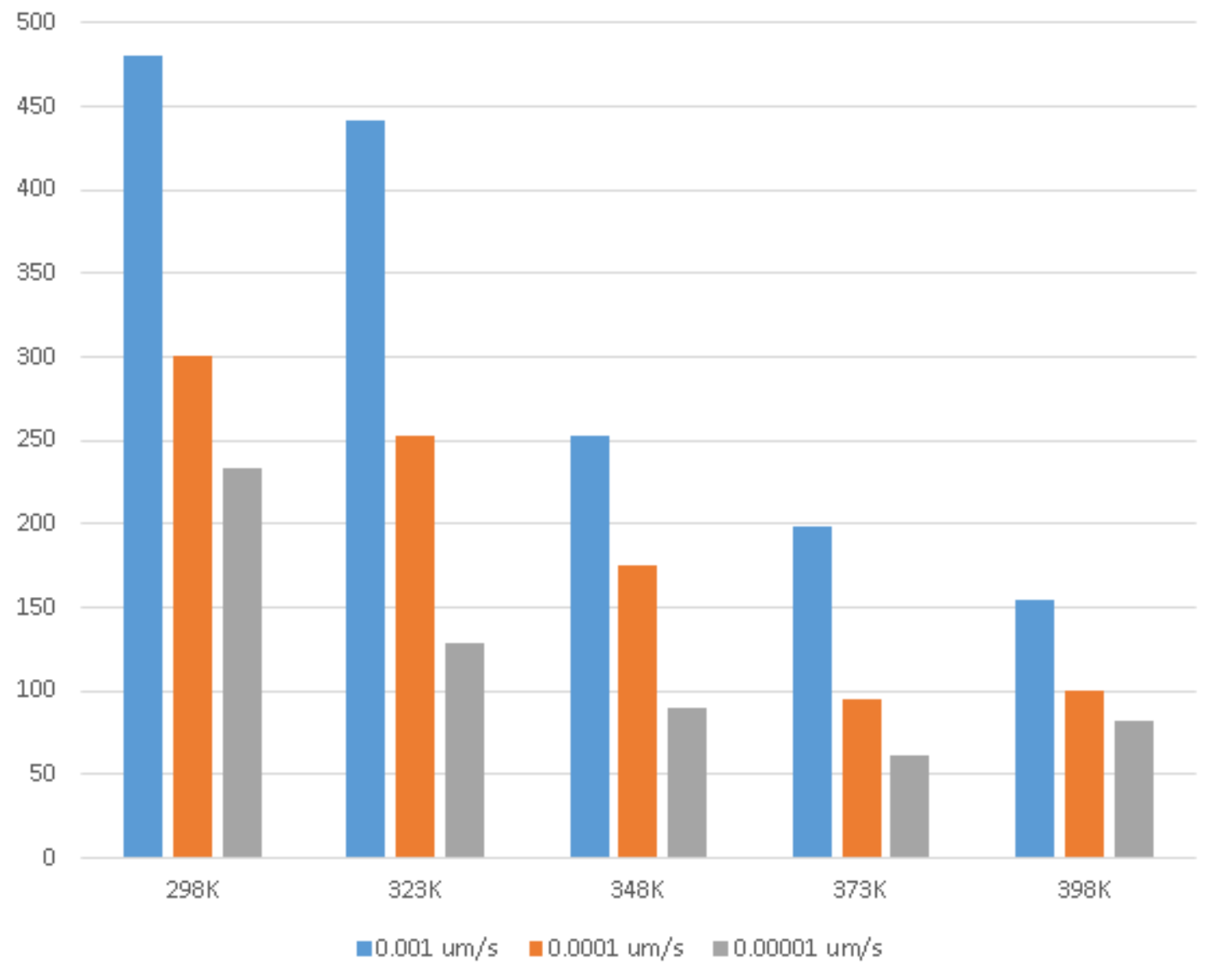

Figure 2.26: Kolmogorov-Smirnov Curve-Fit Maximum Dissimilarity For Each Variation of Strain Rate and Temperature between Motalab Experimental and Motalab Model Data 


\begin{tabular}{cccccc}
\hline Strain Rate & $\mathbf{2 9 5}$ K & $\mathbf{3 2 3} \mathbf{K}$ & $\mathbf{3 4 8} \mathbf{K}$ & $\mathbf{3 7 3} \mathbf{K}$ & $\mathbf{3 9 8} \mathbf{K}$ \\
$\mathbf{. 0 0 1}$ & 480.34 & 441.25 & 252.66 & 198.22 & 154.53 \\
$\mathbf{. 0 0 0 1}$ & 301.35 & 253.05 & 175.10 & 94.685 & 100.02 \\
$\mathbf{. 0 0 0 0 1}$ & 234.12 & 129.05 & 90.095 & 61.514 & 82.068 \\
\hline
\end{tabular}

Table 2.3: Kolmogorov-Smirnov Curve-Fit Maximum Dissimilarity For Each Variation of Strain Rate and Temperature between Motalab Experimental and Motalab Model Data

\begin{tabular}{cccccc}
\hline Strain Rate & $\mathbf{2 9 5}$ K & $\mathbf{3 2 3} \mathbf{K}$ & $\mathbf{3 4 8} \mathbf{K}$ & $\mathbf{3 7 3} \mathbf{K}$ & $\mathbf{3 9 8} \mathbf{K}$ \\
$\mathbf{. 0 0 1}$ & 324.43 & 301.04 & 13.550 & 33.674 & 165.25 \\
$\mathbf{. 0 0 0 1}$ & 137.69 & 241.80 & 205.95 & 78.342 & 482.055 \\
$\mathbf{. 0 0 0 0 1}$ & 159.479 & 110.326 & 82.788 & 52.972 & 21.893 \\
\hline
\end{tabular}

Table 2.4: Kolmogorov-Smirnov Curve-Fit Maximum Dissimilarity For Each Variation of Strain Rate and Temperature between Motalab Experimental and Present Study Model Data 


\subsubsection{Discussion of Error}

Figures 2.1-2.16 show that the present study model matches experimental data more accurately than the Motalab model for 13 out of the 15 data sets. The present model fails to delivery more accurate results for temperatures $373 \mathrm{~K}$ and $398 \mathrm{~K}$ at a strain rate of $0.0001 \mathrm{~mm} / \mathrm{s}$.

Figures 2.17-2.19 represent the maximum distance between Motalab experimental and Motalab numerical stress saturation values along a strain range between 0 and 22 micrometers. In comparing the three strain rates for each of the five temperature conditions the error is significantly higher within the first three percent of uniaxial strain for the research group's modeled data. However, Figures 2.18 and 2.19 show that at strain rates of 0.0001 and $0.00001 \mathrm{~mm} / \mathrm{s}$ the numerical values of stress converge to a steady-state value of stress at a lower strain than that seen with a strain rate of 0.001 $\mathrm{mm} / \mathrm{s}$; a general trend observed that is not specific to any one temperature. The precision of the converged stress to that of the experimental stress is higher with a strain rate of 0.0001 than with $0.00001 \mathrm{~mm} / \mathrm{s}$.

Figures 2.20-2.23 illustrate results from the Kolmogorov-Smirnov test for dissimilarity between experimental and numerical stress-strain curves, or "goodness of fit." Figures 2.21 and 2.22 further show that the model can achieve better similarity with lower strain rates: in general, the experimental and numerical curve shapes are represented with more precision at strain rates of 0.0001 and $0.00001 \mathrm{~mm} / \mathrm{s}$. It is important to note that Figures 2.20-2.23 only reveal similarity between curves, and do not reveal information on strain specific error in stress value, which is where Figures 1-3 are used for comparison. 
All variations of strain rate and temperature there is observable dissimilarity between experimental and numerical results for the Motalab experimental and numerical data. The figure shows that high strain rate is the largest factor, and increases linearly with the calculated maximum dissimilarity, which is confirmed by the corresponding "goodness of fit" curves. In comparing this observation with the simple-difference results, it can be confirmed that high strain rate is the most prominent factor that prevents accurate modeling. In comparison to strain rates of 0.0001 and $0.00001 \mathrm{~mm} / \mathrm{s}$, the results of the highest tested strain rate of $0.001 \mathrm{~mm} / \mathrm{s}$ shows observed maximum error is larger across all five temperatures, and the average converged value is off by 1.5-3.5 Mpa for the five temperatures tested. With a strain rate of $0.0001 \mathrm{~mm} / \mathrm{s}$, Figure 2 shows that the maximum observed difference is lower in all cases, converges to a steady-state stress value at lower strain, and the converged value is off by $0-1 \mathrm{Mpa}$. However with the lowest strain rate seen in Figure 3, the numerically calculated stress data converge to an error band between 0-2.75 Mpa off from zero.

The second factor is low temperature, and it is inversely proportional to maximum dissimilarity for strain rates of 0.001 and $0.0001 \mathrm{~mm} / \mathrm{s}$, but not for a strain rate of 0.00001 $\mathrm{mm} / \mathrm{s}$. It is interesting to note that at higher temperatures, Anand model fits tend to switch from under-estimates to over-estimates at certain progressions of strain.

In observation of the new fitted results data, Tables 2.3 and 2.4 show that the Present Study Model data contains less accumulated error for twelve out of the fifteen unique variations of temperature and strain rate, and often times, the error has been minimized to a significant degree. Therefore, it is feasible to assume that the Anand parameters extracted 
from the new model will be considered more accurate with respect to the original testing data provided by Motalab et. Al.

\subsubsection{Verification of Experimental Data}

Vendor data sheets are referenced to verify the accuracy of experimentally determined measures of strength in the lead-free solder, which are provided by Motalab et al. The experimental data is used to calculate the yield strength, ultimate tensile strength, and elastic modulus for fifteen variations of both temperature and strain rate.

For each variation, the yield strength is calculated through applying a regression equation to the linear portion of strain based on a $0.2 \%$ strain offset. As seen in table 2.3, the calculated yield strength ranges from 20-34 GPa depending on the temperature and strain rate of the test specimen.

\begin{tabular}{cccc}
\hline & $\begin{array}{c}\text { E at Strain rate } \\
\text { of 0.001 1/sec } \\
\text { [Gpa] }\end{array}$ & $\begin{array}{c}\text { E at Strain rate of } \\
\mathbf{0 . 0 0 0 1} \mathbf{1} / \mathbf{s e c} \\
\text { [Gpa] }\end{array}$ & $\begin{array}{c}\text { E at Strain rate of } \\
\mathbf{0 . 0 0 0 0 1 ~ 1 / s e c} \\
\text { [Gpa] }\end{array}$ \\
\hline $\mathbf{2 9 8 K}$ & 26.21 & 33.49 & 33.44 \\
\hline $\mathbf{3 2 3 K}$ & 22.74 & 31.93 & 33.74 \\
$\mathbf{3 4 8 K}$ & 21.66 & 28.86 & 26.27 \\
$\mathbf{3 7 3 K}$ & 20.04 & 26.10 & 26.52 \\
\hline $\mathbf{3 9 8 K}$ & 19.21 & 24.21 & 22.74 \\
\hline
\end{tabular}

Table 2.5: Calculated Elastic Modulus for Motalab Experimental Stress-Strain Data 
The yield strength is calculated through the offset yield method, where the upper limit of stress before plastic deformation is detected as the yield point through linear regression. To verify the data, vendor data sheets are cited (Techsil 2016) for comparing the yield strength of SAC-305 solder material. One source [1] reports shear strength of $27 \mathrm{~N} / \mathrm{mm}^{2}$ at $20^{\circ} \mathrm{C}$, which is comparable to the Motalab experimentally determined yield strength for $25^{\circ} \mathrm{C}$ at strain rates of $0.001,0.0001$, and $0.00001 \mathrm{~mm} / \mathrm{s}$ which are $26.21,33.49$, and 33.44 $\mathrm{N} / \mathrm{mm}^{2}$, respectively. It is important to discuss the variation of yield strength among the three strain rates, which can be attributed to experimental error, which we will take into consideration for further analysis of fatigue life. 


\section{Chapter 3}

\section{Numerical Simulation}

Ultimately, the benefits of improving the accuracy of curve-fitting experimental data are realized as improved creep strain and creep energy density outputs from finite-element modeling. This is because extracted Anand parameters are used as material library inputs and the resulting outputs will vary to a significant degree based on relatively small changes to these parameters. Using Abaqus simulation software, Finite Element analysis is performed to first verify the assumptions embedded through using the Anand viscoplastic model, which is primarily concerned with verifying the fact that the initial portion of strain only contains elastic components of strain, and that the plastic, time-dependent region of strain is creep-dominated. Once the model is verified in the simple uni-axial case, we apply these assumptions towards performing FE analysis on a simple Ball Grid Array (BGA) package to evaluate stresses and strains on this model. 


\subsection{Uni-axial tensile model}

Using Abaqus CAE software, finite element analysis is performed on a rectangular bar composed of the SAC-305 lead-free solder. First, the model is employed to show that elastic strain dominates below the yield point and that creep strain dominates post-yield. This is important because it verifies the applicability of the Anand viscoplastic equations for this case. Second, this finite-element is employed to obtain appropriate damage parameters for calculating fatigue life. Two verification models are built to verify the results, where a thermal solution will help verify the thermal behavior of the system, and another where a uni-axial loading solution will help to verify the expected material behavior that will be used to model creep in a full-package configuration.

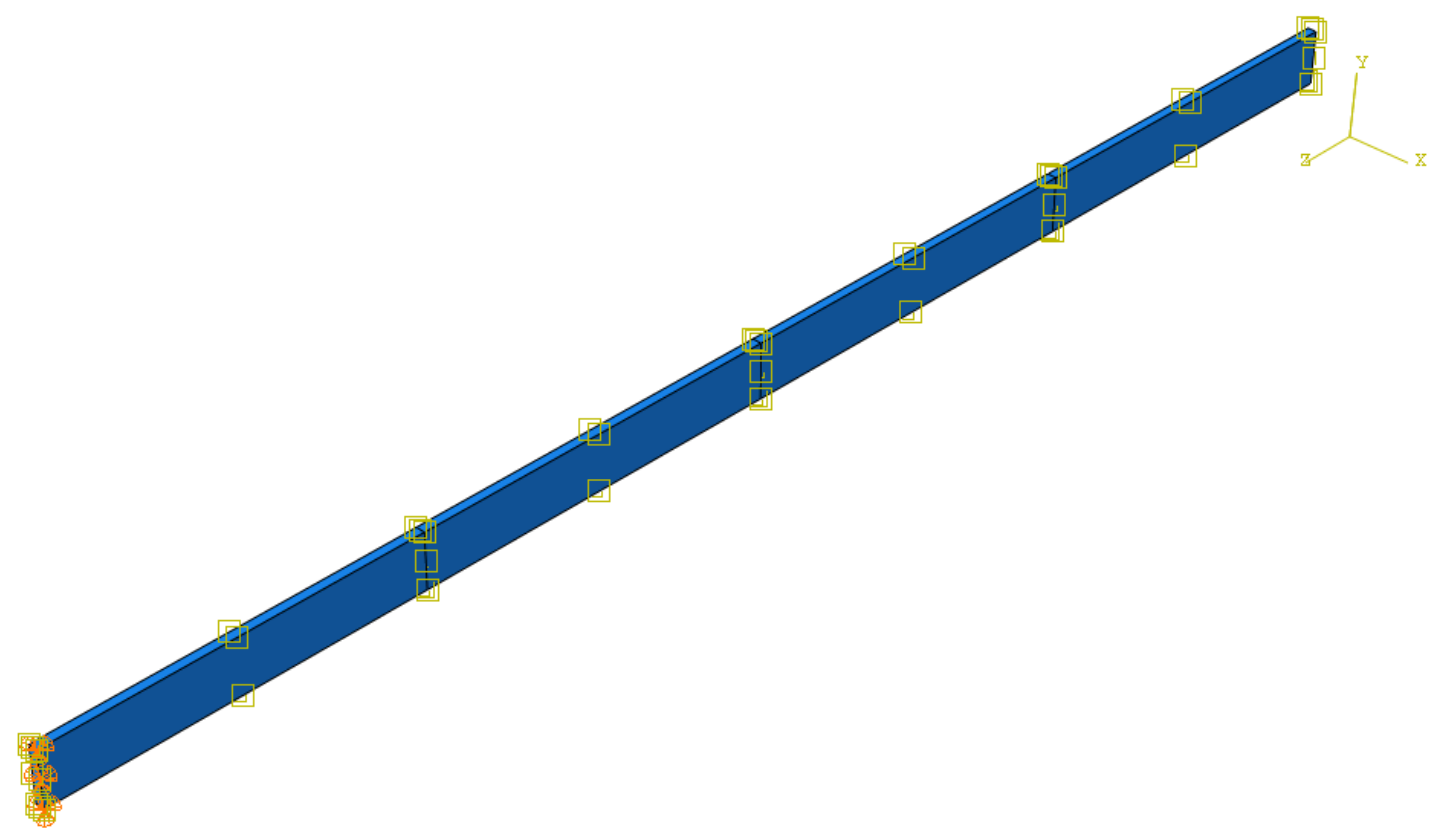

Figure 3.1: Solder beam geometry, boundary conditions, and loading conditions used to obtain accelerated thermal testing response 


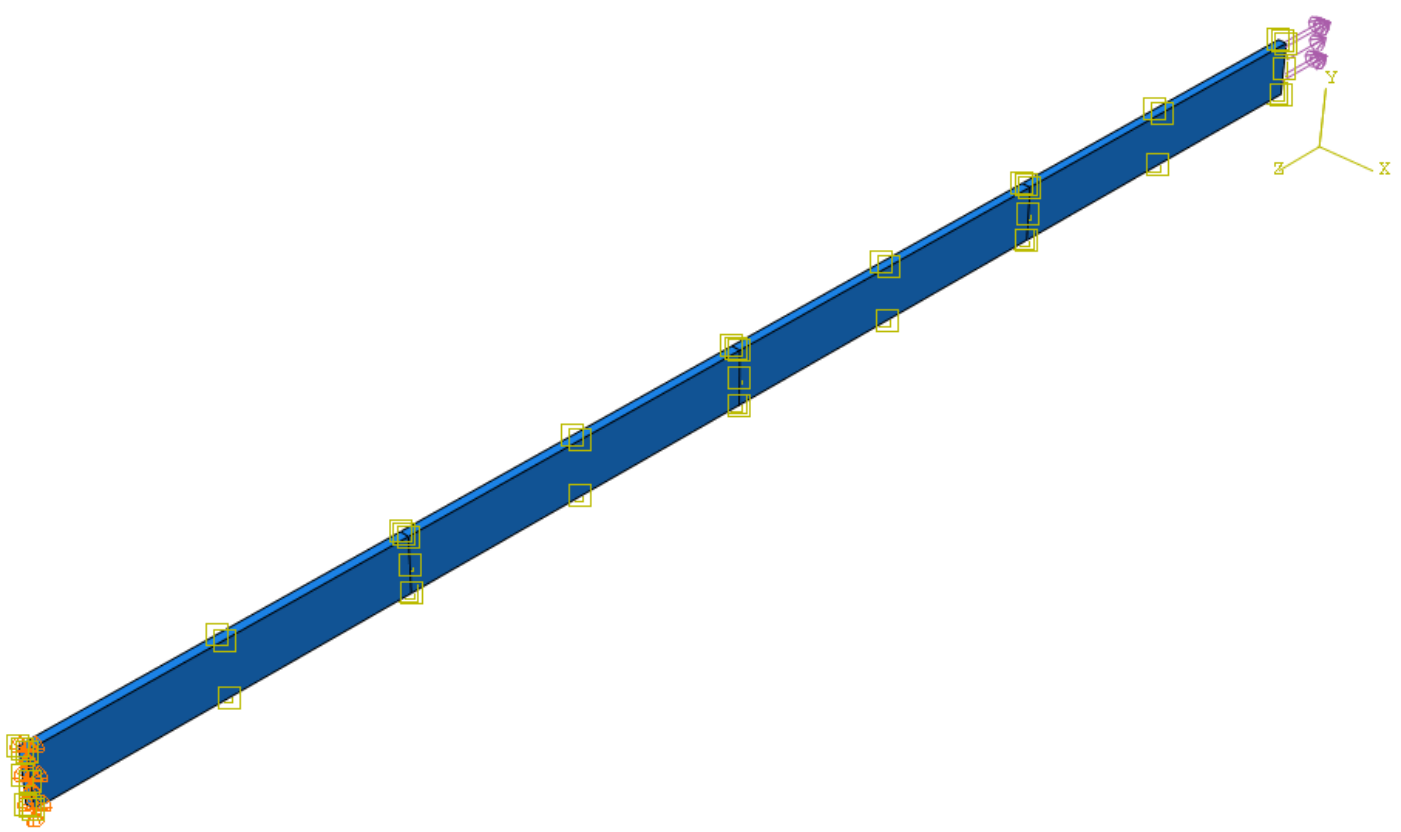

Figure 3.2: Solder beam geometry, boundary conditions, and loading conditions used to obtain uni-axial loading result

A linear-static convergence study is performed, and it is found that 250 elements will be used to accurately compute stresses, strains, and strain-energy outputs.

The construction of the thermal finite-element model is designed to emulate the conditions of the thermo-torsion tester used in the Motalab et. al. paper. First boundary conditions are applied at the ends of the rectangular bar of solder. A standard accelerated testing thermal profile is applied, ranging from 0 to $100^{\circ} \mathrm{C}$ with a ramp rate of $0.167^{\circ} \mathrm{C}$ / s. The progression of heating and cooling cycles will influence measures of elastic and/or visco-plastic strains to be measured.

Second, a boundary condition is applied to one end of the bar, and a edge load is applied to the opposite end such that varying magnitudes of stress can be used to measure elastic and viscoplastic strains. 


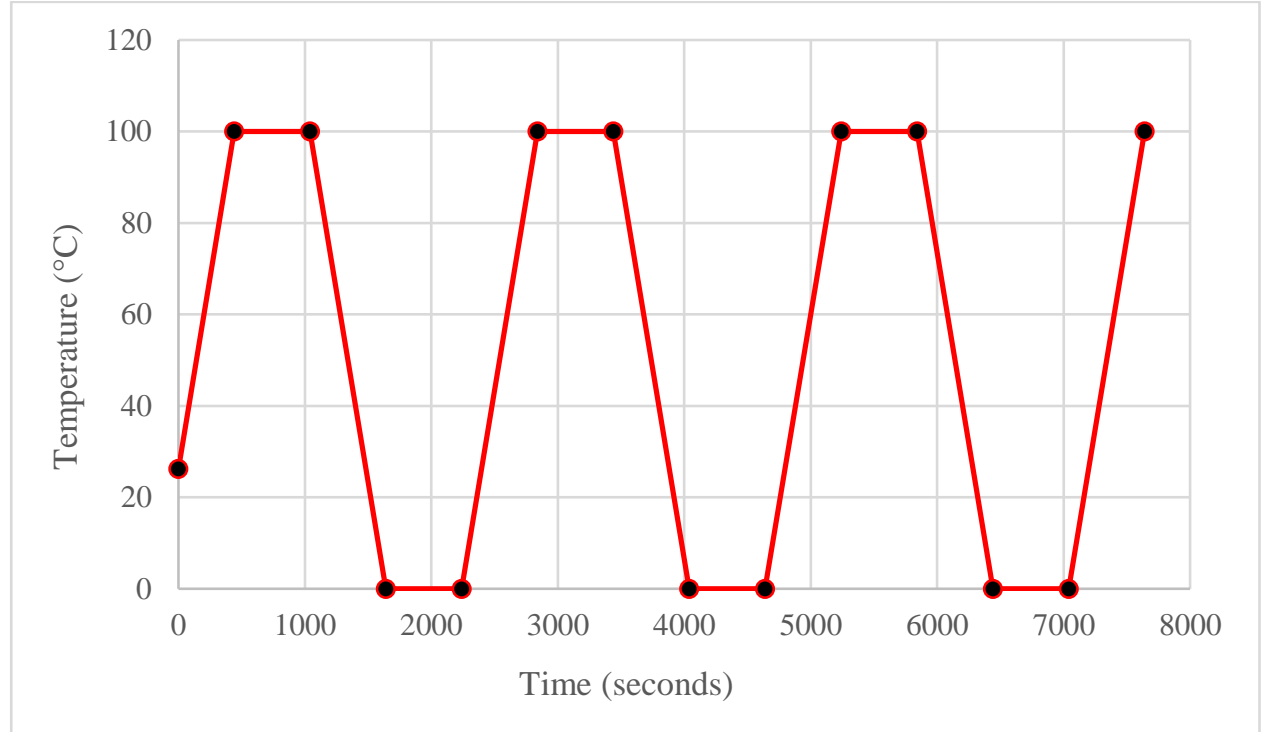

Figure 3.3: Thermal Profile used for both Uni-axial and PBGA models 


\subsection{Plastic Ball Grid Array (PBGA) model}

Finite element analysis is performed on a plastic ball grid array (PBGA) package. Symmetry in the package construction is taken advantage of such that a quarterrepresentation of the model is used, thereby maintaining numerical accuracy using twentyfive percent of the potential computational resources required.

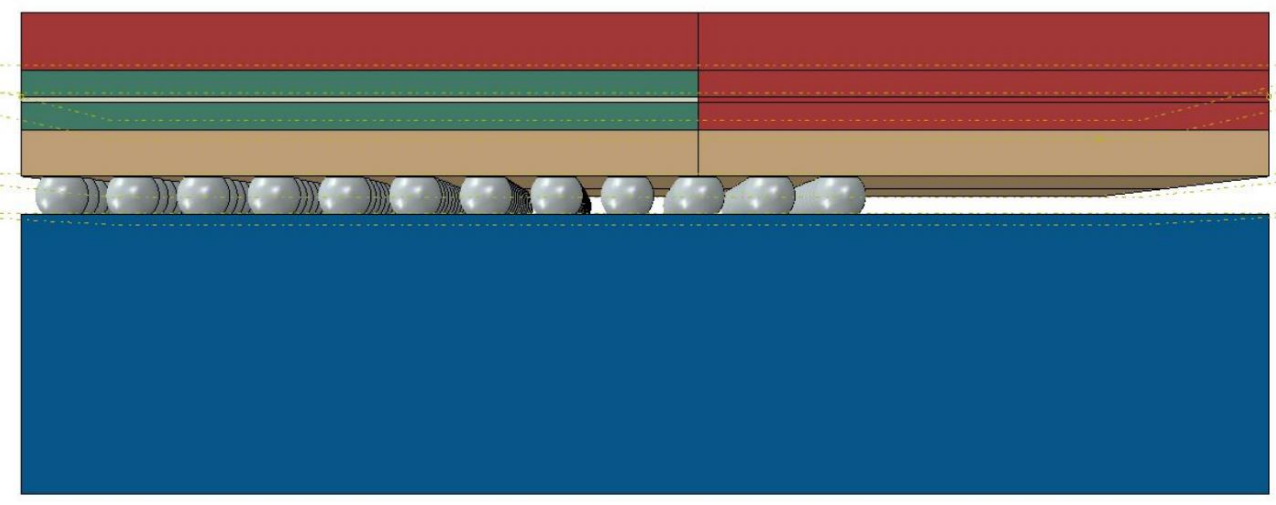

Figure 3.4: PBGA package model construction

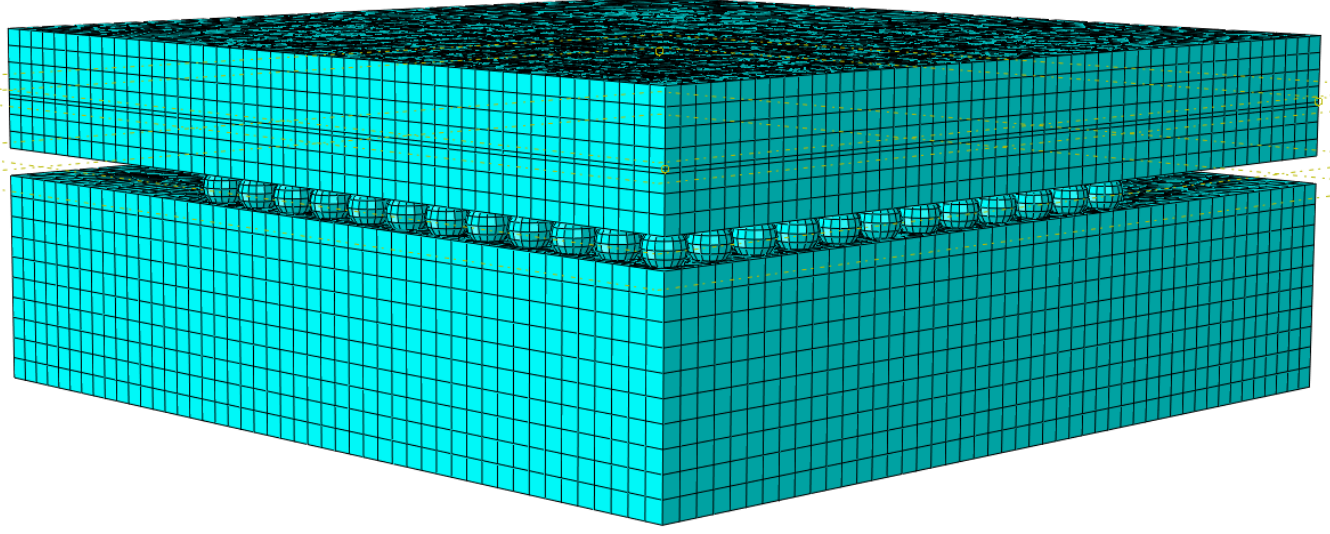

Figure 3.5: PBGA package model mesh distribution 
This package contains two stacked die (highlighted as green rectangles in Figure 3.3), and other material properties and package elements described in Tables 3.1 and 3.2 correspond to the printed circuit board (blue), the molding compound (red), the die attach (white), substrate (beige), and the solder joints (gray).

\begin{tabular}{|c|c|c|c|c|}
\hline Part & Thickness & Length & Width & Other \\
\hline Molding Compound & $0.65 \mathrm{~mm}$ & $7.0 \mathrm{~mm}$ & $7.0 \mathrm{~mm}$ & \\
\hline PCB & $1.56 \mathrm{~mm}$ & $7.0 \mathrm{~mm}$ & $7.0 \mathrm{~mm}$ & \\
\hline Silicon Die & $0.12 \mathrm{~mm}$ & $3.8 \mathrm{~mm}$ & $3.8 \mathrm{~mm}$ & \\
\hline Substrate & $0.26 \mathrm{~mm}$ & $7.0 \mathrm{~mm}$ & $7.0 \mathrm{~mm}$ & \\
\hline Solder Joints & $0.21 \mathrm{~mm}$ & $0.3 \mathrm{~mm}$ & $0.3 \mathrm{~mm}$ & Pitch $=0.4 \mathrm{~mm}$ \\
\hline
\end{tabular}

Table 3.1: PBGA Package Dimensions

The material properties assigned for performing finite-element analysis can be found in Table 3.2. 


\begin{tabular}{|c|c|c|c|c|}
\hline Material & $\begin{array}{c}\text { Modulus of } \\
\text { Elasticity (MPa) }\end{array}$ & $\begin{array}{l}\text { Poisson's } \\
\text { Ratio }\end{array}$ & CTE & $\begin{array}{c}\text { Additional } \\
\text { Information }\end{array}$ \\
\hline $\begin{array}{l}\text { Molding } \\
\text { Compound }\end{array}$ & 15000 & 0.3 & 16 & \\
\hline \multirow{6}{*}{ Die } & $1.305 \mathrm{e} 5$ & 0.2785 & $2.78343 e-6$ & $200 \mathrm{~K}$ \\
\hline & & & $3.0004 \mathrm{e}-6$ & $250 \mathrm{~K}$ \\
\hline & $1.298 \mathrm{e} 5$ & & $3.14811 \mathrm{e}-6$ & $293 \mathrm{~K}$ \\
\hline & & 0.2782 & $3.16888 \mathrm{e}-6$ & $300 \mathrm{~K}$ \\
\hline & & & $3.30238 \mathrm{e}-6$ & $350 \mathrm{~K}$ \\
\hline & $1.298 \mathrm{e} 5$ & 0.278 & $3.40867 \mathrm{e}-6$ & $400 \mathrm{~K}$ \\
\hline
\end{tabular}

SAC-305 Lead-

Free Solder
Anand Visco-plastic Material Model

\begin{tabular}{ccccc}
\hline & $\mathrm{x}=18,000$ & $\mathrm{x}, \mathrm{z}=0.11$ & $\mathrm{x}=14.5$ & $G_{x y}=5,535 \mathrm{Mpa}$ \\
PCB & $\mathrm{z}=18,000$ & $\mathrm{x}, \mathrm{y}=0.11$ & $\mathrm{z}=14.5$ & $G_{y z}=5,535 \mathrm{Mpa}$ \\
& $\mathrm{y}=7,380$ & $\mathrm{z}, \mathrm{y}=0.39$ & $\mathrm{y}=67.2$ & $G_{x z}=11,712 \mathrm{Mpa}$ \\
\hline Substrate & $\mathrm{z}=26,000$ & $\mathrm{x}, \mathrm{z}=0.11$ & $\mathrm{x}=15$ & $G_{x y}=8,250 \mathrm{Mpa}$ \\
& $\mathrm{y}=78,600$ & $\mathrm{z}, \mathrm{y}=0.3$ & $\mathrm{y}=15$ & $G_{x z}=11,712 \mathrm{Mpa}$ \\
\hline Die Attach & 1,800 & 0.3 & $80 \mathrm{e}-6$ & \\
\hline
\end{tabular}

Table 3.2: PBGA Package Material Properties 


\section{Chapter 4}

\section{Results}

Results for the uni-axial tensile model show that the initial strain observed in the loading only reveals elastic strains, and successive regions of strain are dominated by creep strain components post-yield. In this region highlighted, elastic strain is non-existent, and plastic strain is greatly minimized in comparison to magnitude of creep strain. In Figure 4.2, it is seen that with each successive loading cycle, the accumulation of creep is a greater dominating force in this system than the elastic strains. Note than this figure also shows that the elastic strains in this model are time independent, but the creep strains are time dependent. Therefore, this confirms that the viscoplastic material model is valid for the uni-axial bar since secondary creep is obtained through equivalent creep-strain and creep strain-energy density output. Figure 4.1 shows the concentration of creep strains that are probed for this analysis along the fixed-end of the solder bar. 

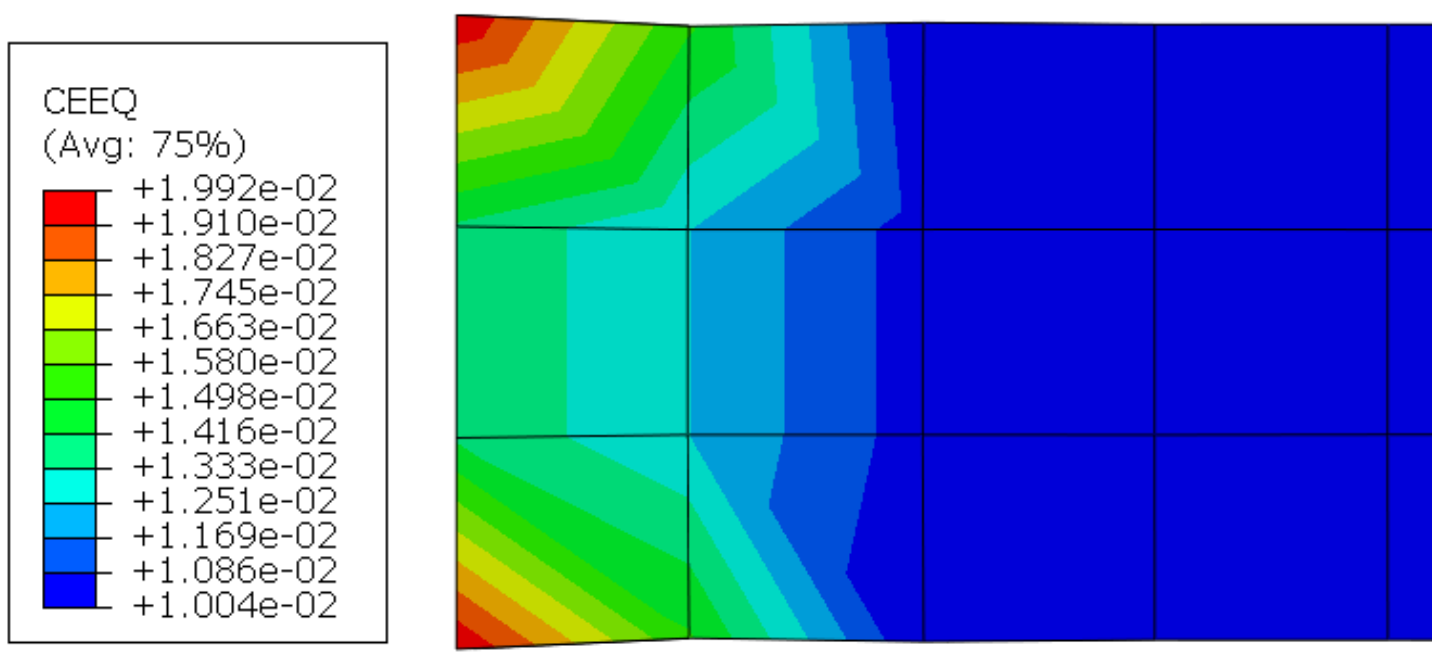

Figure 4.1: Contoured Equivalent Creep Strain Distribution for the Solder Bar

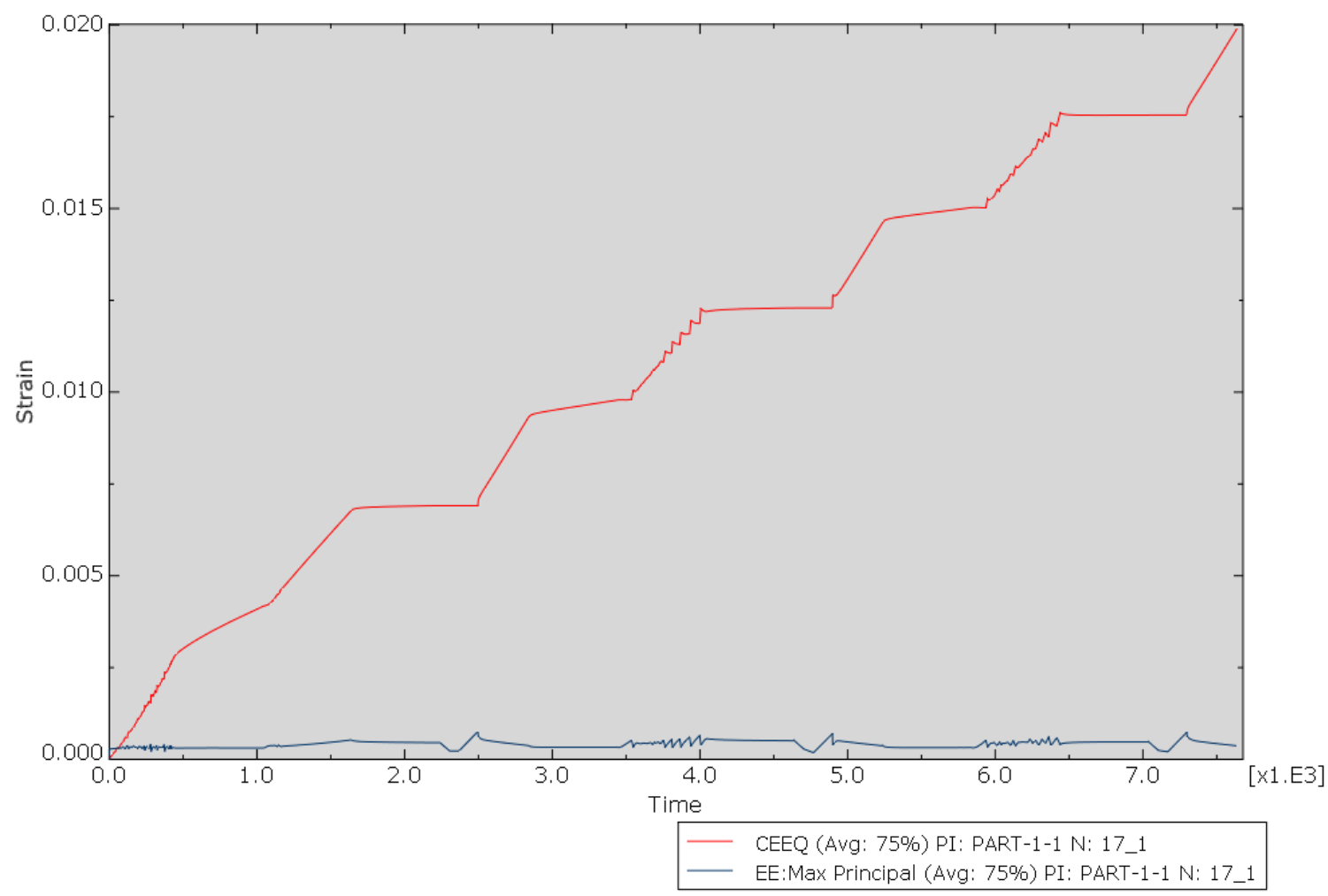

Figure 4.2: Equivalent Creep Strain and Maximum Elastic Principal Strains vs. Time 
To interpret the PBGA model results, the array is numbered so that individual solder joint-level results can be identified and explained with ease. Columns are labeled numerically from 1-12, and rows are labeled alphabetically from A-L.

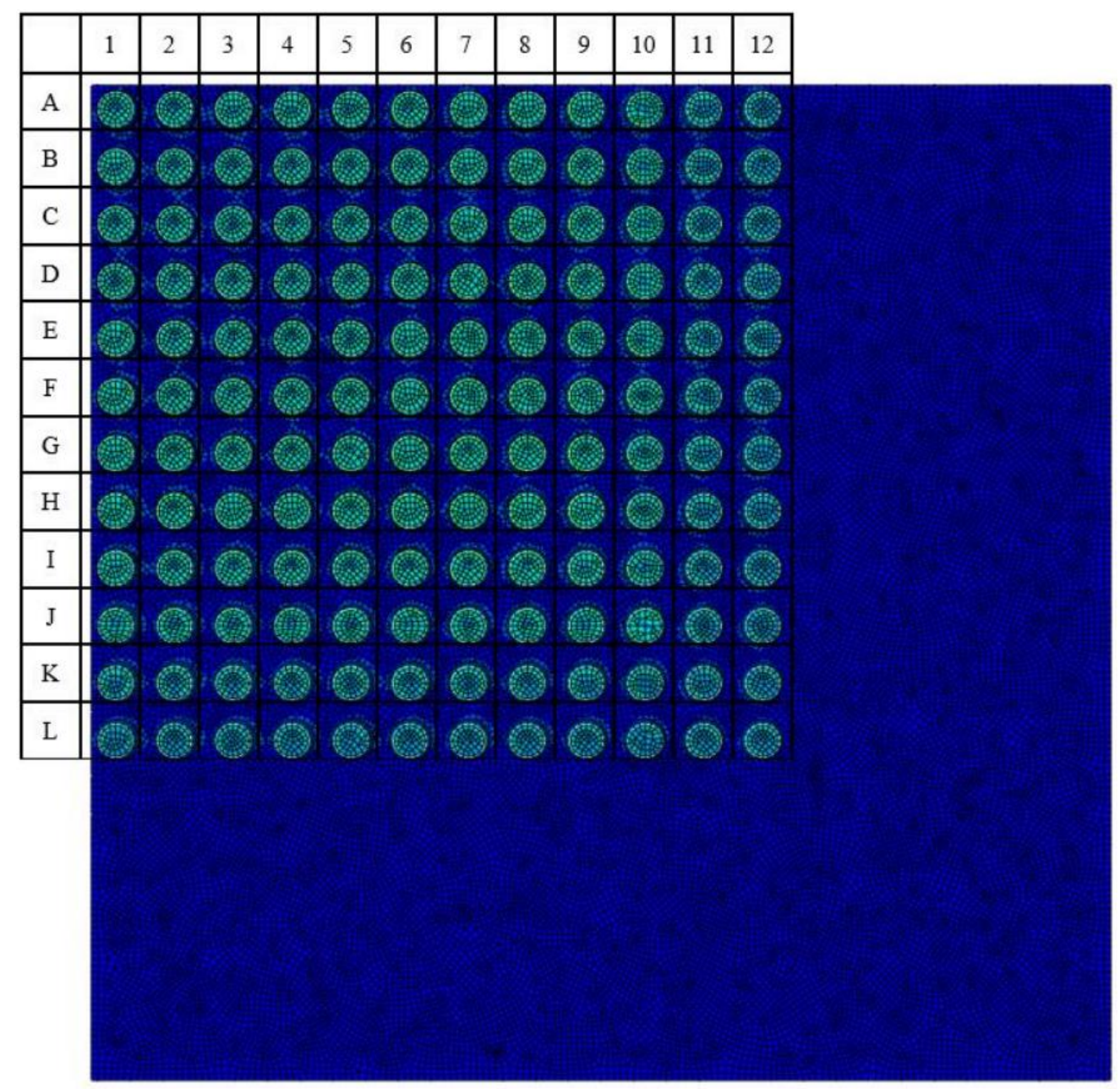

Figure 4.3: Solder Joint Array Classification

The results show that the location of both highest creep strain and highest von-mises stress is located at J-10, as depicted in Figures 4.4 and 4.5. This location is expected to accumulate creep at higher levels because the package corner is typically most 
susceptible to damage during thermocycling. This is because the CTE mismatch between the printed circuit board and the substrate causes z-directional deformation that is realized with the highest magnitude at the furthest point from the package center. The reason why the location is not at L-12 instead of J-10 is explained by the presence of silicon-die material at this solder-ball joint, but lack thereof at proceeding solder joints beyond row $\mathbf{J}$ and column 10 (see Figure 3.3 for more details). 


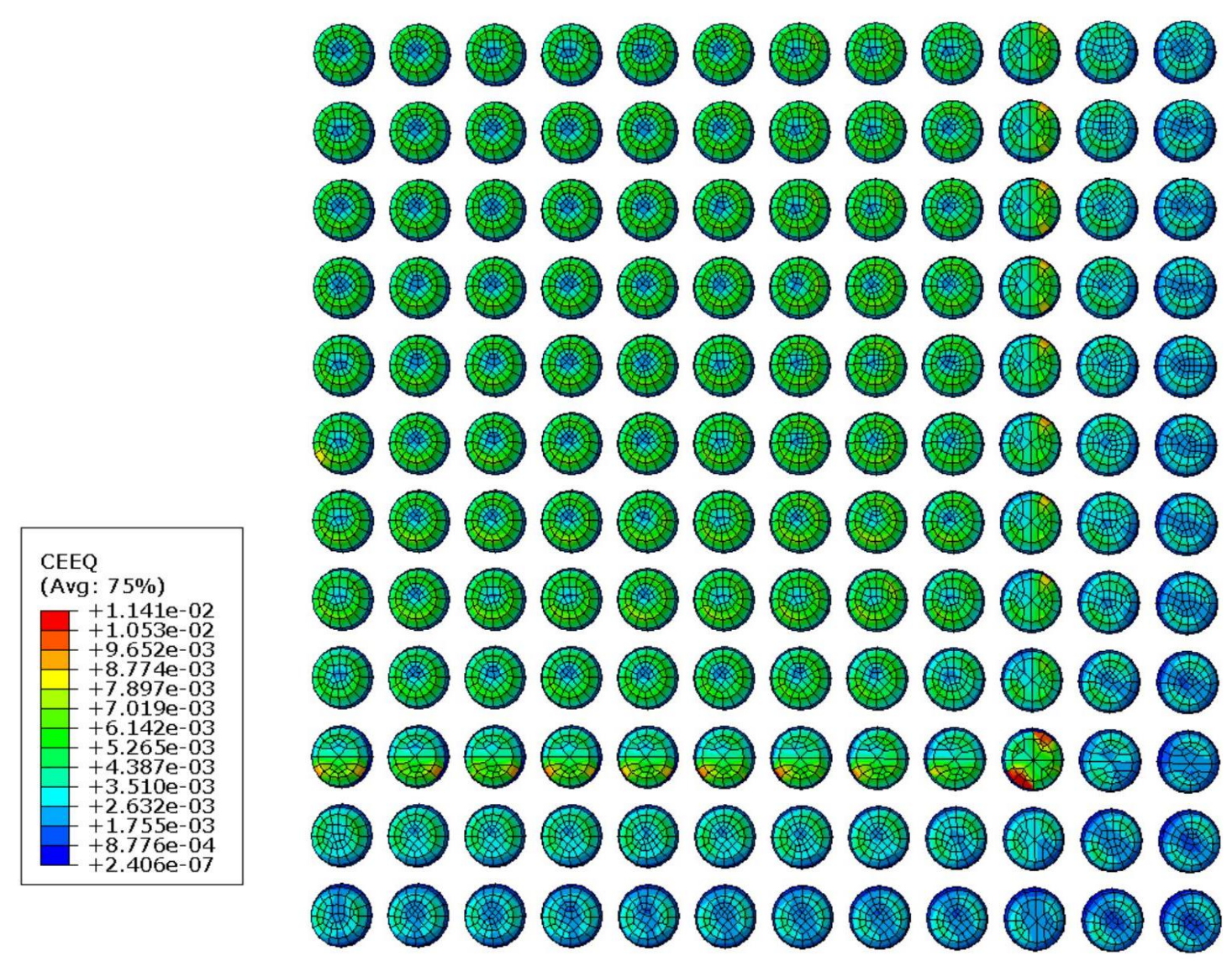

Figure 4.4: Equivalent Creep-Strain Results for Solder Ball-Grid Array 


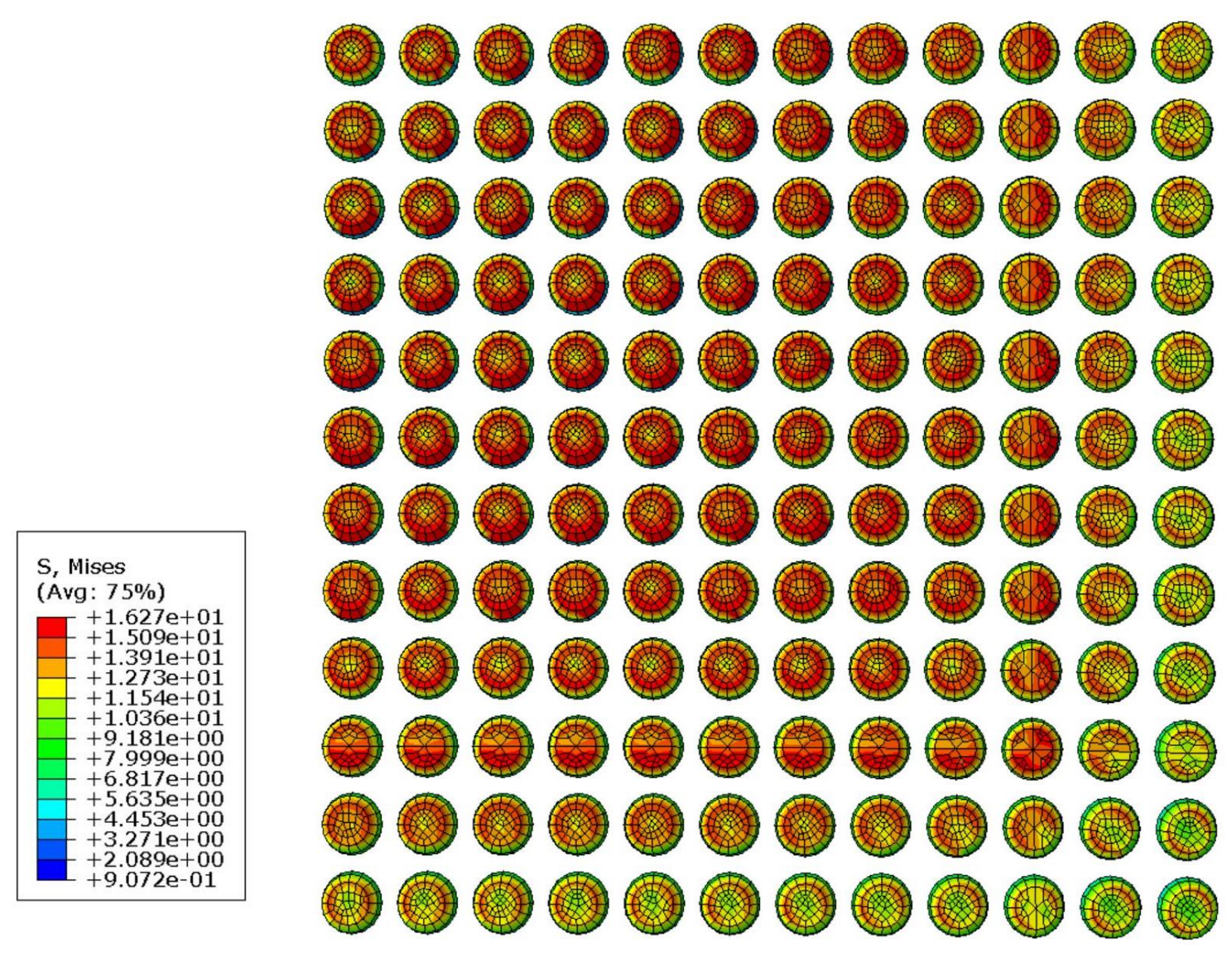

Figure 4.5: Von-Mises Stress Results for Solder Ball-Grid Array

The top-most $0.28 \%$ of solder height is probed and volume-averaged for the purpose of calculating fatigue life, which will be explained in Chapter 5 of this analysis. 


\section{Chapter 5}

\section{Fatigue Models}

\subsection{Overview on various fatigue-life prediction methods}

With regards to implementing an appropriate model to predict reliability, we must consider the compatibility of parameters that contribute to fatigue life to those of the constitutive model chosen for solder material analysis. On the one hand, we must develop an understanding for the loading conditions affecting the system to characterize the fatigue type realized through continuous thermo-cycling of solders.

Equations associated with calculating fatigue life are often derived in terms of strain versus the number of cycles to failure (Che et. Al, 2006 In a highly cited journal article published to Microelectronics Reliability, authors W.W. Lee et. Al. review fourteen different fatigue models that are appropriate for solder.

First, we must consider the temperature conditions, cyclic periods, and end-use operational conditions of the device of interest. Assuming that the reliability of a computer processor is to be evaluated for the purposes of this investigation, we expect short dwell periods at large temperature differences. (Lee 2000). Mechanical fatigue is primarily defined as either high-cycle fatigue or low-cycle fatigue, where the typical lifetime is either above or below 100,000 cycles, respectively. The failure mechanisms contributing to highcycle fatigue are elastic stress and strain contributions, where loading conditions are relatively small, such as in cases where vibrational loads influence package failure. Conversely, mechanisms influencing fatigue in the low-cycle regime are more common with our purpose, which are associated with large, cyclic temperature changes over 
moderate to long dwell periods, like those seen with CPUs and ASICs developed for mobile, desktop, and data-center applications. In a wide-encompassing study on various fatigue models and their applicability to specific use-cases, researchers W. W. Lee et. Al. explain how existing fatigue models are formulated and assign each a specific classification based on which fatigue components they account for, which are either stress-based, plastic strain-based, creep-strain based, energy-based, or damage-based. In addition, they review each model's applicability toward certain package types, which are segregated depending on the parameters required to predict a certain type of permanent deformation.

\begin{tabular}{|c|c|c|c|c|c|c|c|c|}
\hline & \multirow[t]{2}{*}{ Fatigue model } & \multirow[t]{2}{*}{ Equation nos. } & \multirow[t]{2}{*}{ Stress } & \multicolumn{2}{|l|}{ Strain } & \multirow[t]{2}{*}{ Energy } & \multirow[t]{2}{*}{ Damage } & \multirow[t]{2}{*}{ Other } \\
\hline & & & & Plastic & Creep & & & \\
\hline 1 & Coffin-Manson & 2 & & $x$ & & & & \\
\hline 2 & Total strain & 3 & & $x$ & & & & \\
\hline 3 & Soloman & 4 & & $x$ & & & & \\
\hline 4 & Engelmaier & 5 & & $x$ & & & & \\
\hline 5 & Miner & 6,7 & & $x$ & $x$ & & & \\
\hline 6 & Knecht and Fox & 8 & & & $x$ & & & \\
\hline 7 & Syed & 9 & & & $x$ & $x$ & & \\
\hline 8 & Akay & 10 & & & & $x$ & & \\
\hline 9 & Liang & 11 & & & & $x$ & & \\
\hline 10 & Heinrich & 12,13 & & & & $x$ & & \\
\hline 11 & Pan & 17 & & & & $x$ & & \\
\hline 12 & Darveaux & 14 & & & & $x$ & $x$ & \\
\hline 13 & Stolkarts & 18 & & & & & $x$ & \\
\hline 14 & Norris and Landzberg & 19 & & & & & & $x$ \\
\hline
\end{tabular}

Table 5.1: Fatigue Models and Classifications (Lee 2000) 


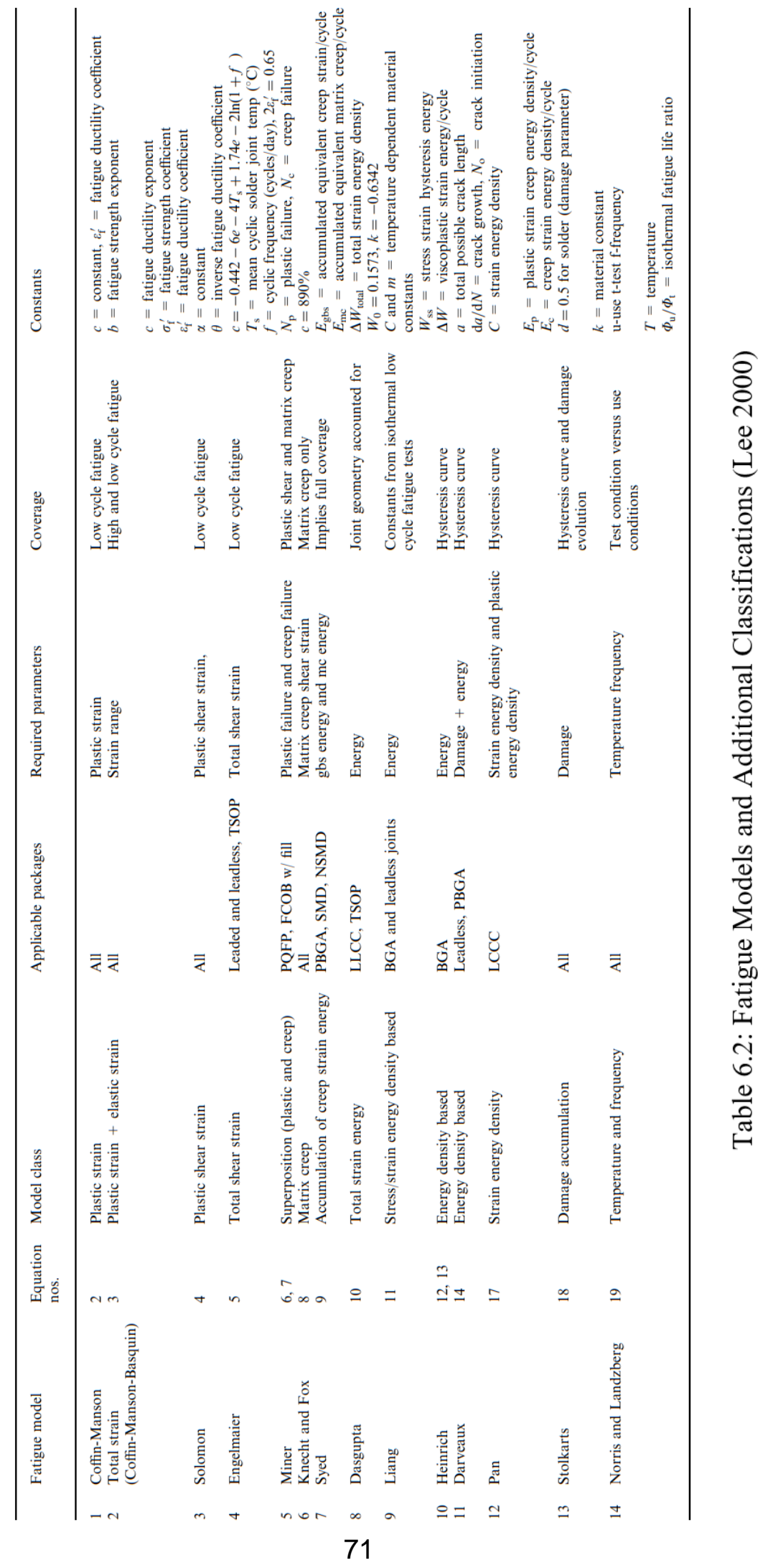




\subsubsection{Coffin-Manson Model}

The Coffin-Manson fatigue model is used to predict fatigue life in applications where plastic strain is assumed to be the fundamental fatigue component of interest. Typically, this model is used to describe mechanical behavior when low-cycle fatigue phenomena is dominant, thus, this model is used to predict plastic deformation in solder for packaging applications that are likely to see this type of in-field operational condition. This satisfies our requirements related to end-use packaging considerations. Lastly, according to literature, the Coffin-Manson model is applicable to all package types, which fulfills our final requirement for developing an all-encompassing method of predicting reliability across a variety of package types.

The Coffin-Manson fatigue model accounts for the total number of cycles to failure by establishing a direct relationship to plastic strain amplitude. The equation is written as

$$
\frac{\Delta \varepsilon}{2}=\varepsilon_{f}^{\prime}\left(2 N_{f}\right)^{c}
$$

where $\Delta \varepsilon$ represents the strain range, $\varepsilon_{f}^{\prime}$ represents the fatigue ductility, $N_{f}$ represents the total number of cycles to failure, and $c$ is the fatigue ductility exponential factor. 


\subsubsection{Alternate models}

However, since the Coffin-Manson model only accounts for plastic deformations, we will combine the equation with Basquin's equation to form:

$$
\frac{\Delta \varepsilon}{2}=\frac{\sigma_{f}^{\prime}}{E}\left(2 N_{f}\right)^{b}+\varepsilon_{f}^{\prime}\left(2 N_{f}\right)^{c}
$$

where $\sigma_{f}^{\prime}$ represents the fatigue-strength coefficient, $\mathrm{E}$ is Modulus of Elasticity, and $b$ is the fatigue strength exponential factor,

In the following figure, we can see the relationship between each exponential factor's effect on modeling the elastic and plastic contributions for fatigue life, where the 'lowcycle region is dominated by the plastic strain amplitude (Coffin-Manson equation), and the high-cycle region to the right of $\mathrm{Nf}$ is governed by the elastic-strain amplitude (Basquin's equation).' [3]

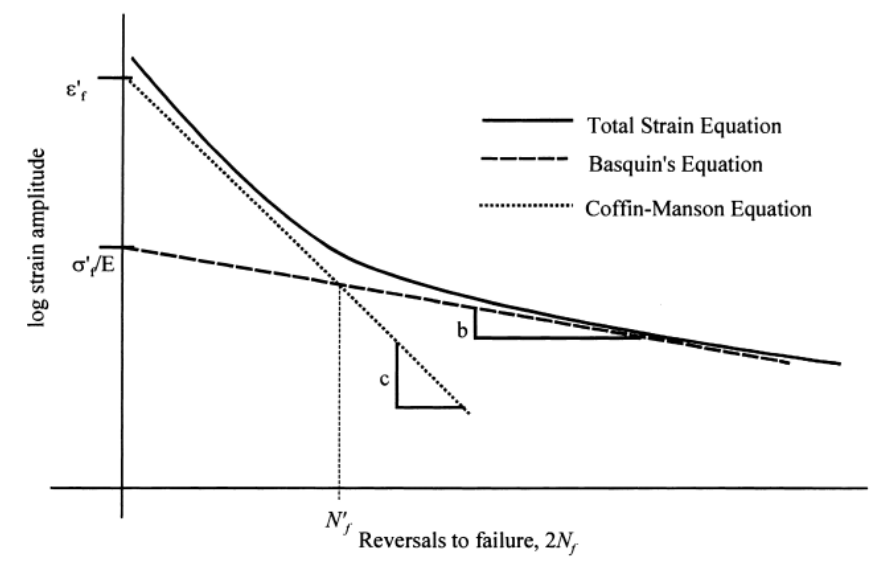

Figure 5.1: Total strain versus life equation 
Since we are interested in exploring more all-encompassing fatigue models that can be employed to increase the accuracy of our prediction. The Palmgren-Miner rule of linear accumulation of inelastic fatigue damage is used to predict solder fatigue life in replacement of the well-known Coffin-Manson model if inelastic strains are avoided in regions of high interfacial stresses.

$$
N=N_{f}\left(\frac{\tau_{f}}{\tau_{a}}\right)^{m}
$$

where $N_{f}$ is the number of cycles corresponding to reaching the fatigue curve, $\tau_{f}$ is the level of fatigue, $\tau_{a}$ is the amplitude of the variable shearing stress, and $\mathrm{m}=\tan \alpha$, which is the tangent of the angle that the limited-fatigue portion of the diagram below forms with the vertical line that divides the limited fatigue and steady-state fatigue regions.

As a strain-based fatigue model that accounts for both plastic and creep strain components, the model applies a linear superposition principal that incorporates the Solomon fatigue model with the Knecht and Fox creep model to obtain a more allencompassing fatigue-life prediction. The equation is written as

$$
\frac{1}{N_{f}}=\frac{1}{N_{p}}+\frac{1}{N_{c}}
$$

where $N_{p}$ and $N_{c}$ represent the number of cycles to failure due to plastic and creep strain, respectively. The plastic strain components are obtained directly from the Solomon fatigue model, written as 


$$
\Delta \gamma_{p} N_{p}^{\propto}=\theta
$$

where $\Delta \gamma_{p}$ is the plastic shear strain amplitude, $\theta$ is the inverse fatigue ductility coefficient, and $\propto$ is a material constant. By this point, we can see there are many differences between the models, and it is important to note that only the models that account for creep, i.e. Miner, Knecht and Fox, Syed, or modified variations of other models, can be implemented because finite-element analysis confirmed that creep-strain is the dominant component of non-linear strains accumulation.

For the purposes of this study, we will be using the Coffin Manson fatigue model with a damage-accounting term in replacement, written as

$$
N_{f}=\left(\frac{C}{D}\right)^{\frac{1}{m}}
$$

such that we can account for characteristic life as a function of volume-averaged damage accumulation, D, based on both equivalent creep strain and creep energy density. Because we assume visco-plastic solder post-yield, this damage-based prediction methodology is appropriate because of the inextricable tie between our chosen material model, dominating components of plastic strain observed in the finite-element model, and measures of permanent deformation that are predicted in our chosen fatigue model. Some material models only consider plastic deformation, and some models only consider creep, and referring to Eq. (1.2), inelastic strain is composed of both plastic strain and creep 
strain. According to the finite element analysis performed on both the uni-axial model and PBGA package model, creep strain dominates at least ninety-nine percent of plastic strain observed post-yield. Therefore, we must consider creep, and therefore, must choose a damage model.

Literature available shows a wide range of different fatigue models used to predict the lifetime, which differ in methods of probing solder volumes of interest, and in equations used to highlight specific measures of permanent deformation.

By this point, we can see that the At a minimum, the chosen fatigue model shall accommodate for the appropriate measure of the phenomena accelerating fatigue. Since there are several different phenomena that influence fatigue life, and because we wish to obtain an all-encompassing mathematical model for predicting creep strain, we shall choose a model that will focus on the component that will likely influence fatigue life with the highest magnitude. It is found that the calculated fatigue life prediction is most dependent on the chosen material model used to represent lead-free solder, and thus. The chosen Anand viscoplastic constitutive equations used to model solder material behavior consider creep as the dominating strain component in predicting stress at a given deformation, so in choosing a model, it is important that we apply a model that accounts for creep. For this reason, we will use the widely used Coffin-Manson model, with a damage-accounting formulation that will allow for tracking creep strains and creep energy density as primary drivers of permanent deformation for solders beyond the elastic region of strain.

According to Suh et. Al, the calculation of Fatigue life using inelastic strains is mostaccurately obtained by calculating a volume-averaged inelastic strain amplitude, which is 
found by calculating the difference in the local maximum and minimum of the stabilized inelastic strain amplitude, which in this case, is obtained from the equivalent creep strain amplitude.

The parameters used for both fatigue-life calculations are found in Tables 6.1 and 6.2, where Table 6.2 includes the creep-accounting fatigue life calculation parameters

\begin{tabular}{|c|c|c|}
\hline Constant & Parameter & SAC-305 Value \\
\hline$\epsilon_{f}^{\prime}$ & Fatigue ductility coefficient & 0.325 \\
\hline $\mathrm{c}$ & Fatigue ductility exponent & -0.57 \\
\hline$\sigma_{f}^{\prime}$ & Fatigue strength coefficient & 64.8 \\
\hline $\mathrm{b}$ & Fatigue strength exponent & -0.1443 \\
\hline
\end{tabular}

Table 5.3: Coffin-Manson Strain-life parameters for SAC-305 Lead-Free Solder

\begin{tabular}{|c|c|}
\hline Constant & SAC-305 Value \\
\hline $\mathrm{C}$ & 5920 \\
\hline $\mathrm{m}$ & -1.3 \\
\hline $\begin{array}{l}D \text { (damage } \\
\text { parameter) }\end{array}$ & $\begin{array}{c}\text { Equivalent Creep Strain } \\
\text { Amplitude Result }\end{array}$ \\
\hline
\end{tabular}

Table 5.4: Creep-accounting fatigue life parameters 
Results from the calculation of fatigue life, using the Coffin-Manson model, are tabulated in Table 6.3.

\begin{tabular}{ccc}
\hline & $\begin{array}{c}\text { Volume-Averaged } \\
\text { Equivalent Creep Strain } \\
\text { Amplitude (CEEQ) }\end{array}$ & Fatigue Life \\
\hline PBGA Model: & 0.005851 & 7,250 cycles \\
Coffin-Manson & & \\
\hline $\begin{array}{c}\text { PBGA Model: } \\
\text { Modified Coffin- } \\
\text { Manson }\end{array}$ & 0.00581 & 9,000 cycles \\
& & \\
\hline
\end{tabular}

Table 5.5: Fatigue-life results and corresponding finite-element result 


\section{Chapter 6}

\section{Conclusions}

The Anand parameters provided by Motalab et. al. enable non-linear curve fit numerical data that does not accurately match experimental, however, the curve-fitting method applied for this study improves the numerical accuracy to a high degree. The simple-difference method of investigating error revealed that the parameters provided by Motalab's group at Auburn University allow more accurate curve-fitting at the lowest tested strain rate, but decrease numerical performance with the two higher tested strain rates. The Kolmogorov-Smirnov test confirmed that higher strain rates are more difficult to curve-fit with the given Anand parameters. Though the lowest strain rate of 0.00001 $\mathrm{mm} / \mathrm{s}$ achieved the lowest dissimilarity values, it is important to note that it also produces large errors in the final stress value converged upon. The present study model produced Anand parameters that more effectively minimize error between experimental and numerical stress predictions, and thus, the difference in calculated fatigue life should be considered an improvement from work derived from other methods of curve-fitting. Anand parameters extracted through curve-fitting only post-yield stress-strain data will contribute to more accurate predictions because the elastic region of strain is set to obey Hooke's law. The issue with applying the Anand model to the entire region of strain arises due to the implied assumption that the initial region of strain exhibits both time and temperature-dependent behavior. Finite-element results show that this is not true, as the initial region of strain only contains elastic strain components.

Further studies will be conducted to determine which Anand parameters should be used in modeling experimental stress most accurately with respect to reliability 
prediction. Investigation should reveal which strain magnitudes are most important to maintain model accuracy with respect to reliability analysis, because we hypothesize that there are bounds of strain magnitude where stresses should be modeled most accurately in determining their role in predicting plastic strain accumulation on solder material.

As the industry progresses toward developing more powerful processors, the adoption of smaller feature sizes and larger current loads will require greater technological strides to improve reliability in tandem with performance. The use of predictive models and numerical simulation is a proven method of helping researchers address new operational constraints, especially as technology nodes provide more challenging packaging requirements. Thus, new materials and process capabilities enable promising advances in reliable, high-performance electronic packaging which ultimately, play an important role in sustaining the drumbeat of Moore's Law.

Moving forward, the most critical steps to be taken in improving the accuracy of solder fatigue life prediction is to determine a unified damage-calculation methodology, using a deeper understanding of lead-free solder material physics, a more encompassing statistical approach, or an ingenious combination of the two. Most researchers and engineers choose fatigue models based on compatibility to a specific set of experimental data, which sacrifices accuracy for precision. Consequently, this further complicates the process of fatigue life prediction because with a wide variety of application specific methods being used in industry and academia, there is a lack of standardization. 


\section{References}

[1] techsil.co.uk. "Lead Free Solder Sn96 (SAC305) 4900 Technical Data Sheet." M.G. Chemicals Ltd. , Burlington, Ontario, 13-Feb-2016.

[2] T. Siewert, S. Liu, D. R. Smith, J. C. Madeni, "Properties of Lead-Free Solders: Database for Solder Properties with Emphasis on New Lead-free Solders" in National Institute of Standards \& Technology \& School of Mines, February 2002. Colorado.

[3] Karl Seelig and David Suraski, "The Status of Lead-Free Solder Alloys," Proc. 50th IEEE 2000 Electronic Components and Technology Conference (May 21-24, 2000), Las Vegas, NV.

[4] W. W. Lee, L.T. Nguyen, G.S. Selvaduray. "Solder joint fatigue models: review and applicability to chip scale packages." Microelectronics Reliability. June 2000.

[5] M. Motalab, Z. Cai, J.C. Suhling, P. Lall. "Determination of Anand constants for SAC Solders using Stress-Strain or Creep Data.” Conference Paper. May 2012. DOI: 10.1109/ITHERM.2012.6231522.

[6] S. Yi, Y.F. Chu, P. Geng. "Thermal fatigue life prediction of solder joints of plastic ball grid array packages.” Int. J. Materials and Structural Integrity 
[7] E. Suhir, R. Ghaffarian, S. Yi. "Probabilistic Palmgren-Miner rule, with application to solder materials experiencing elastic deformations." Journal of Materials Science: Mater Electron, 2017. DOI 10.1007/s10854-016-5845-y .

[8] F. X. Che, H. L. Pang, W. H. Zhu, W. Sun, and A. Y. S. Sun, "Modeling constitutive model effect on reliability of lead-free solder joints," in 7th International Conference on Electronic Packaging Technology (ICEPT), pp. 1-6, Aug. 2006.

[9] I. W. Suh, H. S. Jung, Y. H. Lee, and S. H. Choa, "Numerical Prediction of Solder Fatigue Life in a High Power IGBT Module Using Ribbon Bonding," in Journal of Power Electronics, Vol. 16, No. 5, pp. 1843-1850, September 2016.

[10] W. C. Chuang, W. L. Chen, "Fatigue Prediction for Molded Wafer-Level package During Temperature Cycling," in Journal of Power Electronics. September 2016.

[11] S. Yi, "Lectures 1-13," in ME-478/578: Introduction to Electronics Packaging, lecture notes. December 2019. 